\title{
Flowsheet Modifications for Dissolution of Sand, Slag, and Crucible Residues in the F-Canyon Dissolvers
}

David G. Karraker

Tracy S. Rudisill

Frank R. Graham

Alice M. Murray

John I. Mickalonis
John H. Gray

Ronald R. Livingston

Edward A. Kyser, III

Robert A. Pierce

David B. Allen

December 1997

\section{Westinghouse Savannah River Company \\ Savannah River Site \\ Aiken, SC 29808}

Prepared for the U. S. Department of Energy under contract DE-AC09-96SR18500. 


\section{Flowsheet Modifications for Dissolution of Sand, Slag, and Crucible Residues in the F-Canyon Dissolvers}

by

T. S. Rudisill

Westinghouse Savannah River Company

Savannah River Site

Aiken, South Carolina 29808

D. G. Karraker

WSRC

F. R. Graham

WSRC

A. M. Murray

WSRC

J. I. Mickalonis

WSRC

J. H. Gray

WSRC
RECEIVED

JAN 301998

OSTI
R. R. Livingston

WSRC

E. A. Kyser, ill

WSRC

R. A. Pierce

WSRC

D. B. Allen

WSRC

This paper was prepared in connection with work done under the above contract number with the U.S.

Department of Energy. By acceptance of this paper, the publisher and/or recipient acknowledges the U.S. Government's right to retain a nonexclusive, royalty-free license in and to any copyright covering this paper, along with the right to reproduce and to authorize others to reproduce all or part of the copyrighted paper. 


\section{DISCLAIMER}

This report was prepared as an account of work sponsored by an agency of the United States Government. Neither the United States Government nor any agency thereof, nor any of their employees, makes any warranty, express or implied, or assumes any legal liability or responsibility for the accuracy, completeness, or usefulness of any information, apparatus, product, or process disclosed, or represents that its use would not infringe privately owned rights. Reference herein to any specific commercial product, process, or service by trade name, trademark, manufacturer, or otherwise does not necessarily constitute or imply its endorsement, recommendation, or favoring by the United States Government or any agency thereof. The views and opinions of authors expressed herein do not necessarily state or reflect those of the United States Government or any agency thereof.

This report has been reproduced directly from the best available copy.

Available to DOE and DOE contractors from the Office of Scientific and Technical Information, P. O. Box 62, Oak Ridge, TN 37831; prices available from (423) 576-8401.

Available to the public from the National Technical Information Service, U. S. Department of Commerce, 5285 Port Royal Road, Springfield, VA 22161. 


\section{DISCLAIMER}

Portions of this document may be illegible electronic image products. Images are produced from the best available original document. 
WSRC-TR-97-00395

Revision 0

Flowsheet Modifications for Dissolution of Sand, Slag', and Crucible Residues in the F-Canyon Dissolvers

David G. Karraker

Tracy S. Rudisill

Frank R. Graham

Alice M. Murray

John I. Mickalonis
John H. Gray

Ronald R. Livingston

Edward A. Kyser, III

Robert A. Pierce

David B. Allen

Issued December 1997

Technical Reviewers
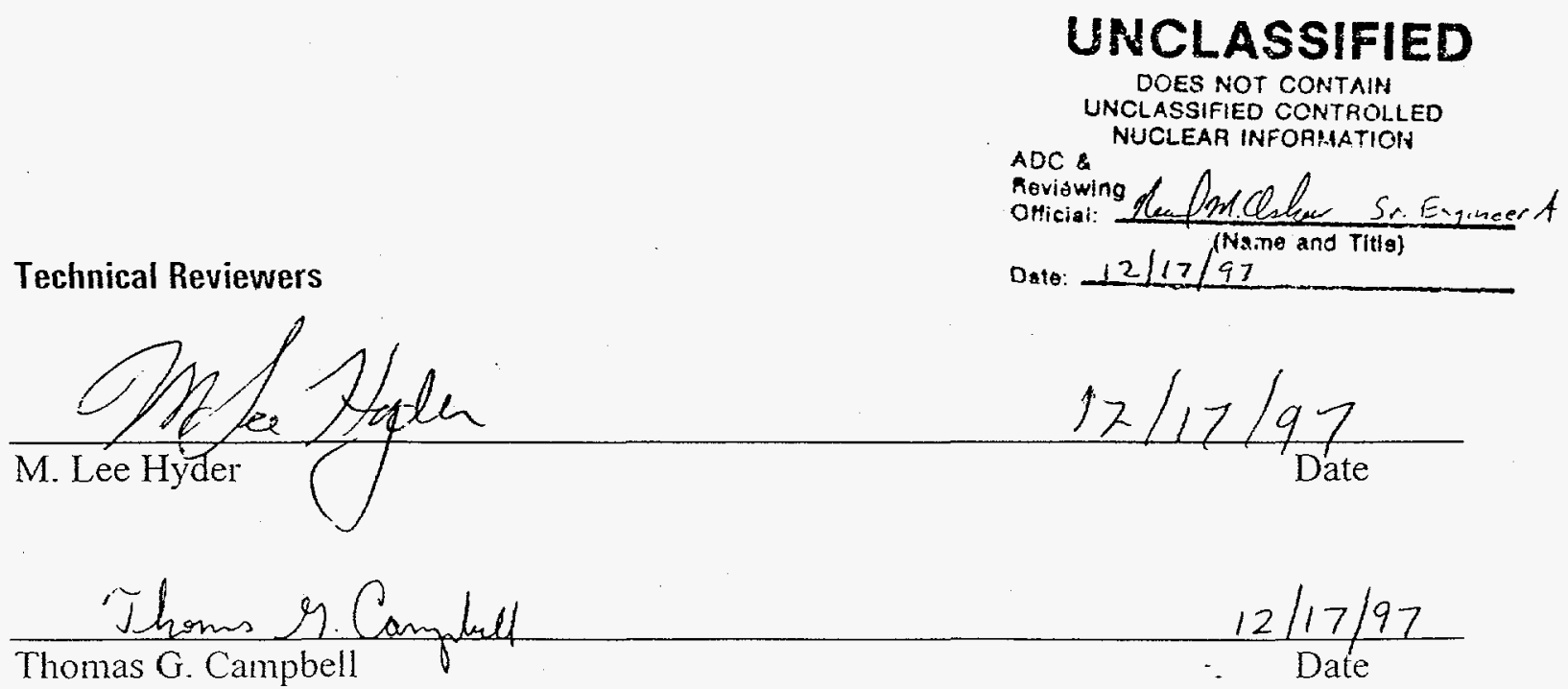


\section{This page has been left blank intentionally.}




\section{Table of Contents}

Section

Page

I. Summary

II. Conclusions

III. Flowsheet Recommendations

IV. Introduction to Experimental Work

V. Scaled Dissolver Insert Tests

VI. Fluoride Complexation 23

VII. Dissolution of Actual SS\&C

VIII. Dissolution of High-Fired Plutonium Oxide

IX. Gas Generation from Slag.

X. Effects on Down-Stream Processing

XI. Corrosion Studies

69

XII. References

XIII. Figures 


\section{List of Figures}

Figure Number

Page

Figure 1 Charging Bundle and Dissolver Insert for SS\&C Dissolution 75

Figure 2 Ionization of Hydrogen Fluoride as a Function of $\mathrm{pH}$ 77

Figure 3 Typical Calibration Curve for Free Fluoride 79

Figure 4 Free Fluoride in Dissolver Solution

Figure 5 Effect of Iron/Aluminum on Free-Fluoride Concentration 83

Figure 6 Effect of Plutonium on Free-Fluoride Concentration 85

Figure 7 Effect of Boron on Free-Fluoride Concentration 87

Figure 8 Effect of Fluoride Source on Free-Fluoride Concentration 89

Figure 9 Dissolution of SS\&C Fines at $85^{\circ} \mathrm{C}$ 91

Figure 10 Dissolution of $\mathrm{PuO}_{2}-$ Fluoride Optimization 93

Figure 11 Dissolution of $\mathrm{PuO}_{2}$ - Calcium Effect 95

Figure 12 Effect of Calcium and Fluoride on the Dissolution of $\mathrm{PuO}_{2}$ 97 
Figure Number

\section{List of Figures (continued)}

Figure 13 Dissolution of $\mathrm{PuO}_{2}$ without Iron

99

Figure 14 Dissolution of $\mathrm{PuO}_{2}$ with Iron 101

Figure 15 Effect of Free Fluoride on the Dissolution of $\mathrm{PuO}_{2}$ 103

Figure 16 Dissolution of $\mathrm{PuO}_{2}$ as a Function of High Fluoride 105

Figure 17 Dissolution of $\mathrm{PuO}_{2}$ as a Function of Low Fluoride 107

Figure 18 Hydrogen Generation Rate from Spherical Pieces of Slag 109

Figure $19 \mathrm{Pu}^{+3}, \mathrm{Pu}^{+4}$, and $\mathrm{Pu}^{+6}$ Spectra of SS\&C Dissolver Solution

Figure 20 Dissolved SS\&C and High Fired Oxide Spectra

Figure $21 \mathrm{Pu}^{+6}$ Sensitivity using Spectral Absorbance in the 800 to $840 \mathrm{~nm}$ Range

Figure $22 \mathrm{Pu}^{+6}$ Sensitivity using Second Derivatives of Absorbance in the 800 to $840 \mathrm{~nm}$ Range

Figure 23 Corrosion of 304 L Stainless Steel Coupons 


\section{List of Tables}

Table Number

Page

Table 1 Selected Stability Constants for Metal Fluorides

28

Table 2 Dissolution of SRS and Rocky Flats SS\&C Particles

29

Table 3 Dissolution of Crushed Slag Chunks

Table 4 Dissolution of New Slag Chunks 32

Table 5 Dissolution Conditions for SS\&C Fines 34

Table 6 Nominal Composition of RF and SRS SS\&C 38

Table 7 Composition of Corrosion Test Solutions 39

Table 8 Results of Three Hour Dissolution Test on High-Fired $\mathrm{PuO}_{2}$ 40

Table 9 Composition of Test Solutions and Free-Fluoride Concentrations

Table 10 Solution Compositions 43

Table 11 Composition of Test Solutions 44

Table 12 Estimated Maximum Concentrations During SS\&C Dissolution 47

Table 13 Total and Free-Fluoride Concentrations in Initial Solutions 48

Table 14 Gas Evolution During Dissolution 51 


\section{List of Tables (continued)}

Table Number

Page

Table 15 Estimated Hydrogen Generation Rate for Slag Chunks of Varying

Diameter

Table 16 Feed Adjustment for Pu Pickup Test Pu 97

60

Table 17 Results from Dissolved SS\&C Pu Pickup Test Pu97

Table 18 Impurity Carryover of Dissolved SS\&C with ANN

Table 19 Distribution Coefficients for $\mathrm{HNO}_{3}, \mathrm{HF}$, and $\mathrm{B}(\mathrm{OH})_{3}$ with

TBP

Table 20 Effect of Aluminum on Impurity Carryover of Acid,

Fluoride, and Boron

Table 21 Effect of Aluminum, Boric Acid, and Ferric Nitrate on ISE

Analysis for Total Fluoride.

Table 22 Volatilization of Fluoride during the Evaporation of Solutions

Containing Fluoride, Boric Acid, Aluminum in Nitric Acid 68

Table 23 Summary of Corrosion Rates and Solution Compositions 70 


\section{This page has been left blank intentionally.}




\title{
Flowsheet Modifications for Dissolution of Sand, Slag, and Crucible Residues in the F-Canyon Dissolvers
}

\author{
Westinghouse Savannah River Company \\ Savannah River Site \\ Aiken, SC 29808
}

\author{
David G. Karraker \\ Tracy S. Rudisill \\ Frank R. Graham \\ Alice M. Murray \\ John I. Mickalonis
}

\author{
John H. Gray \\ Ronald R. Livingston \\ Edward A. Kyser, III \\ Robert A. Pierce \\ David B. Allen
}

\section{Summary}

An initial flowsheet for the dissolution of sand, slag, and crucible (SS\&C) was developed for the F-Canyon dissolvers as an alternative to dissolution in FB-Line. In that flowsheet, the sand fines were separated from the slag chunks and crucible fragments. Those two SS\&C streams were packaged separately in mild-steel cans for dissolution in the 6.4D dissolver. Nuclear safety constraints limited the dissolver charge to approximately 350 grams of plutonium in two of the three wells of the dissolver insert and required $0.23 \mathrm{M}$ (molar) boron as a soluble neutron poison in the $9.3 \mathrm{M}$ nitric acid/ $0.013 \mathrm{M}$ fluoride dissolver solution. During the first dissolution of SS\&C fines, it became apparent that a significant amount of the plutonium charged to the 6.4D dissolver did not dissolve in the time predicted by previous laboratory experiments. The extended dissolution time was attributed to fluoride complexation by boron. An extensive research and development (R\&D) program was initiated to investigate the dissolution chemistry and the physical configuration of the dissolver insert to understand what flowsheet modifications were needed to achieve a viable dissolution process.

A correlation of dissolution rate as a function of free-fluoride concentration showed that a very low level of free fluoride (as was present in the initial dissolver run) substantially increased the dissolution time (i. e., from 30 minutes to more than eight hours). The fluoride in the $6.4 \mathrm{D}$ dissolver solution was strongly complexed by the added boron causing the much slower dissolution of the plutonium oxide $\left(\mathrm{PuO}_{2}\right)$ in the SS\&C fines. Past experience has shown that free fluoride is critical for the dissolution of $\mathrm{PuO}_{2}$, and $\mathrm{PuO}_{2}$ is expected in the SS\&C fines. The complexation of fluoride by boron does eliminate the need for aluminum to facilitate the dissolution of calcium and plutonium fluorides after charging SS\&C slag chunks. 
To achieve complete dissolution of SS\&C in the specified three hours in a $0.23 \mathrm{M}$ boron solution, the total fluoride would have to be very high and outside the range of SRS processing experience. Therefore, a compromise consisting of a longer dissolution time combined with an increase in the initial charge of potassium fluoride (KF) from $0.013 \mathrm{M}$ to a minimum of $0.075 \mathrm{M}$ and charging crushed SS\&C material to raise the fluoride concentration to approximately $0.15 \mathrm{M}$ in the first charge is recommended. No aluminum should be added to the dissolver solution because it is not required for either dissolution or corrosion protection. After the first charge is complete (in less than 12 hours as predicted by experiments), subsequent charges of SS\&C fines and chunks can be made until the fluoride reaches about $0.35 \mathrm{M}$. This flowsheet will allow a total of approximately $128 \mathrm{~kg}$ of bulk SS\&C to be charged since there is up to $0.33 \mathrm{M}$ fluoride in that amount of SS\&C plus the initial charge of KF. Nuclear safety may dictate that smaller amounts of bulk SS\&C be charged to limit either the plutonium per charge or final plutonium concentration.

The proposed modifications to the SS\&C dissolution flowsheet are based on dissolution experiments using actual SS\&C and high-fired $\mathrm{PuO}_{2}$ (the slowest $\mathrm{SS} \& \mathrm{C}$ component to dissolve). Tests were run at variable fluoride concentrations to establish the minimum initial concentration required. Previous experiments showed that good agitation was required to achieve rapid dissolution. A concern that the plant dissolver inserts and slotted charging bundles prevented adequate circulation was tested. This concern was found to be insignificant compared to the reduction in free fluoride in the solution.

Studies of dissolver solutions showed that no plutonium valence adjustment should be required. Solvent extraction tests suggest that small amounts of the fluoride will be extracted into the solvent if aluminum nitrate nonahydrate (ANN) is not added. The effect of this extraction is expected to be negligible and would be eliminated by the ionexchange concentration step in FB-Line. No extraction interferences were seen at 0.3 $0.4 \mathrm{M}$ fluoride levels.

The potential for excessive corrosion in the dissolvers was evaluated using coupon exposure in solutions similar to the recommended flowsheet. The measured corrosion was less than 35 mils per year with $0.3 \mathrm{M}$ fluoride/9.3M nitric acid/0.23M boron solutions at $85^{\circ} \mathrm{C}$. 


\section{Conclusions}

The slow dissolution of $\mathrm{PuO}_{2}$ in SS\&C fines during the first 6.4D dissolver run (October 1997) was due to a very low free-fluoride concentration. The low free-fluoride concentration was caused by the strong complexation of fluoride by boron. To increase the dissolution rate to the same level achieved without boron, very high levels (greater than $0.5 \mathrm{M}$ ) of fluoride are required. Modifications to the existing flowsheet to achieve an acceptable dissolution rate are a compromise between free-fluoride concentration and dissolution time. Increasing the initial KF concentration from a maximum $0.05 \mathrm{M}$ to a minimum $0.075 \mathrm{M}$ and charging crushed SS\&C material to the dissolver should result in dissolution times of less than 12 hours. These modifications are based on dissolution experiments using actual $\mathrm{SS} \& \mathrm{C}$ and high-fired $\mathrm{PuO}_{2}$, which should be the most difficult component of the SS\&C to dissolve. In each case, compete dissolution, based on visual observation, was achieved in less than eight hours. The dissolution of large chunks of slag (primarily $\mathrm{CaF}_{2}$ ) appear limited by available surface area. Therefore, improvements in the dissolution rate can be achieved by crushing the slag chunks to obtain smaller particles (less than one-inch diameter).

The complexation of fluoride by boron assists in the dissolution of calcium and plutonium fluorides; therefore, the addition of aluminum to facilitate the dissolution of the slag is not required. As the $\mathrm{CaF}_{2}$ dissolves, it also enhances the dissolution rate of $\mathrm{PuO}_{2}$. That behavior was observed in dissolution experiments with high-fired $\mathrm{PuO}_{2}$. Those experiments showed that increasing concentrations of calcium had a beneficial effect on the dissolution rate. This observation could be attributed to the $\mathrm{Ca}^{2+} / \mathrm{CaF}^{+}$ equilibrium buffering the free-fluoride concentration, which may also decrease the fluoride volatility. There is no reason to segregate the sand fines and slag chunks for separate dissolution, because aluminum is not required for the dissolution of the calcium and plutonium fluorides. Concurrent dissolution of these materials is possible until the total fluoride concentration reaches approximately $0.35 \mathrm{M}$ (limited by the precipitation of fluoride salts) or the limiting plutonium concentration is reached in the dissolver solution. An estimated $128 \mathrm{~kg}$ of bulk material could be charged to the dissolver before the total fluoride limit is reached.

The high fluoride concentration in the dissolver solutions requires substantial amounts of aluminum for complexation if evaporation of acid waste solutions is performed. The complexation of fluoride by boron does not prevent the carryover of HF into evaporator overheads as well as aluminum does. A more detailed study of downstream effects on evaporator corrosion and the acid recovery unit should be performed if acid recycle is performed. This study should evaluate the economics of neutralizing the waste solutions with caustic and evaporating versus the addition of aluminum prior to evaporation and acid recovery. If ANN is not added to the dissolver solution, some fluoride (less than $0.01 \mathrm{M}$ ) is expected to carryover into the solvent and plutonium product stream during solvent extraction operations. Fluoride carryover should not cause problems; the small amount of fluoride present in the plutonium product stream will be rejected by the FB- 
Line ion exchange process. Valence adjustment prior to solvent extraction should not be required. Only the presence of $\mathrm{Pu}^{4+}$ was noted during experiments with solutions containing dissolved SS\&C.

Corrosion testing was conducted using the range of solution concentrations investigated for the dissolution of SS\&C residues. The test solutions contained $9.3 \mathrm{M} \mathrm{HNO}_{3}$ and different concentrations of $\mathrm{KF}, \mathrm{CaF}_{2}$, boron, iron, and aluminum. The corrosion rates ranged from 4 to 77 mils per year. The most aggressive solution was uncomplexed and contained $0.05 \mathrm{M} \mathrm{KF}$. Boron and aluminum decreased the corrosion rate by complexing the fluoride ion. Iron had no effect on the coupon corrosion rate. Although welds appeared to be preferentially attacked, the measured corrosion rates for welded and unwelded coupons were similar. 


\section{Flowsheet Recommendations}

Specific recommendations for the flowsheet conditions required for the dissolution of SS\&C depend upon the strategy used to package the material for dissolution. During repackaging, the sand fines and slag chunks can be segregated for separate dissolution or a combination of both materials packaged for dissolution at the same time. Based on the additional effort required to segregate the material during repackaging and the fact that SS\&C from Rocky Flats will likely consist of a pulverized mixture of all materials, a flowsheet for charging a combination of slag chunks and sand fines is recommended. During the repackaging of the SS\&C slag chunks should be crushed to less than approximately one inch. In addition, any clean crucible shards should be removed to maximize the plutonium and fluoride (i.e. $\mathrm{CaF}_{2}$ ) concentrations in the dissolver.

For the dissolution of a combination of sand fines and slag chunks, the dissolver should initially contain $9.3 \mathrm{M} \mathrm{HNO}_{3} / 0.075 \mathrm{M} \mathrm{KF}$. With these concentrations, a minimum of $95 \%$ of the plutonium should dissolve in less than twelve hours. Subsequent charges to the dissolver will dissolve faster due to the increase in the fluoride concentration. The amount of bulk material charged to the dissolver should be maximized, especially during the first charge, to increase the fluoride concentration as soon as possible. Once the total fluoride concentration has reached approximately $0.15 \mathrm{M}$, sand fines, slag chunks, or a combination of both materials can be charged until the total fluoride concentration reaches $0.35 \mathrm{M}$. Additional dissolution once this point has been reached is not recommended due to the potential for precipitation of fluoride salts. Estimated solution concentrations for five sequential dissolver charges are shown in Appendix I using this flowsheet. 


\section{This page has been left blank intentionally.}




\section{Introduction to Experimental Work}

In 1995 and the first half of 1996, a flowsheet was developed by SRTC that would allow dissolution of SS\&C in the 6.4D dissolver.' In that flowsheet, small batches of SS\&C containing less than approximately 350 grams of plutonium would be dissolved using one charging well in a three-well insert in each of the four dissolver ports. The flowsheet proposed the dissolution of separated SS\&C sand fines and slag chunks in a $9.3 \mathrm{M}$ nitric $\mathrm{acid} / 0.013 \mathrm{M}$ fluoride solution. The addition of ANN was required as a complexant to facilitate the complete dissolution of the calcium and plutonium fluorides associated with the slag. Following the development of that flowsheet, capacity in the 6.4D dissolver was increased by utilizing a second charging well in the three-well insert. A nuclear criticality safety evaluation required the use of $0.23 \mathrm{M}$ boron as a soluble neutron poison. Boron was not a component of the dissolver solutions used in the 1995-1996 laboratory experiments performed to develop the SS\&C flowsheet.

During the initial use of the two-well SS\&C flowsheet, it became apparent that a significant amount of the plutonium charged to the 6.4D dissolver did not dissolve completely in the time predicted by the laboratory experiments. To resolve this issue, SRTC initiated a multiphase R\&D program to explain the slow dissolution behavior and to develop flowsheet conditions which would allow complete dissolution of the SS\&C residue within a reasonable time and ensure minimal corrosion of the dissolver. The R\&D program included experiments designed to investigate both the dissolution chemistry and the physical configuration of the dissolver. Each aspect of the program is summarized in the following sections. 


\section{This page has been left blank intentionally.}




\section{Scaled Dissolver Insert Tests}

\section{A. Experimental Details}

The initial charge of material to the 6.4D dissolver consisted of a can of SS\&C sand fines. As the can dissolved, there was the potential for undissolved fines to accumulate at the bottom of the insert where contact with fresh dissolver solution could be restricted causing extremely slow dissolution times. The dissolver insert was fabricated from 6 inch schedule 80 stainless steel pipe with one-inch holes drilled through the wall to provide contact with the dissolver solution. However, the inside diameter of the insert at the bottom (for the last $63 / 4$ inches) tapers to nominally $23 / 4$ inch and only contains $1 / 2$ inch diameter holes which penetrate through two inches of stainless steel (compared to the 0.432 -inch wall thickness of 6 -inch schedule 80 pipe). The lack of circulation of dissolver solution due to the restricted, smaller holes and the accumulation of plutoniumcontaining solids at the bottom of the insert did not explain the slow plutonium dissolution rate.

Nonradioactive simulation tests were performed to understand the mechanism of SS\&C fines dissolution in the charging insert. A sketch of the charging bundle and insert is shown in Figure 1. The laboratory-scale charging bundle and insert were fabricated from glass. The initial experiment used a 1/4-scale (linear dimensions) insert. The insert was configured to contain small cans of simulated SS\&C. Those small cans were fabricated from actual SS\&C cans. The simulated SS\&C was a mixture of $50 \mathrm{wt} \%$ calcium oxide $(\mathrm{CaO}), 20 \mathrm{wt} \%$ calcium fluoride $\left(\mathrm{CaF}_{2}\right), 20 \mathrm{wt} \%$ cerium oxide, and $10 \mathrm{wt} \%$ magnesium $(\mathrm{MgO})$. The simulant was screened to a particle size less than 125 microns. The SS\&C in each can weighed approximately 12 grams and each can weighed approximately 16.25 grams. Single cans of simulated SS\&C were charged in two separate inserts in 27 liters of $9.3 \mathrm{M} \mathrm{HNO}_{3}$ with $0.013 \mathrm{M}$ fluoride as $\mathrm{KF}$ at $30^{\circ} \mathrm{C}$. No boron was added to the solution. The solution was then heated to $85^{\circ} \mathrm{C}$ with a heating mantle.

In a second experiment with the $1 / 4$-scale insert, a mixture of simulated SS\&C ( 8 grams) and fine silica sand ( 8.5 grams) was charged in a nylon bag. The objective of this test was to observe the effects of agitation on the dispersal of powder in the dissolver insert. The sample was charged to the same solution used in the initial test at $80^{\circ} \mathrm{C}$ and heated to $115^{\circ} \mathrm{C}$ (the solution boiling point). In the early part of the test, an air sparge was provided to promote mixing. Later, the air sparge was turned off and the only mixing came from the boiling solution.

The decision was made to repeat the experiment using a $1 / 2$-scale (linear dimension) charging bundle and insert to contain the cans, because the actual cans of sand fines were added to the $6.4 \mathrm{D}$ dissolver insert using a stainless steel charging bundle. The charging bundle could potentially retard the dissolution by restricting circulation and preventing contact between the sand fines and fresh $\mathrm{HNO}_{3} /$ fluoride solution. The laboratory apparatus was designed such that the holes in the insert and charging bundle did not line 
up. Two cans of simulated SS\&C containing approximately 20 grams of SS\&C fines ( $<125$ microns) were prepared. An end cap for the charging bundle was fabricated from actual can material. The stainless steel tube used with the $6.4 \mathrm{D}$ dissolver is sealed at the bottom with a mild steel cap which dissolves and releases the cans. To simulate the dissolver process as closely as possible, the cap used for this experiment was five times thicker than the actual cans so that the cans would dissolve in the holder before the end cap dissolved. The insert was charged to the solution remaining from the previous experiments at room temperature and heated to $85^{\circ} \mathrm{C}$. No sparging was provided.

A final experiment was performed using the $1 / 2$-scale charging bundle and insert to understand the dissolution characteristics of simulated slag chunks. For this experiment, $0.23 \mathrm{M}$ boron was added as boric acid to the solution left from the previous experiments. No cans were used in the experiment. A small charging cap for the charging bundle was fabricated to hold approximately 55 grams of the simulated slag chunks in the charging bundle. The simulated slag chunks were prepared by fusing a $90 \mathrm{wt} \% \mathrm{CaF}_{2} / 10 \mathrm{wt} \% \mathrm{CaO}$ mixture. The chunks were crushed until the fragments were approximately $1 / 2$-inch wide. The insert was charged at $45^{\circ} \mathrm{C}$ and heated to $85^{\circ} \mathrm{C}$ during the dissolution.

\section{B. Results and Discussion}

The following discussion is based on observations of nonradioactive simulated materials. Tests with actual plutonium and SS\&C samples gave different results and are more nearly typical of plant dissolution rates. These results are discussed in Sections VII and VIII.

In the initial $1 / 4$-scale experiment, the cans dissolved aggressively and expelled much of the powder into the process solution. When the solution cleared, small amounts of powder were observed in the insert below the bottom circulation holes. No powder was observed anywhere else in the insert. The liquid was heated for a total of 2.5 hours with 1.5 hours at $85^{\circ} \mathrm{C}$. After heating, the powder remained in the insert. While at temperature, a light air sparge was applied to the dissolver solution; the sparge did not remove the powder in the bottom of the insert. Upon examination, the powder in the insert was still finely divided and easily suspended by agitation internal to the insert.

In the second experiment the dissolution of the nylon bag created sufficient agitation to expel most of the powder from the insert. Some powder settled into the insert and, once again, its level was only below the bottom circulation holes. Agitation of the system using the air sparge did not displace powder from the insert. Use of boiling as a means of mixing also had little or no effect. As in the first test, no clumping of the powder occurred. Based on the small amount of solids which accumulated on the bottom of the scaled insert in these experiment, one can conclude that the accumulation cannot account for the slow dissolution of the plutonium in the sand fines.

Results from the $1 / 2$-Scale experiment in which simulated SS\&C fines were released from a charging bundle showed that very little powder remained in the insert. Again, there was 
only enough to cover the bottom of the insert below the lower circulation holes. This observation was surprising because the holes in the charging bundle and the insert were not aligned which severely limited the circulation of fresh dissolver solution. It is expected that dissolution of the can and the end cap expelled the powder from the insert before the end cap finished dissolving. Therefore, when the end cap finally dissolved, there was little powder left to fall into the bottom of the insert.

In the $1 / 2$-scale experiment in which simulated slag chunks were charged directly into the dissolver insert, much of the material initially fell into the bottom of the insert. Some of the chunks formed a bridge at the point in the insert where the diameter began to taper. After heating for three hours, an estimated $75 \%$ of the chunks dissolved. The only undissolved material was below the bottom circulation holes. After an additional three hours, the situation remained relatively unchanged. The material at the bottom of the insert was a mixture of small chunks and fines. 


\section{This page has been left blank intentionally.}




\section{Fluoride Complexation}

A series of experiments was conducted to determine the effective concentration of free fluoride, as measured by an Ion Selective Electrode (ISE), which was present when a range of fluoride sources and complexants was added to a $\mathrm{HNO}_{3}$ solution. These tests examined the effects of iron, aluminum, plutonium, and boron concentrations on the measured value. The testing also evaluated the available "free fluoride" from sources such as $\mathrm{CaF}_{2}$, sodium fluoride (NaF), $\mathrm{KF}$, hydrofluoric acid (HF), and mixtures of the above.

\section{A. Free-Fluoride Measurements}

\section{Experimental Details}

A common laboratory setup for measurement of total fluoride in process control samples is based upon the Nernstian response of a fluoride ISE. To measure the total fluoride, the sample is typically diluted into a neutral buffer solution with masking agents like phosphate or acetate that form stronger metal complexes than the fluoride ion. In the neutral buffer solution, the HF (a weak acid) is ionized and the fluoride ISE generates a voltage proportional to the fluoride concentration.

Measuring free fluoride in the presence of complexing agents like metals and boron requires that the sample solution remain undiluted. The SS\&C flowsheet development activities required a direct method (i.e., no sample dilution and reliance on a measured calibration curve) to determine the relative quantity of free fluoride under various processing conditions. The calibration curve for these measurements was developed using $9.3 \mathrm{M} \mathrm{HNO}_{3}$ solutions containing approximately $1,10,100$, and $1000 \mathrm{ppm}$ of a fluoride salt. Typically, $\mathrm{KF}$ was dissolved in the stock $\mathrm{HNO}_{3}$ solution to provide a nominal 0.05 fluoride concentration ( $0.05 \mathrm{M}$ fluoride is equivalent to $950 \mathrm{ppm}$ fluoride) and then serially diluted 1:10 (by volume) with the stock solution to yield each subsequent lower concentration standard. In establishing this protocol, it was realized that the values assigned to each standard were total fluoride values and that the concentration of free fluoride was a much smaller proportion of this total fluoride value. The ionization of HF is only about $2 \%$ at a pH of $1(0.1 \mathrm{M}$ acid $)$ and some smaller fraction in more concentrated acids. Figure 2 shows a published ionization curve for HF. 2 However, even with the low ionization of HF in concentrated acid solutions, the response of a typical fluoride ISE was shown to be linear with respect to the logarithm of the fluoride concentration. The response of a typical fluoride ISE (i. e. ORION 96-09 Combination Fluoride Electrode) for $10^{-5}$ to $10^{-1} \mathrm{M}$ fluoride is given in Figure 3.2

The protocol for making these measurements used the voltage readout of a typical $\mathrm{pH}$ meter along with the described standards and ISE. The response of the electrode to each standard concentration was recorded and used to plot a line describing electrode response. Measurements were made with the solution at the ambient-laboratory temperature in the 
laboratory. After the completion of each set of sample analyses, the electrode calibration was rechecked. New calibration curves were created each day. Typical fit errors for a calibration are less than $10 \%$ with test reproducibility typically better than $5 \%$. The largest deviations from linearity were seen with the one ppm standard concentration as the electrodes aged. That deviation was $+100 \%$ and could have been caused by the contamination of the standard.

\section{Results and Discussion}

Figure 4 shows the free-fluoride response of the ISE at various total fluoride concentrations in a $9.3 \mathrm{M} \mathrm{HNO}_{3} / 0.23 \mathrm{M}$ boron solution. The data points on this figure have been found to agree very well regardless of the fluoride source as long as total fluoride concentrations are less than $0.3 \mathrm{M}$ and free-fluoride concentrations are less than about 50 ppm.

The rugged design of the fluoride ISE allows measurement of small sample volumes (i.e., $1 \mathrm{ml}$ ) with little difficulty. At concentrations less than $10 \mathrm{ppm}$, sample mixing seems to be more important in achieving reproducible results than for solutions with higher concentrations of fluoride, but in general, a very easy measurement protocol similar to the following is acceptable.

a. Measure standards (e.g. 1,10,100, and $1000 \mathrm{ppm}$ ).

b. Check that electrode function is within specifications (i.e., slope between 0.054 and $0.060 \mathrm{mV} /$ decade) and that curve fit adequately describes the data.

c. Measure samples after cooling to ambient temperature.

d. Recheck electrode calibration.

f. Generate a calibration curve by plotting ( $\mathrm{mV}$ against standard total fluoride on a logarithm scale) to estimate free fluoride.

\section{B. Fluoride Complexation}

\section{Experimental Details}

The first ISE experiments measured the effects of iron, aluminum, and plutonium. In these experiments, a $9.3 \mathrm{M} \mathrm{HNO}_{3}$ solution containing $984 \mathrm{ppm}(0.05 \mathrm{M})$ total fluoride was prepared. Next, a cation source was added incrementally as the nitrate salt and the freefluoride concentration was measured to determine the degree of complexation. A separate experiment studied the incremental addition of iron metal, the actual can material used in packaging the SS\&C. A control experiment also was performed in which aluminum was added to a $1 \mathrm{M} \mathrm{HNO}_{3}$ solution. At high acid concentrations aluminum does not effectively complex fluoride.

Further testing closely examined the effect of boron and gadolinium, both neutron poisons, on the effective free fluoride. The test started with a solution of $9.3 \mathrm{M} \mathrm{HNO}_{3}$ to 
which $450 \mathrm{ppm}(0.025 \mathrm{M})$ total fluoride were added. Then boron was added incrementally as boric acid until the $\mathrm{SS} \& \mathrm{C}$ process condition of $0.23 \mathrm{M}$ boron was reached. Afterwards, $\mathrm{CaF}_{2}$ was added incrementally to measure the boron complexation of the additional fluoride. Similarly, the effect of gadolinium was tested. Gadolinium nitrate was added incrementally to a $9.3 \mathrm{M} \mathrm{HNO}_{3}$ solution which had a total fluoride concentration of $450 \mathrm{ppm}$. Measurements were made at the following gadolinium concentrations: $0.0 \mathrm{M}, 0.05 \mathrm{M}$, and $0.10 \mathrm{M}$.

The final studies focused on the effective free fluoride generated by various fluoride sources. The test started with a $9.3 \mathrm{M} \mathrm{HNO}_{3} / 0.23 \mathrm{M}$ boron solution. Next, incremental additions of $\mathrm{CaF}_{2}, \mathrm{NaF}, \mathrm{KF}$, and $\mathrm{HF}$ were made to observe the free-fluoride response and assess what might be occurring during actual SS\&C dissolution. Mixtures of fluoride sources also were measured by first adding $0.5 \mathrm{M}$ calcium nitrate to the $\mathrm{HNO}_{3} /$ boron solution and then adding incremental amounts of $\mathrm{NaF}$ or $\mathrm{KF}$.

\section{Results and Discussion}

The effective free-fluoride concentration measured by an ISE as a function of the iron and aluminum concentrations in $9.3 \mathrm{M} \mathrm{HNO}_{3}$ is shown on Figure 5. The total fluoride concentration in this solution was $984 \mathrm{ppm}(0.05 \mathrm{M})$. As expected, the ability of aluminum to complex fluoride is greater than of iron. This result is consistent with the stability constants reported in the literature (Table 1). Figure 5 also shows the ability of aluminum to complex fluoride in $1 \mathrm{M} \mathrm{HNO}_{3}$. That experiment was done as a control for this set of experiments. The final iron concentration in the canyon dissolver following the four SS\&C dissolution cycles is expected to be approximately $0.1 \mathrm{M}$. Figure 5 shows that $0.1 \mathrm{M}$ iron reduces the effective free-fluoride concentration by approximately $75 \%$. Therefore, complexation by iron cannot be dismissed as a mechanism for free-fluoride depletion. Elimination of the charging bundle end cap by replacement with a stainless steel screen would reduce the iron concentration by at least $25 \%$. However, while that modification to the charging bundle may have a significant waste minimization impact, it is not obvious that there will be any substantial improvement in the free-fluoride concentration.

The complexation of fluoride by plutonium was also measured using an ISE. Stability constants from the literature (Table 1) show that iron forms much stronger fluoride complexes than plutonium does. However, the data in Figure 6 show that plutonium does complex a significant amount of fluoride. The processing of the first batch of SS\&C should have resulted in a plutonium concentration of $0.28 \mathrm{~g} /$ liter. As can be seen from Figure 6 , this concentration is sufficient to complex over $85 \%$ of the total fluoride in the absence of other cations. Consequently, complexation by plutonium cannot be disregarded.

Measuring the free-fluoride concentration in the presence of boron demonstrated that complexation with the boric acid, added as a soluble nuclear safety poison, was the 
primary mechanism for the reduction of free fluoride in the dissolver solution. When $0.23 \mathrm{M}$ boric acid (the flowsheet requirement) was added to a $9.3 \mathrm{M} \mathrm{HNO}_{3}$ solution with $450 \mathrm{ppm}(0.025 \mathrm{M})$ total fluoride, complexation reduced the measured free fluoride from $430 \mathrm{ppm}$ to $12 \mathrm{ppm}$. The addition of even a small amount of boron has a significant effect on the measured free fluoride as can be seen on Figure 7.

A scouting experiment was performed to investigate the ability of gadolinium to complex fluoride because boron has a such a deleterious effect on free fluoride. Gadolinium might be attractive as a substitute for boron, because its cross section for neutron adsorption is approximately 60 times that of boron's. Based on cross section alone, $0.004 \mathrm{M}$ gadolinium should provide the same margin of safety as $0.23 \mathrm{M}$ boron. However, nuclear safety experts claim gadolinium is only four times as effective as boron. In the scouting experiment, the addition of $0.05 \mathrm{M}$ gadolinium only reduced the measured free fluoride from $450 \mathrm{ppm}$ to $260 \mathrm{ppm}$. Despite the potential advantages that gadolinium has with respect to free-fluoride complexation compared to boron, no recommendations to change the neutron poison to gadolinium were made in this report. If gadolinium were used, aluminum would have to be added to complex with fluoride from the dissolved slag to protect the dissolver from corrosion.

The concentration of free fluoride in $9.3 \mathrm{M} \mathrm{HNO}_{3}$ is independent of the fluoride source $\left(\mathrm{CaF}_{2}, \mathrm{NaF}, \mathrm{KF}\right.$, or $\left.\mathrm{HF}\right)$ until the solubility limit of a fluoride salt in the KF solution is exceeded. Calcium fluoride, $\mathrm{NaF}, \mathrm{KF}$, and $\mathrm{HF}$ were added incrementally to solutions of 9.3 $\mathrm{M} \mathrm{HNO}_{3}$ with $0.23 \mathrm{M}$ boron while monitoring the free-fluoride concentration with an ISE. The addition of equivalent amounts of each fluoride source gave the same freefluoride concentration until a precipitate formed at $0.30 \mathrm{M}$ total fluoride in the $\mathrm{KF}$ solution. The three remaining sources produced comparable free-fluoride concentrations up to $0.5 \mathrm{M}$ total fluoride where a divergence occurs with $\mathrm{HF}$. Calcium fluoride and $\mathrm{NaF}$ solutions gave similar results until precipitate formed in the $\mathrm{CaF}_{2}$ solution at $0.75 \mathrm{M}$ total fluoride. The $\mathrm{NaF}$ solution did not form a precipitate until $0.85 \mathrm{M}$ total fluoride. The free-fluoride concentration continued to increase with HF additions up to $1.75 \mathrm{M}$ where the experiment was terminated. The results of these experiments are summarized in Figure 8. The compositions of the precipitates from these experiments are expected to be simple fluoride salts or more complex boron compound. The solubility of sodium and potassium fluoroborates differ by a factor of about 325 in cold water with the sodium compound more soluble. This difference in solubility could explain why precipitates form at $0.3 \mathrm{M}$ potassium and at $0.85 \mathrm{M}$ sodium. These solubility data support the conclusion that complex boron compounds may be part of the precipitate.

Several experiments also were performed to measure the free-fluoride concentrations from mixed fluoride sources. These experiments examined both $\mathrm{CaF}_{2} / \mathrm{KF}$ and $\mathrm{CaF}_{2} / \mathrm{NaF}$ mixtures. Starting with a $9.3 \mathrm{M} \mathrm{HNO}_{3} / 0.5 \mathrm{M} \mathrm{CaF}_{2} / 0.23 \mathrm{M}$ boron solution, incremental additions of $\mathrm{NaF}$ or $\mathrm{KF}$ were made. The free-fluoride measurements showed that the mixture of $\mathrm{CaF}_{2} / \mathrm{KF}$ behaved comparably to that of $\mathrm{KF}$ alone. The only difference was that precipitation occurred at $0.35 \mathrm{M}$ total fluoride instead of at $0.30 \mathrm{M}$. Simitar results 
were observed with the $\mathrm{CaF}_{2} / \mathrm{NaF}$ mixture. The free-fluoride concentration of the mixture was approximately the same as $\mathrm{NaF}$ alone. As with the $\mathrm{KF}$ solution, the presence of $\mathrm{CaF}_{2}$ delayed the onset of precipitation in $\mathrm{NaF}$ solution until higher concentrations of total fluoride. Precipitation did not occur until 1.0M total fluoride was reached. Based on these results, the continued use of $\mathrm{KF}$ as the source of fluoride in the canyon dissolver is acceptable. However, if the initial fluoride concentration required for dissolution exceeds approximately $0.25 \mathrm{M}$, consideration should be given for the use of either $\mathrm{CaF}_{2}$ or $\mathrm{NaF}$ as the source of fluoride for the dissolver. 
Table 1 Selected Stability Constants for Metal Fluorides ${ }^{3}$

\begin{tabular}{|c|c|c|c|c|}
\hline Metal Ion & Equilibrium & $\log K$ & $\log K$ & $\log K$ \\
\hline & & $25^{\circ} \mathrm{C}, 0.1^{\mathrm{a}}$ & $25^{\circ} \mathrm{C}, 1.0^{\mathrm{a}}$ & $25^{\circ} \mathrm{C}, 0^{\mathrm{a}}$ \\
\hline \multirow[t]{10}{*}{$\mathrm{Al}^{3+}$} & $M L / M \bullet L$ & $6.11 \pm 0.03$ & & \\
\hline & & $6.43^{b} \pm 0.03$ & & \\
\hline & $\mathrm{ML}_{2} / \mathrm{M} \cdot \mathrm{L}^{2}$ & $11.12 \pm 0.1$ & & \\
\hline & & $11.63^{b} \pm 0.04$ & & \\
\hline & $M L_{3} / M \cdot L^{3}$ & $15.0 \pm 0.3$ & & \\
\hline & & $15.5^{b} \pm 0.0$ & & \\
\hline & $\mathrm{ML}_{4} / \mathrm{M} \cdot \mathrm{L}^{4}$ & $18.0 \pm 0.8$ & & \\
\hline & & $18.3^{b} \pm 0.4$ & & \\
\hline & $\mathrm{ML}_{5} / \mathrm{M} \cdot \mathrm{L}^{5}$ & 19.4 & & \\
\hline & $\mathrm{ML}_{6} / \mathrm{M} \cdot \mathrm{L}^{6}$ & 19.8 & & \\
\hline \multirow[t]{2}{*}{$\mathrm{Ca}^{2+}$} & $\mathrm{ML} / \mathrm{M} \bullet \mathrm{L}$ & $0.6 \pm 0.1$ & $0.58 \pm 0.05$ & 1.1 \\
\hline & $\mathrm{ML}^{2} / \mathrm{ML}_{2}(\mathrm{~s})$ & & 2.69 & -10.41 \\
\hline \multirow[t]{3}{*}{$\mathrm{Fe}^{3+}$} & $\mathrm{ML} / \mathrm{M} \bullet \mathrm{L}$ & $5.18 \pm 0.04$ & 5.18 & 6.0 \\
\hline & $\mathrm{ML}_{2} / \mathrm{M} \cdot \mathrm{L}^{2}$ & $9.13 \pm 0.04$ & 9.07 & \\
\hline & $\mathrm{ML}_{3} / \mathrm{M} \cdot \mathrm{L}^{3}$ & $11.9 \pm 0.1$ & 12.1 & \\
\hline $\mathrm{Pu}^{4+}$ & $\mathrm{ML} / \mathrm{M} \cdot \mathrm{L}$ & & 6.77 & \\
\hline
\end{tabular}

(a) Ionic Strength

(b) Ionic Strength equal to 0.1

$M$ is the metal ion.

$L$ is the fluoride ion.

The equilibrium is:

$$
M^{+n}+n F^{-}=M F_{n}
$$

concentration of products

$K$ is the

concentration of reactants 


\section{Dissolution of Actual SS\&C}

\section{A. Optimization of Dissolving Conditions}

\section{Experimental Details}

This group of experiments was performed following the suggestion to increase the total fluoride concentration in the existing $6.4 \mathrm{D}$ dissolver solution from $0.025 \mathrm{M}$ to $0.055 \mathrm{M}$ with $\mathrm{KF}$ additions. Four experiments were done in which 0.30 grams of mixed sand and slag fines were added to $100 \mathrm{ml}$ of dissolver solutions. Rocky Flats SS\&C was used in the first experiment; the remaining experiments used SRS SS\&C from the 1980s. These dissolver solutions were made up to match the actual solution in the $6.4 \mathrm{D}$ dissolver after the SS\&C fines were dissolved: $9.3 \mathrm{M} \mathrm{HNO}_{3} / 0.055 \mathrm{M}$ fluoride/0.23M boron $/ 0.022 \mathrm{M}$ iron. The solutions were heated to $88-89^{\circ} \mathrm{C}$, and the dissolution was monitored for about two hours.

\section{Results and Discussion}

The first series of optimization studies (Table 2) established that by increasing the total fluoride concentration in the existing $6.4 \mathrm{D}$ dissolver solution from $0.025 \mathrm{M}$ to $0.055 \mathrm{M}$ (current Technical Standard limit), the complete dissolution of the remaining SS\&C materials could be achieved. The increase in fluoride concentration reduced the dissolving times to about two hours. However, this group of experiments did not establish if the improved dissolving conditions would be sufficient to dissolve any highfired $\mathrm{PuO}_{2}$ that might be present in SS\&C and how long the solution would need to be at $85^{\circ} \mathrm{C}$ for complete dissolution of the high-fired $\mathrm{PuO}_{2}$.

Table 2 Dissolution of SRS and Rocky Flats SS\&C Particles

\begin{tabular}{|c|c|c|c|c|c|}
\hline $\begin{array}{c}\text { Expt. } \\
(\#)\end{array}$ & $\begin{array}{c}\text { Bulk Wt. } \\
(\mathrm{g})\end{array}$ & $\begin{array}{c}\text { Diss. Time } \\
(\text { hr:min })\end{array}$ & $\begin{array}{c}\text { Temp. } \\
(\mathrm{C})\end{array}$ & $\begin{array}{c}\text { F Conc. } \\
(\mathrm{M})\end{array}$ & $\begin{array}{c}\text { All SS\&C } \\
\text { Dissolved }\end{array}$ \\
\hline B-1 & $0.30(\mathrm{RF})$ & $1: 50$ & 89 & 0.055 & Yes \\
\hline B-2 & $0.30(\mathrm{RF})$ & $1: 48$ & 89 & 0.055 & Yes \\
\hline B-3 & $0.30(\mathrm{SRS})$ & $2: 00$ & 88 & 0.055 & Yes \\
\hline B-4 & $0.30(\mathrm{SRS})$ & $2: 00$ & 88 & 0.055 & Yes \\
\hline
\end{tabular}




\section{B. Laboratory Testing of Slag Material}

\section{Experimental Details}

In the first four experiments, SRS slag material that had been generated in the mid-1980s was used. In Experiment \#1, 1.50 grams of slag chunks were added to $150 \mathrm{ml}$ of a $9.3 \mathrm{M}$ $\mathrm{HNO}_{3} / 0.50 \mathrm{M}$ fluoride/0.23M boron/0.2M calcium solution. That first experiment was done in a glass beaker with a stirring bar providing mild agitation. The dissolution time at a solution temperature between 84 and $90^{\circ} \mathrm{C}$ was measured.

In the second and third experiments, crushed slag material was used. Those experiments were performed in a $1 / 2$-scale, glass-well insert using 1.5 liters of the $9.3 \mathrm{M} \mathrm{HNO}_{3} / 0.50 \mathrm{M}$ fluoride $/ 0.23 \mathrm{M}$ boron $/ 0.2 \mathrm{M}$ calcium solution. The solution temperatures were $80-88^{\circ} \mathrm{C}$. In Experiment \#2, the dissolution of three slag chunks, totaling 9.43 grams of slag material, was monitored for 2.2 hours. The slag chunks were added directly to the bottom of the well insert. For Experiment \#3, two more slag chunks, weighing 2.92 grams; were added to the solution from Experiment \#2. The two additional slag chunks were confined in the upper portion of the insert to determine if dissolution behavior was different in the upper portion where the circulation holes in the insert are much larger. The dissolution was monitored for six hours.

Experiment \#4 was performed to test the dissolving characteristics of crushed slag chunks in a new dissolver solution. The crushed chunks were not screened and were less than one-inch diameter pieces. The solution contained $9.3 \mathrm{M} \mathrm{HNO}_{3} / 0.06 \mathrm{M}$ fluoride $/ 0.23 \mathrm{M}$ boron $/ 0.021 \mathrm{M}$ iron $/ 0.006 \mathrm{M}$ calcium. The fluoride content $(0.06 \mathrm{M})$ was based on the flowsheet used to complete the dissolution of plutonium remaining in the $6.4 \mathrm{D}$ dissolver from the first SS\&C batch. Three chunks of crushed slag weighing 5.2 grams were added to $750 \mathrm{ml}$ of the dissolver solution in the insert. The solution was $85^{\circ} \mathrm{C}$ and the dissolution was monitored.

The next series of laboratory experiments was performed using slag chunks generated from a reduction run made in early March 1997. The recently-generated slag material represented the best opportunity to find a significant fraction of high-fired $\mathrm{PuO}_{2}$ in the $\mathrm{PuO}_{2}$ present in the slag. In Experiment $\mathrm{NSC \# 1}$, a 5.0 gram slag chunk was added directly into an insert containing $750 \mathrm{ml}$ of dissolver solution. The dissolver solution was $9.3 \mathrm{M} \mathrm{HNO}_{3} / 0.06 \mathrm{M}$ boron $/ 0.021 \mathrm{M}$ iron $/ 0.006 \mathrm{M}$ calcium. The dissolution was monitored for 2.2 hours at a solution temperature of $80-86^{\circ} \mathrm{C}$. Next, 5.19 grams of small slag slivers were added to the solution (NSC\#1a). The slivers were generated from the crushing of the large slag chunks. It was expected that the smaller fragments would contain the bulk of the plutonium. The dissolution was monitored for 1.75 hours at a solution temperature of $80-84^{\circ} \mathrm{C}$.

In the next experiments (NSC\#2, NSCH2a, NSCH2b), there were three separate additions of slag chunks to $380 \mathrm{ml}$ of the dissolver solution $\left(9.3 \mathrm{M} \mathrm{HNO}_{3} / 0.06 \mathrm{M}\right.$ boron $/ 0.021 \mathrm{M}$ 
iron/0.006M calcium). The dissolution for each addition was monitored for approximately two hours at a solution temperature between $80^{\circ}$ and $90^{\circ} \mathrm{C}$. Next, 0.05 grams of high-fired $\mathrm{PuO}_{2}$ were added to the dissolver solution (NSC\#2c). The dissolution was followed for 15.8 hours at a solution temperature of $86-90^{\circ} \mathrm{C}$. The dissolution test was performed to determine the dissolving time for a known quantity of high-fired $\mathrm{PuO}_{2}$. The clear dissolver solutions generated in experiments NSC\#1 and NSC\#2 were filtered and the residue on the filter paper submitted for analysis.

\section{Results and Discussion}

Results from the four experiments reported in Table 3 confirm that slag chunks will dissolve in solutions containing boron without any aluminum present in less than eight hours. The longer times required for some of the chunks to dissolve could be an indication that high-fired $\mathrm{PuO}_{2}$ was present. No obvious difference in dissolving rates was noted between inside and outside of well inserts nor was there any dependency on the location within the insert noted.

In Experiment \#1, all solids were dissolved after 5.3 hours. The clear, pale blue-green solution indicated that a significant amount of plutonium had been present in the slag chunk. Subsequent solution analysis found 0.11 grams of plutonium/gram of slag chunk.

Table 3 Dissolution of Crushed Slag Chunks

\begin{tabular}{|c|c|c|c|c|c|}
\hline $\begin{array}{c}\text { Expt. } \\
(\#)\end{array}$ & $\begin{array}{c}\text { Chunk Wt. } \\
(\mathrm{g})\end{array}$ & $\begin{array}{c}\text { Diss. Time } \\
(\mathrm{hr}: \mathrm{min})\end{array}$ & $\begin{array}{c}\text { Temp. } \\
(\mathrm{C})\end{array}$ & $\begin{array}{c}\text { Pu Content } \\
(\mathrm{wt} \%)\end{array}$ & $\begin{array}{c}\text { All SS\&C } \\
\text { Dissolved }\end{array}$ \\
\hline Expt-\#1 & 1.50 & $5: 18$ & $84-90$ & 11.0 & Yes \\
\hline Expt-\#2 & 9.43 & $2: 12$ & $80-85$ & NA & No \\
\hline Expt-\#3 & 12.68 & $7: 57$ & $80-88$ & 14.6 & Yes \\
\hline Expt-\#4(*) & 5.2 & $2: 35$ & $83-85$ & 4.9 & Yes \\
\hline
\end{tabular}

(*) For EXPT-\#4, the initial composition of the dissolving solution was $750 \mathrm{ml}$ of $9.3 \mathrm{M}$ $\mathrm{HNO}_{3} / 0.06 \mathrm{M}$ fluoride/ $0.23 \mathrm{M}$ boron/0.06M calcium.

As the three slag chunks tested in Experiment \#2 crumbled and dissolved, all of the slag chunks and residue particles remained inside the well insert during the entire dissolution process. This containment was maintained even though most of the particles were small enough to escape through insert holes. After 2.2 hours of dissolution, only parts of the two larger chunks remained. This result was the first indication that larger slag chunks may take longer to dissolve in the inserts, and as a result, crushing the slag material may be necessary to meet dissolution time requirements. Analysis of the solution indicated that 0.40 grams of plutonium had dissolved.

In Experiment \#3, all solids had dissolved in about eight hours. Analysis of the clear, pale blue-green dissolver solution found that 1.85 grams of plutonium had dissolved; that 
amount of plutonium was equivalent to $14.6 \mathrm{wt} \%$ plutonium in the slag chunks. The chunks tested in Experiment $\# 4$ dissolved after 2.5 hours at $85^{\circ} \mathrm{C}$. The solution contained 0.255 grams of plutonium which is equivalent to $4.9 \mathrm{wt} \%$ plutonium in the slag chunks.

Results from the last series of slag dissolving experiments (NSC\#1x and NSC\#2x) are presented in Table 4.

The chunk tested in experiment NSC\#1 dissolved completely after 2.2 hours at $80-86^{\circ} \mathrm{C}$. The solution remained the pale yellow color from dissolved iron indicating that little plutonium had dissolved. Analysis of the dissolver solution found less than $1 \mathrm{wt} \%$ plutonium was in the slag chunk. Only 1.75 hours were needed for the complete dissolution of the slag slivers that were tested in experiment NSC\#1a. The pale yellow solution had turned to pale blue-green indicating that a significant amount of plutonium was in solution. Solution analysis showed that the slag slivers were about $10 \mathrm{wt} \%$ plutonium.

Results from experiments NSC\#1 and NSC\#la indicate that little, if any, high-fired $\mathrm{PuO}_{2}$ is present in this batch of recently-generated crushed slag chunks. If the plutonium in NSC\#la were high-fired $\mathrm{PuO}_{2}$, it should not have completely dissolved in less than two hours.

Each of the slag additions in experiments NSC\#2, NSC\#2a, and NSC\#2b were dissolved in less than two hours at solution temperatures between $80-90^{\circ} \mathrm{C}$. The solution was analyzed after the three additions and the average plutonium content of the three chunks was about $1 \mathrm{wt} \%$.

Table 4 Dissolution of New Slag Chunks

\begin{tabular}{|c|c|c|c|c|c|}
\hline $\begin{array}{c}\text { Expt. } \\
(\#)\end{array}$ & $\begin{array}{c}\text { Chunk Wt. } \\
(\mathrm{g})\end{array}$ & $\begin{array}{c}\text { Diss. Time } \\
(\mathrm{hr}: \mathrm{min})\end{array}$ & $\begin{array}{c}\text { Temp. } \\
(\mathrm{C})\end{array}$ & $\begin{array}{c}\text { Pu Content } \\
(\mathrm{wt} \%)\end{array}$ & $\begin{array}{c}\text { All SS\&C } \\
\text { Dissolved }\end{array}$ \\
\hline NSC\#1 & 5.00 & $2: 10$ & $80-86$ & 0.92 & Yes \\
\hline NSC\#1a & 5.19 & $1: 45$ & $80-84$ & 9.83 & Yes \\
\hline NSC\#2 & 4.24 & $1: 07$ & $80-90$ & 1.2 & Yes \\
\hline NSC\#2a & 2.71 & $1: 24$ & $84-88$ & 0.90 & Yes \\
\hline NSC\#2b & 1.8 & $1: 20$ & $88-90$ & 1.0 & Yes \\
\hline NSC\#2c & $0.0503\left(\mathrm{PuO}_{2}\right)$ & $4: 48$ & $96-90$ & $96.6 \%$ & $\begin{array}{c}\text { high-fired } \\
\text { PuO2 } \\
\text { dissolved }\end{array}$ \\
\hline NSC\#2d & -- & $7: 48$ & 86 & $99.7 \%$ & $\begin{array}{c}\text { high-fired } \\
\text { PuO } 2 \\
\text { dissolved }\end{array}$ \\
\hline NSC\#2e & -- & $15: 30$ & $80-84$ & $97.0 \%$ & $\begin{array}{c}\text { no plutonium } \\
\text { in remaining } \\
\text { solids }\end{array}$ \\
\hline
\end{tabular}


Experiments NSC\#2c, NSC\#2d, and NSC\#2e tested the dissolution of high-fired $\mathrm{PuO}_{2}$. The $\mathrm{PuO}_{2}$ was added to the solution used for experiments NSC\#2, NSC\#2a, and NSC\#2b. The dissolution of the $\mathrm{CaF}_{2}$ in the slag chunks in the three experiments increased in the fluoride concentration in the solution from 0.2 to $0.3 \mathrm{M}$. That fluoride concentration was estimated using the assumption that $60 \mathrm{wt} \%$ of the slag chunks was $\mathrm{CaF}_{2}$.

After 4.8 hours at $86-90^{\circ} \mathrm{C}$, solution analysis indicated $96.6 \%$ of the high-fired $\mathrm{PuO}_{2}$ had dissolved (NSC\#2c). After another three hours at $86^{\circ} \mathrm{C}$, solution analysis indicated $99.7 \%$ of the high-fired $\mathrm{PuO}_{2}$ was in solution (NSC\#2d). The final solution sample was taken after 15.5 hours at $80-84^{\circ} \mathrm{C}$. The analysis of the solution did not show that any additional plutonium had dissolved during the last 6 to 7 hours. The solutions for the NSC\#1x and NSC\#2x experiments were filtered. There were a few small white specks visible on the filter paper but scanning electron microscope SEM analysis did not show any plutonium.

\section{Dissolution of Sand and Slag Fines - Rate vs. Free-Fluoride Concentration}

\section{Experimental Details}

As follow-up to the tests demonstrating fluoride complexation by boron, experiments were done to measure the rate sand and slag fines dissolved as a function of free-fluoride concentration. These rate measurements were conducted using the standard dissolution apparatus ( $400 \mathrm{ml}$ beaker, hot plate, large watch glass immersion dial thermometer, Teflon ${ }^{\mathrm{TM}}$ coated magnetic stir bar) used in original flowsheet development. The sample of fines used in these tests was from a can marked SC-178 (SRS fines separated from SS\&C), which contained nominally $20 \mathrm{wt} \% \mathrm{Pu}$. Each rate measurement used $100 \mathrm{ml}$ of the $9.3 \mathrm{M} \mathrm{HNO}_{3} / 0.23 \mathrm{M}$ boron test solution with varying amounts of total fluoride. The fluoride in these tests was from two sources - either KF or HF or a combination of both. The free fluoride was measured at ambient temperature both before and after dissolution of the SRS fines. These experiments were conducted according to the following protocol.
a. Solutions prepared and free fluoride measured.
b. $\quad 100 \mathrm{ml}$ of solution added to beaker and heated to $85^{\circ} \mathrm{C}$. Solution temperature was controlled between $85-90^{\circ}$.
c. $\quad 0.03$ grams of fines weighed out on two-place Mettler AE 204 balance.
d. Fines added to heated solution and stirred: water was kept on watch glass during heating to minimize loss from evaporation.
e. Solution monitored closely to determine time required for particulates to dissolve and solution to become clear.
g. Samples removed from heat and transferred to polyethylene storage bottles.
h. Free-fluoride measurements were repeated after samples cooled. 
i. Beakers and related equipment were rinsed with dilute acid and drained prior to use for subsequent samples.

Using this protocol, ten solutions were tested to generate Figure 9. Table 5 contains the descriptions of the solutions' compositions. After the dissolution tests, the solutions were stored and then used in tests for downstream chemistry effects. The solutions' identification for the tests on downsteam chemistry are given in Column 10 of Table 5.

Table 5 Dissolution Conditions for SS\&C Fines

\begin{tabular}{|c|c|c|c|c|c|c|c|c|c|}
\hline $\begin{array}{c}\text { Run } \\
\#\end{array}$ & $\begin{array}{c}\text { Boron } \\
(\mathrm{M})\end{array}$ & $\begin{array}{c}\mathrm{HNO}_{3} \\
(\mathrm{M})\end{array}$ & $\begin{array}{c}\text { Total F } \\
(\mathrm{M})=\end{array}$ & $\begin{array}{c}\mathrm{HF} \\
(\mathrm{M})\end{array}$ & $\begin{array}{c}\mathrm{KF} \\
(\mathrm{M})\end{array}$ & $\begin{array}{c}\text { Free F- } \\
(\mathrm{star})\end{array}$ & $\begin{array}{c}\text { Free F- } \\
(\mathrm{end})\end{array}$ & $\begin{array}{c}\text { Dissolution } \\
\text { Time (min) }\end{array}$ & $\begin{array}{c}\text { Bottle } \\
\text { ID }\end{array}$ \\
\hline 1 & 0 & 9.3 & 0.05 & 0.05 & 0 & 825 & 325 & 0 & $\mathrm{~b} 5$ \\
\hline 2 & 0.23 & 9.3 & 0.05 & 0.05 & 0 & 19 & 25 & 35 & $\mathrm{~b} 6$ \\
\hline 3 & 0.23 & 9.3 & 0.9 & 0.9 & 0 & 117 & 117 & 2 & $\mathrm{~b} 7$ \\
\hline 4 & 0.23 & 9.3 & 0.025 & 0.025 & 0 & 13 & 21 & 60 & $\mathrm{~b} 8$ \\
\hline 5 & 0.23 & 9.3 & 0.325 & 0.025 & 0.3 & 48 & 41 & 8 & $\mathrm{~b} 9$ \\
\hline 6 & 0.23 & 9.3 & 0.175 & 0.025 & 0.15 & 30 & 38 & 10 & $\mathrm{~b} 10$ \\
\hline 7 & 0.23 & 9.3 & 0.175 & 0.025 & 0.05 & 19 & 25 & 30 & $\mathrm{~b} 11$ \\
\hline 8 & 0.23 & 9.3 & 0.1 & 0 & 0.1 & 23 & 29 & 20 & $\mathrm{~b} 12$ \\
\hline 9 & 0.23 & 9.3 & 0.15 & 0 & 0.15 & 31 & 31 & 14 & $\mathrm{~b} 13$ \\
\hline 10 & 0.23 & 9.3 & 0.25 & 0 & 0.25 & 41 & 41 & 9 & $\mathrm{~b} 14$ \\
\hline
\end{tabular}

\section{Results and Discussion}

The data generated in this series of tests were indicative of actual conditions in the $6.4 \mathrm{D}$ dissolver during the initial charge in October 1997. Analysis of the dissolver solution showed a free-fluoride concentration to be on the order of $15 \mathrm{ppm}$. For this value, many hours at $85^{\circ} \mathrm{C}$ would be required to dissolve any $\mathrm{PuO}_{2}$. By spiking an aliquot of the dissolver sample with a known quantity of $\mathrm{KF}$ proportional to the amount allowed by the standard $(0.05 \mathrm{M})$, the free-fluoride concentration rose to between 20 and $25 \mathrm{ppm}$ which should reduce the dissolution time consistent with the curve in Figure 9. When additional $\mathrm{KF}$ was added to the $6.4 \mathrm{D}$ dissolver solution to increase the total (added) fluoride to $0.05 \mathrm{M}$, essentially all the remaining plutonium dissolved in the 12 -hour cycle as would be predicted by Figure 9 .

The balance used to weigh samples for these and the initial $\mathrm{PuO}_{2}$ dissolution tests was sufficient to measure plutonium recovery based on solution assay. The choice of evaluating dissolution rate based on visual observation was maintained from the initial flowsheet development efforts. In similar tests with high-fired $\mathrm{PuO}_{2}$ at much lower solution volumes, the visual observation was replaced by filtering the solution and evaluating the solids contained on each filter paper by SEM. 
The SEM analysis demonstrated that micron-size plutonium particles may be present in solutions that are visually very clear. The presence of these particles in dissolver solutions is anticipated whenever high-fired $\mathrm{PuO}_{2}$ is dissolved. These particles are not insoluble but their dissolution slows down as the particles' surface area decreases, as observed in multiple experiments. Any microscopic particulates of $\mathrm{PuO}_{2}$ remaining after the allotted dissolution time for a given charge will continue to dissolve with the subsequent charges. The micron-size particles will remain suspended in the dissolver solution as long as the sparge is on. The remaining dense microscopic $\mathrm{PuO}_{2}$ particles will be removed from the dissolver solution during the centrifuge step and will impose no risk for plutonium solids in downstream process vessels. Discussions with NMSP Engineering personnel indicate that microscopic plutonium particles should not present a nuclear safety concern under the current Technical Standard of plutonium recovery requirements.

The plutonium Diode Array Spectrophotometric (DAS) analysis is used frequently to measure the plutonium concentration of process solutions. The DAS analysis does not respond to particles in solution. The alpha assay measurements also would be biased low and lead to the calculation of more conservative values of plutonium recovery from an SS\&C charge. To determine if any microscopic plutonium particles are suspended in a solution, an SEM analysis is needed. As an example, selected solutions in which the plutonium recovery had been noted as complete were tested. Those solutions were similar to the solutions that were used for plutonium solids analysis in process tanks. The solutions were filtered. The filter papers were rinsed, dried, and analyzed by SEM for plutonium particles Plutonium was identified by Energy Dispersive X-Ray measurements. A qualitative estimate of the amount of plutonium was made by comparing the amount of material on the filter papers from the filtration of the solutions with the "completely" dissolved $\mathrm{PuO}_{2}$ and with the amount of material left from the filtration of a control solution. The control solution was an acid solution in which a known amount of $\mathrm{PuO}_{2}$ was suspended. That amount of suspended $\mathrm{PuO}_{2}$ was $5 \%$ of the amount of $\mathrm{PuO}_{2}$ that had been used in the dissolution tests. The comparison indicated that much less than $5 \mathrm{wt} \%$ of the $\mathrm{PuO}_{2}$ had been collected on the filter paper of the solutions with "completely" dissolved $\mathrm{PuO}_{2}$. 


\section{This page has been left blank intentionally.}




\section{Dissolution of High-Fired Plutonium Oxide}

Experimental results with SRS fines demonstrated that even solutions that visually do not appear to have any undissolved particles may contain micron-size particles. The particles become evident when the solutions are filtered. High-fired $\mathrm{PuO}_{2}$ dissolves slowly and thus could be a source of particles in the F-Canyon dissolvers. The SRS SS\&C does contain some fraction of high-fired $\mathrm{PuO}_{2}$ because the reduction of $\mathrm{PuF}_{4}$ and $\mathrm{PuO}_{2}$ to plutonium metal is incomplete. It is estimated that $0-20 \mathrm{wt} \%$ of the plutonium in SRS $\mathrm{SS} \& \mathrm{C}$ may be from high-fired $\mathrm{PuO}_{2}$. High-fired $\mathrm{PuO}_{2}$ has been universally acknowledged as difficult to dissolve and requires long dissolution times even at $0.1 \mathrm{M}$ $\mathrm{HF}$ (>1000 ppm free fluoride) without boron.

To determine the conditions required for the dissolution of high-fired $\mathrm{PuO}_{2}$ in $\mathrm{HNO}_{3}$ /fluoride solutions with $0.23 \mathrm{M}$ boron, a broad range of processing conditions were investigated and the conditions that were most amenable for a modified processing flowsheet in F-Canyon were tested in greater detail. The selected conditions represent a balance of the dissolution rates with corrosion rates, material solubilities, and downstream processing conditions. Multiple experiments were done and are described and discussed in the following sections.

\section{A. Dissolution of High-Fired $\mathrm{PuO}_{2}$ as a Worst Case Surrogate for SS\&C}

\section{Experimental Details}

Results from original flowsheet development efforts that included SS\&C materials from Rocky Flats (RF) showed that the fines dissolved in relatively short periods of time even with boron present and low concentrations of free fluoride. This observation, in conjunction with the recent dissolution experience with SRS SS\&C fines, resulted in a more detailed look at these two sources of SS\&C.

At SRS, the feed to the reduction process is produced by the conversion of plutonium trifluoride $\left(\mathrm{PuF}_{3}\right)$ to a 3:1 molar mixture of $\mathrm{PuF}_{4}$ and $\mathrm{PuO}_{2}$ by reaction with oxygen at $500^{\circ} \mathrm{C}$ [Equation (1)].

$$
4 \mathrm{PuF}_{3}+\mathrm{O}_{2} \rightarrow 3 \mathrm{PuF}_{4}+\mathrm{PuO}_{2}
$$

The resulting mixture is reduced to plutonium metal with calcium as shown in Equations (2) and (3).

$$
\begin{aligned}
& \mathrm{PuF}_{4}+2 \mathrm{Ca} \rightarrow \mathrm{Pu}+2 \mathrm{CaF}_{2} \\
& \mathrm{PuO}_{2}+2 \mathrm{Ca} \rightarrow \mathrm{Pu}+2 \mathrm{CaO}
\end{aligned}
$$

At RF, the feed to the reduction process was primarily $\mathrm{PuF}_{4}$ which was produced by reaction of $\mathrm{PuO}_{2}$ feed with hydrogen fluoride gas [Equation (4)]. 


$$
\mathrm{PuO}_{2}+4 \mathrm{HF} \rightarrow \mathrm{PuF}_{4}+2 \mathrm{H}_{2} \mathrm{O}
$$

Conversion of the $\mathrm{PuO}_{2}$ to $\mathrm{PuF}_{4}$ during the hydrofluorination process was typically greater than $95 \%$, and much of the remaining $\mathrm{PuO}_{2}$ was likely co-reduced with the $\mathrm{PuF}_{4}$ to metal during the reduction process. Therefore, the amount of high-fired $\mathrm{PuO}_{2}$ in the RF SS\&C is probably very small in contrast to the SS\&C from SRS. The difference in the high-fired $\mathrm{PuO}_{2}$ content may explain the observed differences in dissolution conditions required for SRS and RF SS\&C materials.

Table 6 shows the range of concentrations of SRS and RF SS\&C slag and fines. To assess the impact of the possible $20 \%$ high-fired $\mathrm{PuO}_{2}$ in the SRS SS\&C material on the plant dissolution rates, a series of dissolution tests were done using a broad range of freefluoride concentrations and conditions similar to those described for the SRS fines dissolution. The tests used solutions prepared for the initial corrosion evaluation of the anticipated dissolver make-up. The compositions of the corrosion test solutions are given in Table 7.

Table 6 Nominal Compositions of RF and SRS SS\&C*

\begin{tabular}{|c|c|c|}
\hline Component & $\begin{array}{c}\text { Sand Composition } \\
(\mathrm{wt} \%)\end{array}$ & $\begin{array}{c}\text { Slag Composition } \\
(\mathrm{wt} \%)\end{array}$ \\
\hline Plutonium (SRS) & $12-56$ & $3-10$ \\
\hline Calcium (SRS) & $0-2$ & $1-20$ \\
\hline Plutonium (RF) & $25-54$ & $1-8$ \\
\hline Calcium (RF) & $0-1$ & $0-5$ \\
\hline $\mathrm{CaO}$ & $30-50$ & $5-10$ \\
\hline $\mathrm{CaF} 2$ & $10-30$ & $60-80$ \\
\hline $\mathrm{MgO}$ & $5-15$ & $1-5$ \\
\hline
\end{tabular}

* No large crucible shards present in any of these samples. 
Table 7 Compositions of Corrosion Test Solutions

\begin{tabular}{|c|c|c|c|c|c|l|}
\hline $\begin{array}{c}\text { Solution } \\
\#\end{array}$ & $\begin{array}{c}\mathrm{KF} \\
\text { Molar })\end{array}$ & $\begin{array}{c}\mathrm{B} \\
(\text { Molar })\end{array}$ & $\begin{array}{c}\mathrm{CaF}_{2} \\
(\text { Molar })\end{array}$ & $\begin{array}{c}\mathrm{Fe} \\
(\mathrm{g} / \text { /iter })\end{array}$ & $\begin{array}{c}\mathrm{MgO} \\
(\mathrm{g})\end{array}$ & \multicolumn{1}{|c|}{ Comments } \\
\hline 1 & 0.05 & 0 & 0 & 0 & 0 & Control solution \\
\hline 2 & 0.05 & 0.23 & 0 & 0 & 0 & Corrosion as a function of $\mathrm{F}^{-}$ \\
\hline 3 & 0.1 & 0.23 & 0 & 0 & 0 & Corrosion as a function of $\mathrm{F}^{-}$ \\
\hline 4 & 0.2 & 0.23 & 0 & 0 & 0 & Corrosion as a function of $\mathrm{F}^{-}$ \\
\hline 5 & 0.3 & 0.23 & 0 & 0 & 0 & Corrosion as a function of $\mathrm{F}^{-}$ \\
\hline 6 & 0.2 & 0.23 & 0 & 0 & 0 & $\begin{array}{l}\text { Aluminum effect }-1 \text { part } 60 \% \\
\text { ANN }+3 \text { parts solution }\end{array}$ \\
\hline 7 & 0.05 & 0.23 & 0.075 & 0 & 0 & $0.2 \mathrm{M} \mathrm{F}^{-}$from two sources \\
\hline 8 & 0.2 & 0.23 & 0 & 1.2 & 1.25 & more complete simulant \\
\hline
\end{tabular}

The dissolutions were done in $50-\mathrm{ml}$ beakers with $10 \mathrm{ml}$ of the corrosion test solution. Two high-fired $\mathrm{PuO}_{2}$ loadings were tested: 0.1 grams and 0.03 grams. A two-place balance was used to weigh the high-fired $\mathrm{PuO}_{2}$. The samples were stirred with Teflon ${ }^{\mathrm{TM}}$ coated magnetic stirrer bars and heated and maintained at reflux conditions for three hours using a combination stirrer/hot plate. After cooling to ambient temperature, the final free-fluoride concentration was measured and an aliquot of each cooled solution was submitted for alpha assay by liquid scintillation counting (Rad Screen). Selected solutions also were filtered and the solids were submitted for evaluation by the SEM.

\section{Results and Discussion}

The alpha assays were corrected for known inefficiencies. The approximate plutonium concentrations for the solutions were calculated from the alpha assay. A sample calculation for converting the alpha-activity values $(\mathrm{dpm} / \mathrm{ml})$ to grams plutonium/liter is:

Total alpha activity $(\mathrm{dpm} / \mathrm{ml}) *(1000 \mathrm{ml} /$ liter $) /\left(1.6 \times 10^{11} \mathrm{dpm} / \mathrm{g}\right)=\mathrm{g}$ plutonium $/$ liter.

The three-hour dissolution results are presented in Table 8. Dissolution of the high-fired $\mathrm{PuO}_{2}$ samples was notably slower than for similar quantities of SS\&C fines. The data in Table 8 show that the dissolution rate is dependent on the free-fluoride concentration. Solution \#1 is the control solution (recommended maximum fluoride concentration of the original flowsheet prior to boron addition). Comparison of the results (Samples 1 and 1B) from Solution \#1 to the results from Solution \#2 (Samples 2 and 2B) clearly demonstrates the influence of boron on dissolution rates. Dissolution of Sample 7 indicates a rate similar to the control solution in spite of the anticipated trend toward slower dissolution rates with boron present. This anomalous data point was shown in subsequent testing to be caused by calcium ions in the dissolution solution. (More details of this synergistic effect will be covered later in this section.) 
Flowsheet Modifications for Dissolution of Sand, Slag, and Crucible Residues in the F-Canyon Dissolvers

Table 8 Results of Three Hour Dissolution Tests on High-Fired $\mathrm{PuO}_{2}$

\begin{tabular}{|c|c|c|c|c|}
\hline Sample \# & $\begin{array}{c}\text { Amount of } \mathrm{PuO}_{2} \\
\text { in } 10 \mathrm{ml}(\mathrm{grams})\end{array}$ & $\begin{array}{c}\text { Initial Free } \\
\text { Fluoride }(\mathrm{ppm})\end{array}$ & $\begin{array}{c}\% \mathrm{Pu} \\
\text { Dissolved }\end{array}$ & $\begin{array}{c}\text { Free Fluoride in } \\
\text { cooled solution }\end{array}$ \\
\hline 1 & 0.1 & 904 & $>100$ & 53 \\
\hline $1 \mathrm{~B}$ & 0.03 & 904 & $>100$ & 18 \\
\hline 2 & 0.03 & 21 & 70 & 16 \\
\hline $2 \mathrm{~B}$ & 0.1 & 21 & 50 & 8 \\
\hline 3 & 0.1 & 29 & 60 & 13 \\
\hline 4 & 0.1 & 41 & 65 & 15 \\
\hline 5 & 0.1 & 50 & 65 & 19 \\
\hline $5 \mathrm{~B}$ & 0.03 & 50 & $>100$ & 24 \\
\hline 7 & 0.1 & 40 & $>100$ & 109 \\
\hline 8 & 0.1 & 41 & 40 & 13 \\
\hline
\end{tabular}

The sample numbers refer to the solution compositions in Table 7. The suffix $B$ in the sample numbers indicates that a second test was done for a particular test solution from Table 7.

In summary, the dissolution tests show that, in general, $<75 \%$ of the $\mathrm{PuO}_{2}$ dissolved within three hours over the range of 10-50 ppm free fluoride in the starting solution.

\section{B. Optimization of Total Fluoride for "Complete" Dissolution}

\section{Experimental Details}

The first series of high-fired $\mathrm{PuO}_{2}$ dissolution tests were done in solutions with total fluoride concentrations ranging from 0.05 to $0.3 \mathrm{M}$. These tests demonstrated that dissolution rates for the high-fired $\mathrm{PuO}_{2}$ are too slow to recover $>95 \%$ plutonium from the material in three hours of processing at $85-90^{\circ} \mathrm{C}$. To identify the conditions required to dissolve high-fired $\mathrm{PuO}_{2}$ within three hours, tests were done using the $9.3 \mathrm{M}$ $\mathrm{HNO}_{3} / 0.23 \mathrm{M}$ boron stock solution with 0.15 or $0.25 \mathrm{M} \mathrm{CaF}_{2}$. Another set of tests was done using a $7.0 \mathrm{M} \mathrm{HNO}_{3} / 0.23 \mathrm{M}$ boron stock solution with 0.15 or $0.30 \mathrm{M} \mathrm{CaF}_{2}$. The experiments were done using $50 \mathrm{ml}$ beakers and $10 \mathrm{ml}$ of solution with $0.03 \mathrm{~g}$ of highfired $\mathrm{PuO}_{2}$ added to each $10 \mathrm{ml}$ solution. The plutonium loading was selected to provide about two times the final plutonium concentration allowed in the $6.4 \mathrm{D}$ dissolver. Samples were taken at one, two, and three hours to monitor the plutonium recovery. The free-fluoride concentration was measured in each solution before starting the dissolution and after each of the hourly samples cooled to ambient temperature. The compositions of the test solutions, along with concentration data, are presented in Table 9. The results of the tests are presented in Figure 10. 
Table 9. Composition of Test Solutions and Free-Fluoride Concentrations

\begin{tabular}{|c|c|c|c|c|c|}
\hline Sample \# & $\begin{array}{c}\text { Concentration } \\
\text { of Acid (M) }\end{array}$ & $\begin{array}{c}\text { Concentration } \\
\text { of Boron (M) }\end{array}$ & $\begin{array}{c}\text { Concentration } \\
\text { of } \mathrm{CaF}_{2}(\mathrm{M})\end{array}$ & $\begin{array}{c}\text { Initial Free } \\
\text { Fluoride } \\
(\mathrm{ppm})\end{array}$ & $\begin{array}{c}\text { Final Free } \\
\text { Fluoride } \\
(\mathrm{ppm})\end{array}$ \\
\hline $\mathrm{A}$ & 9.3 & 0.23 & 0.15 & 60 & 49 \\
\hline $\mathrm{B}$ & 9.3 & 0.23 & 0.25 & 78 & 57 \\
\hline $\mathrm{C}$ & 7.0 & 0.23 & 0.15 & 89 & 58 \\
\hline $\mathrm{D}$ & 7.0 & 0.23 & 0.30 & 153 & 128 \\
\hline
\end{tabular}

\section{Results and Discussion}

The initial SS\&C flowsheet design required the 6.4D dissolver to be heated for three hours to dissolve the SS\&C fines. These tests were used to demonstrate that rapid dissolution rates can be attained with sufficient free fluoride in the dissolver solution even though a significant fraction of the charge is high-fired $\mathrm{PuO}_{2}$. The inaccuracy of the twoplace balance used to weigh the $\mathrm{PuO}_{2}$ prevented an accurate measurement of the highfired $\mathrm{PuO}_{2}$ additions and thus prevented an accurate assessment of complete dissolution. However, complete dissolution was assumed once the plutonium concentration became constant, e.g., in the 0.5 and $0.6 \mathrm{M}$ fluoride curves, complete dissolution is assumed after one to two hours at temperature. The difference in dissolution rates between $9.3 \mathrm{M} \mathrm{HNO}_{3}$ at $80 \mathrm{ppm}$ free fluoride and $7.0 \mathrm{M} \mathrm{HNO}_{3}$ at $90 \mathrm{ppm}$ free fluoride suggested that processing with $9.3 \mathrm{M} \mathrm{HNO}_{3}$ offers advantages in reduced corrosion rates because corrosion rates have been shown to be a function of the free-fluoride concentration. The advantages offered by lower-acid concentrations for dissolver solutions include less dilution of the solution content to prepare it as feed for the Second Plutonium Cycle and increased boron solubility.

The rapid, complete dissolution observed with the $0.25 \mathrm{M}$ and $0.30 \mathrm{M} \mathrm{CaF} 2$ solutions suggested that sufficient calcium ions can lower the amount of initial fluoride that is required in the dissolver solution for the adequate dissolution of high-fired $\mathrm{PuO}_{2}$. While it is desirable to recover $100 \%$ of the plutonium, an optimized flowsheet requires good balance among corrosion rates, impacts on downstream processing (evaporator operation, total waste generation, etc.), and dissolution time. To support the investigation of broader processing options, additional tests were done using $7.0 \mathrm{M} \mathrm{HNO}$ at lower total fluoride to identify conditions that could provide acceptable dissolution rates and feed for the Second Plutonium Cycle with less plutonium in the dissolver. These additional tests are described later in this section. 


\section{Evaluation of Calcium Effect on the Dissolution Rate}

\section{Experimental Details}

The range of calcium and fluoride concentrations evaluated in this group of tests spanned those of earlier tests with the intent of adding additional data points and improving the material balance for plutonium during the dissolution. A four-place analytical balance (Mettler Model AE240) was introduced into the glovebox to improve accuracy for the high-fired $\mathrm{PuO}_{2}$ and solution weight measurements. The weight of a known volume of a cooled solution was used to determine its density. The solution measurements were corrected for evaporation of the dissolver solution. The experimental setup was changed to use Teflon ${ }^{\mathrm{TM}}$ beakers because silica solids were found in previous tests with highfluoride concentrations ( $0.5 \mathrm{M}$ fluoride). The standard $9.3 \mathrm{M} \mathrm{HNO}_{3} / 0.23 \mathrm{M}$ boron solution was used with the calcium and fluoride concentrations as defined in Table 10. The plutonium recovery data for the tests are presented in Figure 11. The sample times were also adjusted to 60,90 , and 120 minutes in an attempt to refine the precision of the dissolution rate data.

\section{Results and Discussion}

A review of Table 10 shows three experiments with a constant fluoride concentration of $0.6 \mathrm{M}$ with the calcium concentration varied at $0.1,0.2$, and $0.3 \mathrm{M}$. Three other experiments were performed with the calcium concentration held constant at $0.3 \mathrm{M}$ and the fluoride concentration varied at $0.4,0.5,0.6$, and $0.7 \mathrm{M}$. The samples were heated on hot plates with the settings positioned to provide good reflux of solution but below the solution's boiling point. However, post-experiment review of the data indicated that the hot plate for samples DD, EE, and FF must have been defective because the $\mathrm{PuO}_{2}$ was dissolved in less than one hour (Figure 11). Based on an examination of the defective hot plate, the temperatures of the solutions DD, EE, and FF probably were in excess of $100^{\circ}$.

Another point that should be made from Figure 11 is that density and volume corrections do not account for the uncertainties in the calculations of plutonium recovery. Sample $\mathrm{BB}$ makes this observation evident with a calculated recovery $>>100 \%$. The explanation for the Sample BB results may have two sources. First, the volume, solution weight, or initial oxide measurements may have been inaccurate and/or second, the stirrer bar may not have been cleaned effectively from previous dissolution experiments and provided an additional source of plutonium in the test. To address these concerns, new stirrer bars with more uniform outer surfaces were introduced and the Teflon ${ }^{\mathrm{TM}}$ beakers were replaced with fused silica (quartz) for subsequent tests. 
Table 10 Solution Compositions*

\begin{tabular}{|c|c|c|c|c|}
\hline Solution \# & $\begin{array}{c}\text { Calcium } \\
(\mathrm{M})\end{array}$ & $\begin{array}{c}\text { Total Fluoride } \\
(\mathrm{M})\end{array}$ & $\begin{array}{c}\text { Initial } \\
\text { Free } \mathrm{F}^{-} \\
(\mathrm{ppm})\end{array}$ & $\begin{array}{c}\text { Final } \\
\text { Free } \mathrm{F}^{-} \\
(\mathrm{ppm})\end{array}$ \\
\hline $\mathrm{AA}$ & $\begin{array}{c}0.1 \\
\left(\mathrm{CaF}_{2}\right)\end{array}$ & $\begin{array}{c}0.6 \\
(0.1 \mathrm{M} \mathrm{CaF} / 0.4 \mathrm{M} \mathrm{NaF})\end{array}$ & 119 & 114 \\
\hline $\mathrm{BB}$ & $\begin{array}{c}0.2 \\
\left(\mathrm{CaF}_{2}\right)\end{array}$ & $\begin{array}{c}0.6 \\
(0.2 \mathrm{M} \mathrm{CaF} / 0.2 \mathrm{M} \mathrm{KF})\end{array}$ & 122 & 116 \\
\hline $\mathrm{CC}$ & $\begin{array}{c}0.3 \\
{\left[\mathrm{Ca}\left(\mathrm{NO}_{3}\right)_{2} \cdot 4 \mathrm{H}_{2} \mathrm{O}\right]}\end{array}$ & $\begin{array}{c}0.4 \\
(\mathrm{NaF})\end{array}$ & 79 & 79 \\
\hline $\mathrm{DD}$ & $\begin{array}{c}0.3 \\
{\left[\mathrm{Ca}\left(\mathrm{NO}_{3}\right)_{2} \cdot 4 \mathrm{H}_{2} \mathrm{O}\right]}\end{array}$ & $\begin{array}{c}0.5 \\
(\mathrm{NaF})\end{array}$ & 93 & 86 \\
\hline $\mathrm{EE}$ & $\begin{array}{c}0.3 \\
\left(\mathrm{CaF}_{2}\right)\end{array}$ & $\begin{array}{c}0.6 \\
(\mathrm{CaF})\end{array}$ & 117 & 114 \\
\hline $\mathrm{FF}$ & $\begin{array}{c}0.7 \\
(\mathrm{NaF})\end{array}$ & 143 & 133 \\
\hline
\end{tabular}

*all solutions at $9.3 \mathrm{M} \mathrm{HNO}_{3}$ and $0.23 \mathrm{M}$ Boron

Fused silica is about ten times more resistant to fluoride-induced corrosion than borosilicate (Pyrex) and allows observation of solutions as they dissolve. The fused silica beakers also were heavy enough to hold thermometers during dissolution, which could not be done with Teflon ${ }^{\mathrm{TM}}$ or the small $50-\mathrm{ml}$ borosilicate glass beakers.

The data for the sample $\mathrm{CC}$ test indicate a dissolution rate and plutonium recovery consistent with earlier experiments that provide greater than $95 \%$ recovery in three hours. Comparing the initial slope of the results from the $\mathrm{AA}, \mathrm{BB}$, and $\mathrm{CC}$ tests shows an improved rate of dissolution with increasing calcium concentrations. Based on concerns about the limited solubility of $\mathrm{KF}$ in the presence of $\mathrm{CaF}_{2}$, the calcium concentration was not increased to greater than $0.3 \mathrm{M}$ in these or subsequent experiments.

\section{Effects of Temperature and Iron on Calcium-Enhanced Dissolution}

\section{Experimental Details}

Using fused silica beakers $(150 \mathrm{ml})$ with Teflon ${ }^{\mathrm{TM}_{-}}$-coated stirrer bars, and a thermometer positioned to monitor the solution temperature on each of the two stirrer/hot plates, parallel experiments were conducted at $70^{\circ}$ and $90^{\circ} \mathrm{C}$. All experiments in this set used 25 $\mathrm{ml}$ of solution and $0.03 \mathrm{~g}$ of high-fired $\mathrm{PuO}_{2}$. As described for previous tests, samples were collected from each beaker at 10,20,30,60, and 90 minutes to evaluate dissolution rates. Upon completion of each test, solutions were cooled to ambient temperature, the free-fluoride concentrations were measured by ISE, and the densities were determined with a four-place analytical balance. Solution densities were determined by weighing a 1 $\mathrm{ml}$ aliquot of each sample. The pipette (Ranin $1 \mathrm{ml}$, handheld adjustablè) used to obtain 
the solution sample had been tested with water to verify its volumetric accuracy. The description of each test solution and test condition is provided in Table 11. The iron content in Samples KK-NN was provided by dissolving $0.12 \mathrm{~g}$ of "can metal" into $50 \mathrm{ml}$ of Solutions GG-JJ. Only $25 \mathrm{ml}$ of those $50 \mathrm{ml}$ solutions were used for the dissolution tests. Samples were submitted for alpha assay and the results were used to develop Figures 12,13, and 14. The data in these graphs are corrected for evaporation losses by assuming a linear solution loss rate based upon starting and ending volumes and calculating solution volume for each sample time.

Table 11 Composition of Test Solutions.

\begin{tabular}{|c|c|c|c|c|c|}
\hline & Solutions ID & $\frac{\text { Temperature }}{{ }^{\circ} \mathrm{C}}$ & $\frac{\mathrm{F}(\mathrm{M})}{\text { total }}$ & $\underline{\text { Fe (g/liter) }}$ & $\frac{\text { Final Free F }}{\text { ppm }}$ \\
\hline & & 70 & 0.4 & 0 & 53 \\
\hline Run 1 & HH & 70 & 0.5 & 0 & 57 \\
\hline & II & 90 & 0.4 & 0 & 46 \\
\hline & JJ & 90 & 0.5 & 0 & 56 \\
\hline Run 2 & KK & 70 & 0.4 & 2.4 & 56 \\
\hline & LL & 70 & 0.5 & 2.4 & 71 \\
\hline & NM & 90 & 0.4 & 2.4 & 48 \\
\hline & NN & 90 & 0.5 & 2.4 & 68 \\
\hline Run 3 & PP & 90 & 0.2 & 0 & 33 \\
\hline & QQ & 90 & 0.2 & 0 & 45 \\
\hline & RR & 90 & 0.3 & 0 & 49 \\
\hline
\end{tabular}

All solutions were $9.3 \mathrm{M} \mathrm{HNO}_{3} / 0.23 \mathrm{M}$ Boron/*0.3M Calcium)

* OO contains no calcium.

\section{Results and Discussion}

The tests were conducted with careful temperature control, and provided a clear indication of trends that revealed the influence of several parameters including total fluoride $(\mathrm{M})$, temperature $\left({ }^{\circ} \mathrm{C}\right)$, iron (g/liter), and calcium $(\mathrm{M})$. Tests $\mathrm{RR}$ and II were duplicates to give an indication of experimental variability.

Figure 12 shows the changes in dissolution rate as a function of fluoride concentration at $90^{\circ} \mathrm{C}$. Review of this graph shows that the initial dissolution rates are faster at higher fluoride concentrations. Using this series of curves as a starting point, dissolution time plotted as a function of free-fluoride concentration is shown in Figure 15. Projected times for dissolution of high-fired $\mathrm{PuO}_{2}$ increase rapidly around $45 \mathrm{ppm}$ free fluoride. The curve shape found for dissolution of SS\&C (Figure 9) was used to extrapolate beyond data available in this set of measurements (i.e., free-fluoride concentrations less than $45 \mathrm{ppm}$ ). With dissolution time expected to be as much as two times greater without calcium present, projected $\mathrm{PuO}_{2}$ dissolution in $0.1 \mathrm{M}$ total fluoride ( $35 \mathrm{ppm}$ free fluoride) 
without calcium may be completed in as little as 12 hours. This projection is useful only as far as it suggests that where longer processing times are permissible, lower total fluoride may be used. However, as seen with the dissolution of SRS SS\&C fines, there is also a "knee" in this curve where dissolution times begin to increase dramatically for small reductions in free-fluoride concentration.

The effect of calcium in promoting dissolution of $\mathrm{PuO}_{2}$ is most clearly shown by a comparison of the data from samples $\mathrm{OO}$ and PP in Figure 12. The dissolution rate of Sample PP $(0.3 \mathrm{M}$ calcium) is about twice the rate of Sample OO (no calcium). The final free-fluoride values for Samples OO and PP are almost 50\% different even though both samples were initially $0.2 \mathrm{M}$ fluoride. These results indicate that calcium promotes the retention of free fluoride in the dissolver solution.

The effect of calcium was not understood at the time of these tests even though several theories were advanced. As mentioned above, these tests show that calcium enhances dissolution rates even at similar initial free-fluoride concentrations (Figure 12) and predict that complete dissolution of $\mathrm{PuO}_{2}$ may be achieved at $0.2 \mathrm{M}$ fluoride in about three hours. A separate experiment demonstrated that calcium in solution appears to reduce fluoride volatility. Another theory for the effect of calcium suggests that the $\mathrm{CaF}^{+}$ ion provides a catalytic effect in the actual dissolution process. A third theory suggests that buffering of the fluoride concentration by the $\mathrm{Ca}^{++} / \mathrm{CaF}^{+}$equilibrium, allows more of the fluoride to be available for interaction with the $\mathrm{PuO}_{2}$. A special calcium addition is not suggested to take advantage of this effect, because the SS\&C chunks contain a large percentage of calcium (as $\mathrm{CaO}$ and $\mathrm{CaF}_{2}$ ). However, a first charge of slag or of slag combined with fines would give the added benefit of increasing calcium and fluoride in the dissolver, and subsequently provide faster dissolution rates for the fines which likely contain the high-fired $\mathrm{PuO}_{2}$.

Comparing Figures 13 and 14 shows the effect of $2.4 \mathrm{~g} /$ liter iron on dissolution rates both at $70^{\circ}$ and $90^{\circ} \mathrm{C}$. All tests with and without iron at $90^{\circ} \mathrm{C}$ and with 0.4 or $0.5 \mathrm{M}$ fluoride, and $0.3 \mathrm{M}$ calcium resulted in complete dissolution after 90 minutes. Figure 14 shows that the effect of iron on dissolution rates at $70^{\circ} \mathrm{C}$ was far greater than at $90^{\circ} \mathrm{C}$, where dissolution rates decreased by as much as $50 \%$.

Free-fluoride measurements were made upon the completion of each experiment with samples at ambient temperature. The difference in the free fluoride at $0.5 \mathrm{M}$ with and without iron are too large to explain as random error (expected to be about $\pm 5 \%$ ). Factors that influence the free-fluoride measurements include not only complexing materials like iron, boron, silicon, and plutonium; but also changes in acidity. The acid effect is shown in Figure 2. Because iron metal was added to the solutions, there was some loss of acid from the oxidation of the iron, and thus some increase in the free fluoride was not unexpected. It has been demonstrated that the addition of calcium ions to acid solutions decreases the fluoride volatility. That behavior might also be expected with other metals that complex fluoride. Another factor to consider- when comparing free-fluoride concentrations is that as the dissolution progresses, more fluoride is 
complexed by plutonium which on a molar basis is similar to the iron for complexing fluoride (Figures 5 and 6).

The tests at $90^{\circ} \mathrm{C}$ showed little difference in the total $\mathrm{PuO}_{2}$ that was dissolved after 90 minutes with and without iron. Previous tests had shown the decrease in acid concentration was offset by an increase in free-fluoride concentration from the shift in the HF equilibrium. Figure 10 shows that in 9.3 and $7.0 \mathrm{M}$ acid solutions the dissolution rates are similar for 0.5 and $0.6 \mathrm{M}$ fluoride, respectively, even though the free-fluoride concentrations in these solutions were 57 and $128 \mathrm{ppm}$, respectively.

With dissolution rates not affected by the iron concentration at the anticipated operating temperature of the dissolver, no additional effort was put into explaining the effect of iron at $70^{\circ} \mathrm{C}$. Because it is difficult to assess the loss of free fluoride from HF evaporation and reaction with the dissolution vessel, any comparison of data between different sets of experiments must consider the fact that the experiments were of different duration and used different types of beakers (e.g., sizes and materials).

The effect of iron on the dissolution rate of high-fired $\mathrm{PuO}_{2}$ was demonstrated because complexation experiments showed that iron complexes fluoride similar to the way aluminum does in high-acid solutions. Even though $2.4 \mathrm{~g} /$ liter iron has little effect on the dissolution rate at $90^{\circ} \mathrm{C}$, its effect at lower temperatures is much more pronounced.

There is no anticipated need for aluminum (from the addition of $60 \% \mathrm{ANN}$ ) to increase the solubility of slag because $\mathrm{CaF}_{2}$ dissolves readily in $9.3 \mathrm{M} \mathrm{HNO}_{3} / 0.23 \mathrm{M}$ boron up to about $0.8 \mathrm{M}$. If chunks are added to the $9.3 \mathrm{M} \mathrm{HNO}_{3} / 0.23 \mathrm{M}$ boron dissolver solution prior to fines, the anticipated fluoride concentration will increase about $0.07 \mathrm{M}$ per charge. The estimated content of selected components in the $6.4 \mathrm{D}$ dissolver solution is shown for up to three consecutive SS\&C charges in Table 12. The estimates were based on SRS process knowledge and limited measurements by SRTC on SRS and RF SS\&C material (Table 6). 
Table 12 Estimated Maximum Concentrations during SS\&C Dissolution

\begin{tabular}{|c|c|c|c|c|c|c|c|}
\hline & SAND & & Maximum & $\begin{array}{c}1^{\text {st }} \\
\text { Charge }\end{array}$ & $\begin{array}{c}\text { 1st } \\
\text { Charge }\end{array}$ & $\begin{array}{c}2^{\text {nd }} \\
\text { Charge }\end{array}$ & $\begin{array}{c}3^{\text {rd }} \\
\text { Charge }\end{array}$ \\
\hline Component & $\begin{array}{l}\text { Minimum } \\
\text { Wt } \%\end{array}$ & $\begin{array}{c}\text { Maximum } \\
\text { Wt } \%\end{array}$ & Charge(g) & Conc $(\mathrm{g} / \mathrm{L})$ & $\operatorname{Conc}(M)$ & $\operatorname{Conc}(\mathrm{M})$ & $\operatorname{Conc}(\mathrm{M})$ \\
\hline $\mathrm{Pu}$ & $12 \%$ & $56 \%$ & 3200 & 0.48 & 0.002 & 0.004 & 0.006 \\
\hline $\mathrm{Ca}$ & $0 \%$ & $2 \%$ & 608 & 0.1 & 0.002 & 0.005 & 0.007 \\
\hline $\mathrm{CaO}$ & $30 \%$ & $50 \%$ & 15200 & 2.3 & 0.041 & 0.082 & 0.123 \\
\hline CaF2 & $10 \%$ & $30 \%$ & 9120 & 1.4 & 0.018 & 0.035 & 0.053 \\
\hline $\mathrm{MgO}$ & $5 \%$ & $15 \%$ & 4560 & 0.69 & 0.017 & 0.034 & 0.051 \\
\hline $\mathrm{Fe}$ & & & 9000 & 1.4 & 0.024 & 0.049 & 0.073 \\
\hline & SLAG & & Maximum & $\begin{array}{c}1^{\text {st }} \\
\text { Charge }\end{array}$ & $\begin{array}{c}1^{\text {st }} \\
\text { Charge }\end{array}$ & $\begin{array}{c}2^{\text {nd }} \\
\text { Charge }\end{array}$ & $\begin{array}{c}3^{\text {rd }} \\
\text { Charge }\end{array}$ \\
\hline Component & $\begin{array}{c}\text { Minimum } \\
\text { Wt } \%\end{array}$ & $\begin{array}{c}\text { Maximum } \\
\text { Wt } \%\end{array}$ & Charge (g) & Conc $(\mathrm{g} / \mathrm{L})$ & Conc $(M)$ & Conc $(M)$ & Conc(M) \\
\hline$\overline{\mathrm{Pu}}$ & $1 \%$ & $10 \%$ & 3200 & 0.48 & 0.0020 & 0.0040 & 0.0061 \\
\hline $\mathrm{Ca}$ & $0 \%$ & $20 \%$ & 6080 & 0.92 & 0.023 & 0.046 & 0.069 \\
\hline $\mathrm{CaO}$ & $5 \%$ & $10 \%$ & 3040 & 0.46 & 0.0082 & 0.016 & 0.025 \\
\hline $\mathrm{CaF} 2$ & $60 \%$ & $80 \%$ & 24320 & 3.7 & 0.047 & 0.09 & 0.14 \\
\hline $\mathrm{MgO}$ & $1 \%$ & $5 \%$ & 1520 & 0.23 & 0.0057 & 0.011 & 0.017 \\
\hline $\mathrm{Fe}$ & & & 9000 & 1.4 & 0.024 & 0.049 & 0.073 \\
\hline
\end{tabular}

\section{Supporting Assumptions}

max charge(g)

30,400

min charge(g)

10,000 min volume(L)

6600

max volume $(L)$

7500 


\section{E. Dissolution Rate Tests at 0.05 to $0.2 \mathrm{M}$ Total Fluoride}

\section{Experimental Details}

Data generated with the $0.3 \mathrm{M}$ calcium $/ 9.3 \mathrm{M} \mathrm{HNO}_{3} / 0.23 \mathrm{M}$ boron solution indicated that an acceptable dissolution rate of high-fired $\mathrm{PuO}_{2}$ may be achieved with lower concentrations of fluoride even without calcium present in the solution. To test this hypothesis, a stainless-steel block capable of holding nine two-dram vials was fabricated with an additional position for a thermocouple. The block's temperature was adjusted to maintain a solution temperature at $90^{\circ} \mathrm{C}$ using a temperature-regulated hot plate. A 0.005 -gram quantity of high-fired $\mathrm{PuO}_{2}$ was weighed into each of the two-dram vials and the vials were covered with polycone screw caps. Three solutions were tested at each total-fluoride concentration (Table 13). Four milliliters of each test solution were added to the two-dram vials and the sampling clock began when the solutions reached $90^{\circ} \mathrm{C}$. At selected intervals, $0.4 \mathrm{ml}$ of each test solution were removed for the alpha assay. The alpha assays were used to determine the dissolution rate. The first test ran for 22 hours with samples taken at $2,4,20$, and 22 hours. Solutions $A, B$, and $C$ were done in the first test. Only results from two of the three test solutions for each total-fluoride concentration were available because the third solutions were used in tests for down-stream processing (See the Effects on Down-Stream Processing Section for the information on those tests.). The second test was run for 12 hours with samples taken at 3, 5, 9, and 12 hours. Solutions $\mathrm{D}$ and $\mathrm{E}$ were used. In both tests the free-fluoride concentrations were obtained for the starting solutions. Samples for alpha assay analysis were submitted. The alpha assay results were corrected for evaporation loss (as described previously) and used to monitor dissolution rates.

Table 13 Total and Free-Fluoride Concentrations in Initial Solutions

\begin{tabular}{|c|c|c|}
\hline Solution \# & Total Fluoride $(\mathrm{M})$ & Free Fluoride $(\mathrm{ppm})$ \\
\hline A & 0.10 & 29 \\
\hline B & 0.15 & 35 \\
\hline C & 0.20 & 42 \\
\hline D & 0.05 & 22 \\
\hline E & 0.075 & 28 \\
\hline
\end{tabular}

\section{Results and Discussion}

Efforts to correct analytical values for evaporation in the first test were less than satisfactory. However, results from the first test (Figure 16) indicate that dissolution of the $\mathrm{PuO}_{2}$ using 0.15 and $0.20 \mathrm{M}$ fluoride solutions is complete in four hours and the $\mathrm{PuO}_{2}$ dissolution using the $0.1 \mathrm{M}$ fluoride solution is almost complete $(\sim 80 \%)$ in the first four hours. Test 2 provided data for the 0.05 and $0.075 \mathrm{M}$ fluoride solutions (Figure 17) and looked at the first twelve hours of processing in detail. The data set from one of the $0.075 \mathrm{M}$ fluoride solutions does not agree with the data from the other two. $0.075 \mathrm{M}$ 
fluoride solutions. The source of the inconsistency has not been identified. Overall, there was a clear distinction between the dissolution rate of the $0.075 \mathrm{M}$ fluoride solutions and the $0.05 \mathrm{M}$ fluoride solutions. After six hours of dissolution, about $80 \%$ of the high-fired $\mathrm{PuO}_{2}$ had dissolved in the $0.075 \mathrm{M}$ fluoride solutions while only about $60 \%$ of the highfired $\mathrm{PuO}_{2}$ had dissolved in the $0.05 \mathrm{M}$ fluoride solutions. After 12 hours the dissolution was essentially complete in the $0.075 \mathrm{M}$ fluoride solutions with only about $85 \%$ dissolution in the $0.05 \mathrm{M}$ fluoride solutions.

Thus, the minimum initial fluoride concentrations that should be considered for the 12hour dissolution flowsheet of the SRS SS\&C residues is $0.075 \mathrm{M}$. Using this fluoride concentration as a starting point for the 7500 liters of $9.3 \mathrm{M} \mathrm{HNO}_{3}\left(60 \% \mathrm{HNO}_{3}\right)$ containing $0.23 \mathrm{M}$ boron (2.5 grams/liter boric acid) and $0.075 \mathrm{M} \mathrm{KF}$ in the $6.4 \mathrm{D}$ dissolver, the fluoride concentration will increase to about $0.15 \mathrm{M}$ if slag is the principal component of the first charge. For this calculation, the $\mathrm{CaF}_{2}$ content was estimated as 70 $w t \%$. The estimated fluoride concentration is calculated below using this value:

32000 grams bulk * 0.70 grams $\mathrm{CaF}_{2} / \mathrm{l}$ gram bulk $* 2$ mole fluoride/mole $\mathrm{CaF}_{2}$

$=0.077$ M fluoride

78 grams $\mathrm{CaF}_{2} /$ mole $\mathrm{CaF}_{2} * 7500$ liters

The uncertainty of the actual dissolution time in the 6.4D dissolver is impacted by the iron from the dissolution of cans and bundle-end caps. Efforts to minimize iron from the end caps should improve dissolution rates, particularly if adding four or more charges is anticipated. In those cases the iron concentration in the dissolver will reach 10 grams/liter, and would have much greater impact on the availability of free fluoride. 


\section{This page has been left blank intentionally.}




\section{Gas Generation from Slag}

\section{A. Experimental Details}

A slag sample was dissolved in a closed system that included a dissolving vessel (about 50 $\mathrm{ml}$ volume) with a septum for acid addition by hypodermic needle, a glass wool filter to prevent solution spray from contaminating the gas sample, a gas sampling bulb, and an inverted cylinder filled with water to measure the volume of gas. The connections between the components of the apparatus were made from $3 / 16^{\prime \prime}$-inch o.d., Teflon ${ }^{\mathrm{TM}}$ tubing. This system was tested before the dissolution experiment by injecting $10 \mathrm{ml}$ of air and noting that $10 \mathrm{ml}$ of water were displaced in the collection cylinder.

Two small pieces of SS\&C material weighing 1.318 grams were loaded in the dissolving vessel and $10 \mathrm{ml}$ of a solution composed of $9.3 \mathrm{M} \mathrm{HNO}_{3} / 0.23 \mathrm{M}$ boron/0.06M KF/0.04M iron $/ 0.006 \mathrm{M}$ calcium were added by hypodermic needle. The evolution of gas was measured at timed intervals.

\section{B. Results and Discussion}

The results of the gas evolution measurements are shown in Table 14.

Table 14 Gas Evolution during Dissolution

\begin{tabular}{|c|c|c|}
\hline Time (minutes) & Temperature $\left({ }^{\circ} \mathrm{C}\right)$ & Total Gas Volume $(\mathrm{ml})$ \\
\hline 0 & 20 & 0 \\
\hline 4 & 40 & 30 \\
\hline 8 & 50 & 50 \\
\hline 10 & 60 & 54 \\
\hline 25 & 60 & 56 \\
\hline 50 & 50 & $56^{\text {** }}$ \\
\hline
\end{tabular}

* Gas volume not corrected to STP; collected gas temperature was $20^{\circ} \mathrm{C}$.

** sample totally dissolved.

The volume of evolved gas did not displace enough of the dead volume in the system to reach the sample bulb. Therefore, after dissolving the slag material, $40 \mathrm{ml}$ of water were added to the dissolving vessel by hypodermic needle to move the evolved gas to the sample bulb. The stopcocks on the sample bulb were closed, and the sample bulb removed from the system for analysis.

The sample was analyzed for hydrogen by gas chromatography, using $10 \%$ volume $\mathrm{H}_{2}$ in air as a standard. The average of two determinations was $24 \pm 2$ volume $\%$. A faint red color of nitrogen dioxide was visible in the sample. The identity of the major fraction of gas was not determined. 
The initial dissolving rate was estimated by approximating the shape of the two slag pieces as spheres. From their weight and an assumed density of 3.3 grams $/ \mathrm{ml}$, the effective radius of the sphere was calculated; then from the radius, the area of the spheres were calculated. From those calculations, the dissolving rate was estimated as $2.3 \mathrm{ml}$ of gas $/ \mathrm{min}-\mathrm{cm}^{2}$ of slag or $0.55 \mathrm{ml}$ of $\mathrm{H}_{2} / \mathrm{min}-\mathrm{cm}^{2}$ of slag.

The rate of hydrogen generation for a spherical piece of slag can also be estimated from the data given in Table 14. Assuming that metallic calcium is evenly distributed throughout the slag, the hydrogen generation rate $\left(\mathrm{dH}_{2} / \mathrm{dt}\right)$ is proportional to the rate of change of the sphere volume (dV/dt), where $\alpha$ is the proportionality constant (Equation 5).

$$
\frac{d H_{2}}{d t}=-\alpha \frac{d V}{d t}
$$

The generation rate can be expressed as a function of the sphere radius $(\mathrm{r}(\mathrm{t}))$ by substituting for the volume in the Equation 5 and rewriting as Equation 6.

$$
\frac{d H_{2}}{d t}=-4 \alpha \pi r(t)^{2} \frac{d r(t)}{d t}
$$

The sphere radius as a function of time is defined from the data in Table 14 by assuming the radius decreases linearly with time during dissolution (Equation 7),

$$
r(t)=R(I-\beta t)
$$

where $R$ is the sphere radius and $\beta$ is a proportionality constant. Using the effective radius of the slag used in the experiment, a value for $\beta$ was calculated from the observation that 50 minutes were required for the material to dissolve. This value can be scaled using the ratio of any desired radius to the effective radius of the material used in the experiment. Using Equation 7, the hydrogen generation rate can now be written in term of the sphere radius and proportionality constant $\beta$ (Equation 8 ).

$$
\frac{d H_{2}}{d t}=4 \alpha \pi R^{3} \beta(1-\beta t)^{2}
$$

The value of $\alpha$ is defined as the ratio of the volume of hydrogen to the volume of the spherical piece of slag. A numerical value is calculated from the concentration of calcium in the slag (20 wt \%), reaction stoichiometry (Equation 9),

$$
\mathrm{Ca}+2 \mathrm{H}_{2} \mathrm{O} \rightarrow \mathrm{Ca}(\mathrm{OH})_{2}+\mathrm{H}_{2}
$$

and the ideal gas law. 
During SS\&C dissolution, the reaction of calcium metal with water generates only hydrogen as shown in Equation (9). However, calcium will also reacts with the nitric acid in the dissolver solution by Equations (10) and (11).

$$
\begin{aligned}
& 3 \mathrm{Ca}+8 \mathrm{H}^{+}+2 \mathrm{NO}_{3}^{-} \rightarrow 2 \mathrm{NO}+4 \mathrm{H}_{2} \mathrm{O}+3 \mathrm{Ca}^{2+} \\
& 4 \mathrm{Ca}+10 \mathrm{H}^{+}+2 \mathrm{NO}_{3}^{-} \rightarrow \mathrm{N}_{2} \mathrm{O}+5 \mathrm{H}_{2} \mathrm{O}+4 \mathrm{Ca}^{2+}
\end{aligned}
$$

The measured concentration of hydrogen in the gas sample collected during this experiment was 24 volume\%. This value can be used to estimate the amount of calcium which reacts with water to produce hydrogen.

Initially, all of the calcium is assumed to react by either Equation (9) or (10). If one then assumes the moles of calcium which reacts with water to produce hydrogen by equation (9) equals $X$, the amount of calcium which react with nitric acid to produce nitric oxide (NO) equals (1-X). Using the stoichiometry of Equations (9) and (10) and assuming the gases behave ideally (i.e. the mole and volume fraction are equal), Equation (12) can be written and solved for $X$.

$$
\begin{aligned}
& y_{H_{2}}=0.24=\frac{X}{X-\frac{2}{3}(1-X)} \\
& X=0.17
\end{aligned}
$$

If one assumes all of the calcium reacts by either Equation (9) or (11), a similar analysis can be performed which yields a calculated value of $X$ equal to 0.07 . Comparison of the two values for $X$ shows that assuming all the calcium reacts by equations (9) and (10) provide an upper bound for the amount of calcium which reacts with water to produce hydrogen. In order to calculate $\alpha$, this value was doubled (i.e. $X$ equal 0.34 ) to account for any uncertainties in the measured hydrogen concentration. Using this value for the fraction of calcium which reacts with water, the numerical value of $\alpha$ at $25^{\circ} \mathrm{C}$ is 137 .

The hydrogen generation rate as a function of time was calculated for spherical pieces of slag with diameters of 2,1 , and $1 / 2$ inches. The data are plotted on Figure 18 . The curves show that hydrogen will be generated well into the dissolution cycle. However, the curves underestimate the hydrogen generation rate during the initial reaction period due to the assumption that calcium metal is uniformly distributed throughout the slag. In reality, much of the calcium is found on the surface of the slag due to immiscibility with mixtures of $\mathrm{CaF}_{2}$ and $\mathrm{CaO}^{4}$ In slag dissolution experiments, a large evolution of gas occurred when the slag came in contact with the dissolver solution. At least $90 \%$ of the gas evolution occurred within the first 20 minutes of the dissolution cycle. High solution temperatures $\left(70-90^{\circ} \mathrm{C}\right)$ were not required to initiate the reaction and it will proceed at ambient temperature $\left(25^{\circ} \mathrm{C}\right)$ due to the high reactivity of calcium metal with water. The results of this experiment (greater than $90 \%$ of the gas collected in less than 10 minutes) are 
consistent with this observation; no heat was supplied to the dissolving vessel during the gas collection, yet the gas evolution was vigorous during the first few minutes of the reaction period.

The maximum hydrogen generation rate for spherical pieces of slag following the initial evolution of gas can be estimated from the curves on Figure 18 by choosing the time when $90 \%$ of the hydrogen has been generated. This point will define $90 \%$ of the area underneath the curves for each slag diameter. The maximum rates are summarized in Table 15.

Table 15 Estimated Hydrogen Generation Rate for Slag Chunks of Varying Diameter

\begin{tabular}{|c|c|c|c|c|}
\hline Diameter & Total Hydrogen & $90 \%$ of Total & Time & Maximum Rate \\
\hline (inch) & $\left(\mathrm{ft}^{3}\right)$ & $\left(\mathrm{ft}^{3}\right)$ & $(\mathrm{min})$ & $\left(\mathrm{ft}^{3} / \mathrm{hr}\right)$ \\
\hline & & & & \\
\hline 2 & $3.3 \times 10^{-1}$ & $3.0 \times 10^{-1}$ & 147 & $4.8 \times 10^{-2}$ \\
\hline 1 & $4.2 \times 10^{-2}$ & $3.7 \times 10^{-2}$ & 74 & $1.2 \times 10^{-2}$ \\
\hline $1 / 2$ & $5.2 \times 10^{-3}$ & $4.7 \times 10^{-3}$ & 37 & $2.9 \times 10^{-3}$ \\
\hline
\end{tabular}

Gas Volumes are at $25^{\circ} \mathrm{C}$ and $1 \mathrm{~atm}$ 


\section{Effects on Downstream Processing}

\section{A. Valence Adjustment}

\section{Experimental Details}

A shifted HP8452 DAS with a wavelength range of 470 to $1100 \mathrm{~nm}$ and a resolution of 2 $\mathrm{nm}$ was used to measure solution spectra. The literature shows that $\mathrm{Pu}^{+6}$ has a very strong absorbance peak at a wavelength of $830 \mathrm{~nm}$. Near IR grade fibers routed between the instrument and a tungsten-halogen light source and the hood and glovebox allowed samples to be measured in a $1 \mathrm{~cm}$ plastic cuvettes. All spectra were taken with reference to $1 \mathrm{~cm}$ plastic cuvette of distilled water. Small amounts of ferrous sulfamate (FS) solution, ammonium ceric hexanitrate, and silver nitrate/sodium persulfate were used to adjust the plutonium valence so that the effects of the solution matrix on the spectra of each of the plutonium valence states could be observed. A hot plate was required to force $\mathrm{Ce}^{+4}$ to oxidize $\mathrm{Pu}^{+4}$ to $\mathrm{Pu}^{+6}$ in high nitrate solution. Actual plutonium concentrations were determined by analyzing plutonium samples by alpha assay/gamma analyses.

\section{Results and Discussion}

It is generally recognized that some $\mathrm{Pu}^{+4}$ may oxidize to $\mathrm{Pu}^{+6}$ during extended boiling of plutonium-nitric acid solutions. However, the conditions under which this oxidation occurs, the extent to which it occurs, and how long the $\mathrm{Pu}^{+6}$ remains are not well understood. Dissolved SS\&C is intended to be processed by the Second Plutonium Cycle. Traditional feed obtained from the first Cycle, 1BP, would be $\mathrm{Pu}^{+3}$ in a FS/HAN/ $\mathrm{HNO}_{3}$ solution. This feed solution is treated with sodium nitrite $\left(\mathrm{NaNO}_{2}\right)$ to consume the reductants and to oxidize the $\mathrm{Pu}^{+3}$ to $\mathrm{Pu}^{+4}$. One approach to processing solutions of dissolved SS\&C through solvent extraction would be to adjust the solutions with FS followed by $\mathrm{NaNO}_{2}$. This adjustment would assure a pure $\mathrm{Pu}^{+4}$ feed for solvent extraction; however, such an adjustment adds to the waste volume and may not be necessary. An alternative is to perform a plutonium valence check in the laboratory to assure that no $\mathrm{Pu}^{+6}$ is present and not perform a valence adjustment unless proven necessary. Since $\mathrm{Pu}^{+6}$ has a very high molar absorptivity at $830 \mathrm{~nm}$, spectrophotometry is a particularly useful technique to perform this check, but chemical extraction methods also will work well.

During the course of the dissolution work, samples containing dissolved SS\&C were measured to detect the presence of $\mathrm{Pu}^{+6}$ within a few hours to a few days after extended dissolution sequences of 20 or more hours. Because the effects of the solution matrix on the spectra were not known, $\mathrm{Pu}^{+3}, \mathrm{Pu}^{+4}$, and $\mathrm{Pu}^{+6}$ standards were prepared in the dissolver matrix of $9.3 \mathrm{M} \mathrm{HNO}_{3} / 0.23 \mathrm{M} \mathrm{B} / 0.5 \mathrm{M}$ fluoride/0.3M calcium. Pure $\mathrm{Pu}^{+3}$ spectra were obtained by adding a small volume of FS reductant to a dissolution sample to obtain $0.05 \mathrm{M} \mathrm{Fe}^{+2}$. Pure $\mathrm{Pu}^{+4}$ was obtained from the same sample by allowing the high nitrate to oxidize the $\mathrm{Fe}^{+2}$ and $\mathrm{Pu}^{+3}$ overnight. A small percentage of $\mathrm{Pu}^{+4}$ was 
oxidized by adding solid ammonium ceric hexanitrate to a dissolver sample $(0.05 \mathrm{M}$ $\mathrm{Ce}^{+4}$ ) and heating the sample for 15 minutes at $75^{\circ} \mathrm{C}$. This addition appeared to oxidize approximately $10 \%$ of the $\mathrm{Pu}^{+4}$ to $\mathrm{Pu}^{+6}$. It was suspected that strong $\mathrm{Pu}^{+4} \cdot(\mathrm{NO} 3)_{\mathrm{x}}{ }^{4-\mathrm{x}}$ complexes were inhibiting oxidation. The literature 5 indicated that $\mathrm{Ag}^{+2}$ produced with persulfate ions $\left(\mathrm{S}_{2} \mathrm{O}_{8}{ }^{-}\right)$will oxidize plutonium quickly and completely at room temperature in $1 \mathrm{M} \mathrm{HNO}_{3}$. By dissolving $5 \mathrm{mg}$ of $\mathrm{AgNO}_{3}$ and $20 \mathrm{mg} \mathrm{NaS} \mathrm{O}_{8}$ in $100 \lambda$ of $24 \mathrm{~g}$ plutonium/liter in $0.5 \mathrm{M} \mathrm{HNO}_{3}$, pure $\mathrm{Pu}^{+6}$ was prepared. This pure $\mathrm{Pu}^{+6}$ then was diluted with $2 \mathrm{ml}$ of simulated dissolver solution to produce samples which could be

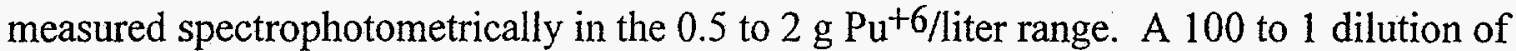
this material produced a very dilute $\mathrm{Pu}^{+6}$ standard $\left(0.013 \mathrm{~g} \mathrm{Pu}^{+6 / i t e r}\right)$. This protocol aided in the determination of the sensitivity of this technique for detecting the presence of $\mathrm{Pu}^{+6}$.

Figure 19 shows pure $\mathrm{Pu}^{+3}$ and $\mathrm{Pu}^{+4}$ in a dissolver solution matrix and $\mathrm{Pu}^{+6}$ in the simulated matrix. The $\mathrm{Pu}^{+3}$ and $\mathrm{Pu}^{+4}$ solutions were obtained from $\mathrm{B}-1$ described in

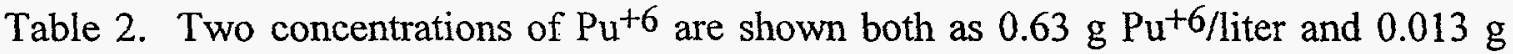

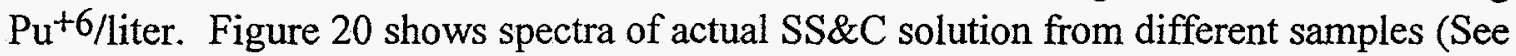
Tables 2,3, and 5.). Figure 21 shows a magnified view of the region of $830 \mathrm{~nm}$ where the maximum $\mathrm{Pu}^{+6}$ absorbance occurs for several $\mathrm{SS} \& \mathrm{C}$ solution samples and two $\mathrm{Pu}^{+6}$ samples. $\mathrm{Pu}^{+6}$ can easily be seen at $0.013 \mathrm{~g} /$ liter. Taking the second derivatives of the spectra should allow detection of $\mathrm{Pu}^{+6}$ near the $0.001 \mathrm{~g} /$ liter level or better. This concentration corresponds to $0.1 \%$ of the plutonium in a 1 g/liter sample. Figure 22 shows second derivatives in the region of the $\mathrm{Pu}^{+6}$ peaks for the $0.013 \mathrm{~g} \mathrm{Pu}^{+6 / 1 i t e r}$ sample and a number of the actual samples. No evidence of $\mathrm{Pu}^{+6}$ at concentrations levels greater than $1 \mathrm{mg} / \mathrm{liter}$ were observed in any dissolved SS\&C sample. Therefore a laboratory check for proper plutonium valence is recommended rather than routinely performing a valence adjustment in the plant process. This check could be performed by either chemical or spectroscopic methods provided sufficient $\mathrm{Pu}^{+6}$ sensitivity is obtained. 


\section{B. Solvent Extraction/Strip Test}

1. Experimental Details

\section{a. Feed Adjustment}

The solutions available for testing from actual SS\&C dissolutions did not contain iron from the dissolved iron can nor aluminum from the complexation of the fluoride. Iron was added by dissolving coupons from a metal can ( 80 to $100 \mathrm{mg}$ each) into $6 \mathrm{ml}$ of $\mathrm{SS} \& \mathrm{C}$ solution and heating the solution to $70-80^{\circ} \mathrm{C}$ for about 10 minutes. After the solution cooled, a $60 \mathrm{wt} \%$ solution of ANN (2.1M), was added to complex the fluoride and the acidity was adjusted to about $4 \mathrm{M}$ with $0.1 \mathrm{M} \mathrm{HNO}_{3}$. No valence adjustment was performed. These operations were tested with the corresponding nonradioactive corrosion solutions $(1,2,3$, and 8$)$. The only solids that were observed were in corrosion Solutions 1 and 2 and were due to the addition of ANN without adjusting the acidity to $4 \mathrm{M}$ at the same time. Aluminum nitrate solids appeared to form, but redissolved after the total nitrate concentration was reduced by the acid adjustment to $4 \mathrm{M}$.

\section{b. Plutonium Pickup Test}

A relatively standard plutonium pickup test was performed with adjusted dissolver solutions to test the extractability/stripability of the plutonium from these dissolver flowsheets. The solutions were initially adjusted with iron and ANN to match or exceed conditions expected in the plant process and the solutions were adjusted to $4 \mathrm{M}$ acidity. An equal volume of freshly prepared and triple washed solvent was used to extract the plutonium from the adjusted sample. Each step of the procedure included a one minute vortex mixing followed by a two minute centrifugation. After removal of the extracted aqueous phase, seven batch acid scrub/strip steps of $0.1 \mathrm{M} \mathrm{HNO}_{3} / 0.1 \mathrm{M} \mathrm{HAN}$ were performed to demonstrate the stripping of the plutonium from the solvent. Organic to aqueous phase ratios varied from about 4.5 to 2.5 during these scrub/strip steps. Small samples were taken of the adjusted feed, the aqueous and organic phases after extraction, and the organic phases after the third, fifth and seventh strips as well as the final (seventh) aqueous strip phase. These samples were analyzed for alpha content by liquid scintillation counting. Due to the unknown americium-241 content of the feed material, both the adjusted feed solution and the extracted aqueous and organic solutions were analyzed for americium-241 by gamma scan. The free acid of the adjusted feed was measured to assure that proper feed adjustment had been performed.

Extraction/Strip tests were performed in a $15 \mathrm{ml}$ glass centrifuge tube. Five milliliters of adjusted feed was extracted. The same centrifuge was retained throughout both the extraction and strip steps. Each strip used $1 \mathrm{ml}$ of $0.1 \mathrm{M} \mathrm{HNO}_{3} / 0.1 \mathrm{M} \mathrm{HAN}$ in contact with $4.5 \mathrm{ml}$ down to 2.5 to $3.5 \mathrm{ml}$ of the remaining organic phase in the centrifuge tube.

\section{c. Impurity Pickup Test}

The standard pickup test was modified to attempt a material balance on impurities as they might behave in solvent extraction. A standard pickup test was performed with the same 
adjusted feed that was used in the plutonium pickup test. All of the aqueous phases from the stripping steps were retained so that the material balance could be done. The acid scrubs from strip steps 1,2 , and 3 were consolidated together as a scrub stream sample and the plutonium strips from strip steps $4,5,6$, and 7 were consolidated together as a product stream sample. The remainder of the adjusted feed was submitted as a feed stream sample and the entire extracted aqueous phase was submitted as a waste stream sample. All four streams were analyzed by an Inductively Coupled Plasma Emission Spectroscopy (ICPES) for cations and by ISE for fluoride.

\section{d. Simplified Plutonium/Impurity Pickup Test}

The standard pickup test involves a large number of strips. The first four serve to scrub out the extracted acid to allow HAN to reduce the plutonium(IV) to plutonium(III) so that the plutonium easily strips out of the solvent. However, with the large number of strips, it is not possible to sample each phase at each stage due to the amount of sampling involved. A simplified test that used essentially equal volumes of strip acid to scrub the acid from the organic in one stage was developed. Three strip stages were used and both an aqueous and an organic sample were taken from the extraction and each strip stage. This procedure allowed a plutonium material balance to be performed.

Due to the amount of nitrate added as ANN, this simplified test used an adjustment to $4 \mathrm{M}$ nitrate rather than $4 \mathrm{M}$ free acid. Extraction/Strip tests were performed in a $15 \mathrm{ml}$ glass centrifuge tube for plutonium. Five $\mathrm{ml}$ of adjusted feed were extracted. The same centrifuge was retained throughout both the extraction and strip steps. Each strip used 5 milliliters of $0.1 \mathrm{M} \mathrm{HNO}_{3} / 0.1 \mathrm{M} \mathrm{HAN}$ in contact with $4.5 \mathrm{ml}$ down to 2 to $3 \mathrm{ml}$ of the remaining organic phase in the centrifuge tube. A parallel test was performed with nonradioactive solutions to observe the behavior of the impurities of concern such as boron and fluoride. Cold tests used $12 \mathrm{ml}$ of sample to $12 \mathrm{ml}$ of organic phase in $40 \mathrm{ml}$ centrifuge tubes. ANN and HF were used to adjust simulated dissolver solutions (prepared for the corrosion testing) to the desired conditions. The larger extraction volume reduced problems associated with the loss of the organic phase during the test due to sampling. Vortex mixing and centrifugation were standard steps in all variants of the pickup test.

\section{Results and Discussion}

Pickup test Pu97 was performed with four SS\&C solutions that were dissolved in $0.05 \mathrm{M}$ to $0.325 \mathrm{M}$ fluoride both with and without boric acid. Table 16 shows the details of the actual feed adjustment. The aluminum concentration was very high because enough aluminum was added to complex the fluoride for the maximum number of $\mathrm{CaF}_{2}$ charges, but only a single charge was dissolved in these solutions. Iron was also raised to the maximum amount expected. Table 16 shows the results of the seven strip pickup test with the four solutions adjusted to $4 \mathrm{M} \mathrm{HNO}_{3}$ and SRTC solvent. Distribution coefficients for plutonium of 14 to 80 were observed in the extraction step. The higher distribution coefficients were observed in those batches with large fluoride concentrations 
with correspondingly large amounts of ANN. The total nitrate on several of these samples was 6 to $7 \mathrm{M}$. With the higher distribution coefficients, only 1 to $5 \%$ of the plutonium remained in the aqueous phase after the single stage batch extraction. This result supports the assumption that valence adjustment is normally not needed. As expected, almost no americium-24I was extracted. After seven strips, the solvent activity remained about $10^{5} \mathrm{dpm} / \mathrm{ml}$ for all four tests. This result is higher than expected; also, the distribution coefficient on the seventh strip was only slightly less than one, meaning that little additional plutonium was stripping out of the solvent. Even with this unexpected experimental result, there is no reason to expect a plutonium stripping problem in the plant process. The sample without boric acid and with $0.05 \mathrm{M}$ fluoride had the same results as those with boric acid and high fluoride. Other recent pickup tests using pure plutonium nitrate feed and SRTC solvent had the same problem indicating that this is not a chemistry problem, but an operational problem not related to boron and fluoride chemistry.

Pickup test Pu98 was performed with the same adjusted feed solutions as Pu97. In this case the aqueous solution was retained and consolidated for impurity analysis by ICPES and fluoride by ISE so that a material balance could be performed. The first three strips make up a sample (when the centrifuge tube was being washed of plutonium, impurities and acid) and the last four strips (when mostly plutonium is being reduced and extracted) make up another sample. The results from these tests are shown in Table 18 for most of the primary elements (aluminum, iron, calcium, fluoride, boron, and phosphorus). The fraction of the mass of each impurity in the extracted aqueous phase and two strip samples compared to that in the feed solution also is shown. The results show some tendency of calcium, fluoride and boron to be extracted more and stripped less than aluminum and iron. Phosphorus is higher after extraction due to the soluble tributyl phosphate. 
Table 16 Feed Adjustment for Plutonium Pickup Test Pu97

\begin{tabular}{|c|c|c|c|c|c|c|c|c|}
\hline Description & $\begin{array}{c}\text { Volume } \\
\mathrm{ml}\end{array}$ & $\begin{array}{c}\mathrm{Pu} \\
\mathrm{g} / \mathrm{l}\end{array}$ & $\begin{array}{c}\mathrm{HNO}_{3} \\
\mathrm{M}\end{array}$ & $\mathrm{M} \mathrm{F}$ & $\mathrm{M} \mathrm{B}$ & $\mathrm{M} \mathrm{AL}$ & $\mathrm{M} \mathrm{NO3}$ & $\mathrm{g} / \mathrm{Fe}$ \\
\hline $\mathrm{B}-5$ & 6 & 0.11 & 9.30 & 0.050 & 0.00 & 0.00 & 9.3 & 0.0 \\
\hline $60 \%$ ANN & 2 & & & & & 2.13 & 6.4 & \\
\hline Fe metal, mg & & & & & & & & 80.0 \\
\hline $0.1 \mathrm{M} \mathrm{HNO} 3$ & 6 & & 0.10 & & & & 0.1 & \\
\hline & 14 & 0.05 & 4.03 & 0.021 & 0.00 & 0.30 & 4.9 & 5.7 \\
\hline & & & & & $\mathrm{Al} / \mathrm{F}=$ & 14.18 & & \\
\hline B-6 & 6 & 0.09 & 9.30 & 0.050 & 0.23 & 0.00 & 9.3 & 0 \\
\hline $60 \% \mathrm{ANN}$ & 2 & & & & & 2.13 & 6.4 & \\
\hline Fe metal, mg & & & & & & & & 80 \\
\hline $0.1 \mathrm{M} \mathrm{HNO} 3$ & 6 & & 0.10 & & & & 0.1 & \\
\hline & 14 & 0.04 & 4.03 & 0.021 & 0.10 & 0.30 & 4.9 & 5.7 \\
\hline & & & & & $\mathrm{Al} / \mathrm{F}=$ & 14.2 & & \\
\hline B-9 & 6 & 0.14 & 9.30 & 0.325 & 0.23 & 0.00 & 9.3 & 0 \\
\hline $60 \% \mathrm{ANN}$ & 6 & & & & & 2.13 & 6.4 & \\
\hline Fe metal, mg & & & & & & & & 80 \\
\hline $0.1 \mathrm{MHNO} 3$ & 2 & & 0.10 & & & & 0.1 & \\
\hline & 14 & 0.06 & 4.00 & 0.139 & 0.10 & 0.91 & 6.7 & 5.7 \\
\hline & & & & & $\mathrm{Al} / \mathrm{F}=$ & 6.55 & & \\
\hline B-13 & 6 & 0.12 & 9.30 & 0.150 & 0.23 & 0.00 & 9.3 & 7.2 \\
\hline $60 \%$ ANN & 3.5 & & & & & 2.13 & 6.4 & \\
\hline Fe metal, mg & & & & & & & & 80 \\
\hline $0.1 \mathrm{M} \mathrm{HNO} 3$ & 4.5 & & 0.10 & & & & 0.1 & \\
\hline & 14 & 0.05 & 4.02 & 0.064 & 0.10 & 0.53 & 5.6 & 6.2 \\
\hline & & & & & $\mathrm{Al} / \mathrm{F}=$ & 8.27 & & \\
\hline
\end{tabular}

Assumptions: 5 batches * $1.2 \mathrm{~g}$ Fe/liter/batch $=6 \mathrm{~g} \mathrm{Fe/l} \mathrm{total}$ Assume $20 \mathrm{Wt} \%$ Pu SS\&C

Assume Max CaF2 in Slag $=820$ moles $F$ per $32 \mathrm{kgs}$ of bulk charge

$=820 / 32 / 1000 / 1000 * 0.3=7.7$ mmoles $F$ per $100 \mathrm{ml}$

$=0.077$ mmoles per $\mathrm{ml}$ of $B-5$ soln $=0.077 \mathrm{M}$

This added to the actual $F$ would make the Al/F ratio 5.0-5.5 
Table 17 Results from Dissolved SS\&C Plutonium Pickup Test Pu97

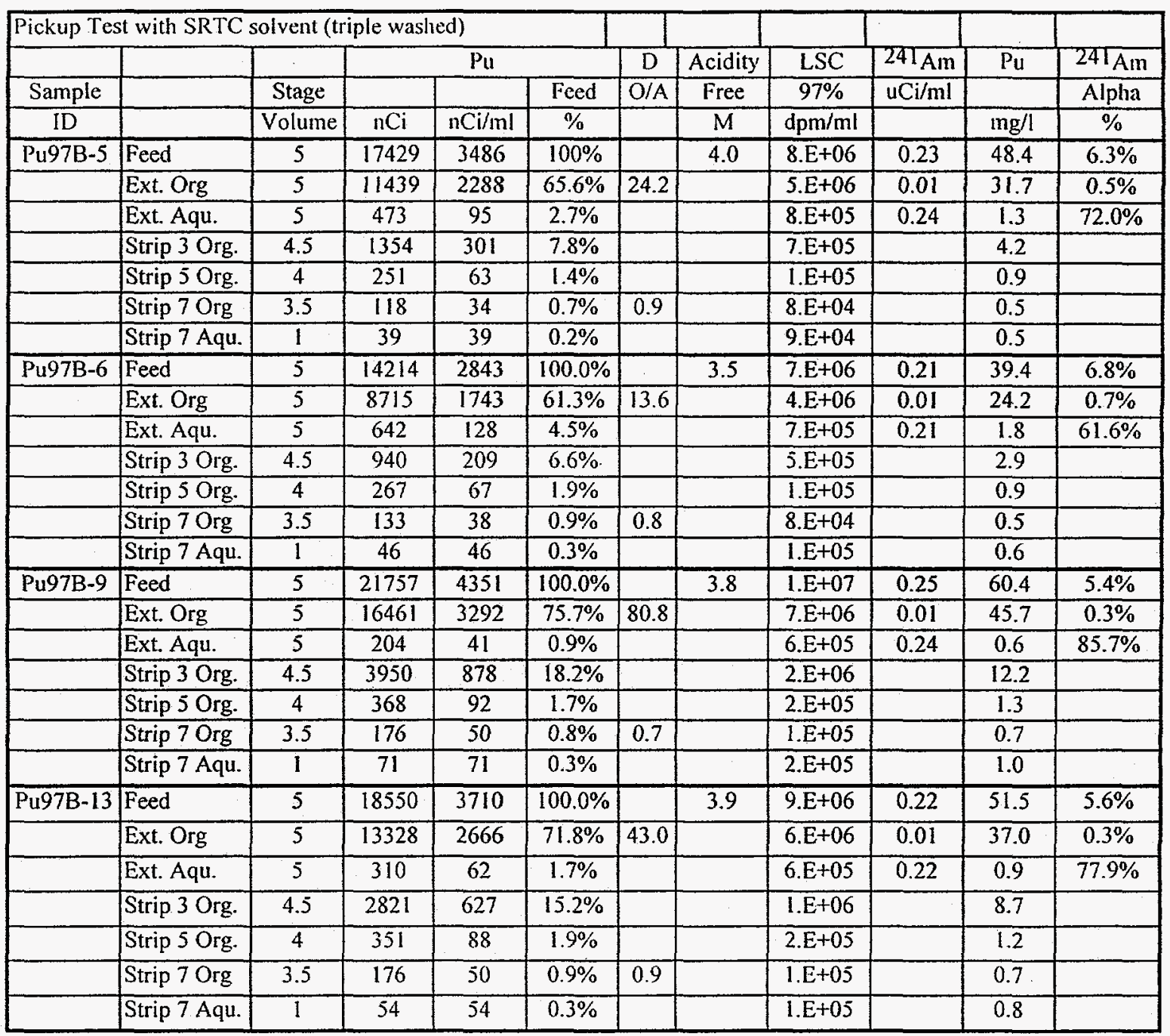

A literature review suggested that fluoroboric acid $\left(\mathrm{HBF}_{4}\right)$ may extract into the solvent. This potential behavior of $\mathrm{HBF}_{4}$ led to the concern that the unrealistic high levels of aluminum in Pu98 may have suppressed the extraction of fluoride and boron. Table 18 shows the distribution coefficients compiled by Shultz 6 that appear applicable to this system. Note that the distribution coefficients for both HF and boric acid go up as the acid concentration goes down. This trend suggests that when fluoride and boron extract they will not easily strip back from the solvent. The consideration that the acid in these solutions would not be worth recovery via acidic evaporation (which will require large quantities of ANN) raised the possibility that the feed solution to solvent extraction will not be adjusted with ANN to 4:1 aluminum:fluoride. For this reason, the simplified pickup test was performed with cold samples to check the acid, fluoride, and boron extraction (both with and without aluminum). 
Table 20 shows the results from tests Pu100, Pul02 and Pu103. This table shows the analyzed results for the feed solution, the aqueous phase after extraction and the aqueous strip solutions for each test. Also shown is the fraction (on a mass basis) of each impurity relative to the feed solution (except $\mathrm{HNO}_{3}$ is adjusted to remove acid in the strip solution). The tests are presented in the order of aluminum fluoride values from zero to four. These tests generally show that 2 to $5 \%$ of the boron and fluoride feed (when ANN is not present) remain in the solvent and can be stripped in the first strip. Because literature distribution coefficients values are high at low acid and the solvent was not analyzed for fluoride or boron, it is not clear that all the fluoride was removed from the solvent. For the single test run at 1:1, aluminum:fluoride, this was reduced to about 1 percent. At 4:1, aluminum:fluoride, the extraction was reduced to tenths of a percent. When the nitrate was left at $9.9 \mathrm{M}$, both fluoride and boron extractions were similarly suppressed but for other reasons.

To understand the different effects better, the major equilibria need to be considered. The following equations represent most of the major equilibrium relationships between the chemical species (Although there are many other reactions involving boron and fluoride species, see reference.). ${ }^{7}$

$$
\begin{aligned}
& \mathrm{B}(\mathrm{OH})_{3}+4 \mathrm{HF}=\mathrm{H}^{+}+\mathrm{BF}_{4}^{-}+3 \mathrm{H}_{2} \mathrm{O} \\
& \mathrm{Al}^{+3}+x \mathrm{~F}-\mathrm{AlF} \mathrm{A}^{3-x} \\
& \mathrm{Al}^{+3}+6 \mathrm{H}_{2} \mathrm{O}=\mathrm{Al}\left(\mathrm{H}_{2} \mathrm{O}\right)_{6}{ }^{+3} \\
& \mathrm{H}^{+}+\mathrm{NO}_{3}^{-}+\mathrm{TBP} \cdot \mathrm{H}_{2} \mathrm{O}=\mathrm{HNO}_{3} \cdot \mathrm{TBP}_{\text {org }}+\mathrm{H}_{2} \mathrm{O} \\
& \mathrm{H}^{+}+\mathrm{F}^{-}+\mathrm{TBP} \cdot \mathrm{H}_{2} \mathrm{O}=\mathrm{HF} \cdot \mathrm{TBP}_{\text {org }}+\mathrm{H}_{2} \mathrm{O} \\
& \mathrm{H}^{+}+\mathrm{BF}_{4}^{-}+\mathrm{TBP} \cdot \mathrm{H}_{2} \mathrm{O}=\mathrm{HBF}_{4} \cdot \mathrm{TBP} \mathrm{Org}_{\text {org }}+\mathrm{H}_{2} \mathrm{O} \\
& \mathrm{H}^{+}+\mathrm{F}^{-}=\mathrm{HF}
\end{aligned}
$$

Since both boric acid and HF are weak acids, higher free acid suppresses their disassociation and shifts the equilibrium of the other reactions. Since all the acids and even water extract to some extent with TBP, an effective change in any one component shifts the others. An increase in $\mathrm{HNO}_{3}$ shifts more TBP into the $\mathrm{HNO}_{3} \bullet \mathrm{TBP}$ species, reducing the amount of TBP associating with $\mathrm{HF}$. Aluminum (III) hydrates with water (reducing the effective water molecule concentration) and complexes with free fluoride. For this reason, it reduces the amount of fluoride that can extract with TBP and also salts more nitric acid into the organic phase. These relationships explain most of the effects observed in the data from the pickup tests. Either ANN or increased $\mathrm{HNO}_{3}$ suppress the extraction of both fluoride and boron. ANN has both the nitrate salting effect and its complexation with fluoride to reduce the $\mathrm{BF}_{4}{ }^{-}$species.

Most of these tests were run without plutonium present. Since plutonium is also a strong fluoride complexant, there is a possibility that the plutonium might help extract fluoride. It is not possible to judge the extent to which plutonium might cause additional fluoride extraction into the solvent, because the only plutonium experiments were run with very high levels of aluminum. The amount of fluoride extracted corresponds to an extraction 
coefficient of about 0.05 without ANN (or plutonium) present. Feeding uncomplexed fluoride (without ANN) to solvent extraction has the potential to both increase the $\mathrm{Pu}$ losses and increase the carryover of fluoride and boron to the plutonium product and the solvent recycle Stream 5 . These issues appear to be relatively minor, but are the subject of further study.

Table 18 Impurity Carryover of Dissolved SS\&C with ANN

\begin{tabular}{|c|c|c|c|c|c|c|c|c|}
\hline \multicolumn{9}{|c|}{ Pickup Test with SRTC solvent (single wash) } \\
\hline & \multirow[b]{2}{*}{ Element } & \multirow{2}{*}{$\begin{array}{l}\text { Adj } \\
\text { ppm }\end{array}$} & \multirow{2}{*}{$\begin{array}{c}\mathrm{EA} \\
\mathrm{ppm}\end{array}$} & \multirow{2}{*}{$\begin{array}{c}\text { STAI23 } \\
\text { ppm }\end{array}$} & \multirow{2}{*}{$\begin{array}{c}\text { STA4567 } \\
\text { ppm }\end{array}$} & \multirow{2}{*}{\multicolumn{3}{|c|}{$\begin{array}{l}\text { EA STA123 STA4567 } \\
\text { Fraction of Feed, mass basis }\end{array}$}} \\
\hline & & & & & & & & \\
\hline \multirow[t]{6}{*}{ Pu98 B-5 } & $\overline{\mathrm{Al}}$ & 8757 & 8965 & 276 & $<3.5$ & 1.02 & 0.05 & 0.0005 \\
\hline & $\mathrm{Fe}$ & 6769 & 6926 & 208 & 0.6 & 1.02 & 0.05 & 0.0001 \\
\hline & $\mathrm{Ca}$ & 736 & 781 & $\overline{43}$ & 10.9 & 1.06 & 0.10 & 0.0185 \\
\hline & $\mathrm{F}$ & 425 & 456 & 11 & $<1.0$ & 1.07 & 0.04 & 0.0029 \\
\hline & $\bar{B}$ & 50 & 43 & 9 & 1.3 & 0.86 & 0.31 & 0.0323 \\
\hline & $\bar{P}$ & 6 & 191 & 97 & 75 & 30 & 26 & 15 \\
\hline \multirow[t]{6}{*}{ Pu98 B-6 } & $\mathrm{Al}$ & 8694 & 8874 & 206 & $<3.5$ & 1.02 & 0.04 & 0.0005 \\
\hline & $\mathrm{Fe}$ & 7024 & 7176 & 165 & 0.6 & 1.02 & 0.04 & 0.0001 \\
\hline & $\mathrm{Ca}$ & 605 & 618 & 24 & 6.1 & 1.02 & 0.07 & 0.0125 \\
\hline & $\bar{F}$ & 221 & 113 & 15 & $<1.0$ & 0.51 & 0.11 & 0.0057 \\
\hline & B & 1256 & 1285 & 38 & 1.9 & 1.02 & 0.05 & 0.0019 \\
\hline & $\mathrm{P}$ & 33 & 249 & 99 & 155 & 7 & 5 & 6 \\
\hline \multirow[t]{6}{*}{ Pu98 B-9 } & $\overline{\mathrm{Al}}$ & 26160 & 27662 & 307 & $<3.5$ & 1.06 & 0.02 & 0.0002 \\
\hline & $\mathrm{Fe}$ & 6796 & 7175 & 84 & 0.3 & 1.06 & 0.02 & 0.0001 \\
\hline & $\overline{\mathrm{Ca}}$ & 739 & 796 & 31 & 5.7 & 1.08 & 0.07 & 0.0096 \\
\hline & $F$ & 1573 & 1618 & 13 & $<1.0$ & 1.03 & 0.01 & 0.0008 \\
\hline & B & 1121 & 1180 & 19 & 1.3 & 1.05 & 0.03 & 0.0014 \\
\hline & $\mathrm{P}$ & 12 & 29 & 50 & 64 & 2.3 & 6.6 & 6.4 \\
\hline \multirow[t]{6}{*}{ Pu98 B-13 } & $\mathrm{Al}$ & 15289 & 15611 & 271 & 3.6 & 1.02 & 0.03 & 0.0003 \\
\hline & $\mathrm{Fe}$ & 6195 & 6332 & 110 & 1.7 & 1.02 & 0.03 & 0.0003 \\
\hline & $\mathrm{Ca}$ & 701 & 714 & 15 & 3.9 & 1.02 & 0.04 & 0.0069 \\
\hline & $F$ & 294 & 211 & 24 & $<1.0$ & 0.72 & 0.14 & 0.0043 \\
\hline & $\mathrm{B}$ & 1089 & 1107 & 26 & 1.8 & 1.02 & 0.04 & 0.0021 \\
\hline & $\mathrm{P}$ & 19 & 63 & 56 & 79 & 3.2 & 4.8 & 5.1 \\
\hline
\end{tabular}


Table 19 Distribution Coefficients for $\mathrm{HNO}_{3}, \mathrm{HF}$ and $\mathrm{B}(\mathrm{OH})_{3}$ with TBP

\begin{tabular}{|c|c|c|c|}
\hline & $\begin{array}{c}30 \% \mathrm{TBP} \\
\mathrm{HNO}_{3}\end{array}$ & $\begin{array}{c}30 \% \mathrm{TBP} \\
\text { in DEB } \\
\mathrm{HF}\end{array}$ & $\begin{array}{c}100 \% \mathrm{TBP} \\
\mathrm{BN}(\mathrm{OH})_{3}\end{array}$ \\
\hline 0.1 & 0.05 & & \\
\hline 0.5 & 0.1 & 0.4 & 0.15 \\
\hline 1 & 0.15 & 0.3 & 0.08 \\
\hline 2 & 0.2 & 0.2 & 0.04 \\
\hline 3 & 0.2 & 0.15 & 0.007 \\
\hline 4 & 0.2 & 0.1 & \\
\hline 5 & 0.2 & 0.05 & 0.44 \\
\hline 6 & 0.17 & 0.03 & \\
\hline with 0.5M HF & \multicolumn{3}{|l}{} \\
\hline
\end{tabular}


Flowsheet Modifications for Dissolution of Sand, Slag, and Crucible Residues in the F-Canyon Dissolvers

Table 20 Effect of Aluminum on Impurity Carryover of Acid, Fluoride and Boron

\begin{tabular}{|c|c|c|c|c|c|c|c|c|c|c|}
\hline \multirow{2}{*}{$\begin{array}{l}\text { Al:F } \\
\text { Ratio }\end{array}$} & \multicolumn{10}{|c|}{ Pickup Test with SRTC solvent (single wash) } \\
\hline & $\begin{array}{c}\text { Sample } \\
\text { ID }\end{array}$ & & \begin{tabular}{|c|} 
Aqu \\
Stage \\
Volume
\end{tabular} & $\begin{array}{c}\text { Org } \\
\text { Stage } \\
\text { Volume }\end{array}$ & $\begin{array}{c}\mathrm{HNO}_{3} \\
\mathrm{Aqu} \\
\mathrm{M}\end{array}$ & $\begin{array}{c}\mathrm{HF} \\
\mathrm{Aqu} \\
\mathrm{M}\end{array}$ & $\begin{array}{c}\mathrm{H}_{3} \mathrm{BO}_{3} \\
\mathrm{Aqu} \\
\mathrm{M}\end{array}$ & $\mathrm{HNO}_{3}$ & n of Feed, & $\mathrm{H}_{3} \mathrm{BO}_{3}$ \\
\hline \multicolumn{11}{|c|}{$4 \mathrm{M} \mathrm{HNO}_{3}, 0.09 \mathrm{M} \mathrm{B}, 0.39 \mathrm{M} \mathrm{F}, 0 \mathrm{M} \mathrm{Al}, 4 \mathrm{M} \mathrm{NO} 3,1 \mathrm{~g} / 1 \mathrm{Fe}, 0.12 \mathrm{M} \mathrm{Ca}$} \\
\hline \multirow[t]{5}{*}{$0: 0.39$} & Pul03 & Feed B & 12 & & 3.31 & 0.24 & 0.10 & 1 & 1 & I \\
\hline & & Extract & 12 & 12 & 2.91 & 0.23 & 0.10 & 0.88 & 0.95 & 0.98 \\
\hline & & lst Strip & 12 & 11.5 & 0.57 & 0.01 & 0.002 & 0.11 & 0.031 & 0.024 \\
\hline & & 2nd Strip & 12 & 11 & 0.21 & 0.001 & 0.0004 & 0 & 0.0062 & 0.0039 \\
\hline & & 3rd Strip & 12 & 10.5 & 0.15 & $<0.00005$ & 0.0002 & 0 & 0.00022 & 0.0023 \\
\hline \multicolumn{11}{|c|}{$9.9 \mathrm{M} \mathrm{HNO}_{3}, 0.23 \mathrm{M} \mathrm{B}, 0.5 \mathrm{M} \mathrm{F}, 0 \mathrm{M} \mathrm{Al}, 2.4 \mathrm{~g} / \mathrm{Fe}, 0.3 \mathrm{M} \mathrm{Ca}$} \\
\hline \multirow[t]{4}{*}{$0: 0.50$} & Pul02 & Feed C & 12 & & 8.38 & 0.30 & 0.23 & 1 & 1 & $\bar{I}$ \\
\hline & & Extract & 12 & 12 & $7.4 \mathrm{I}$ & 0.30 & 0.23 & 0.88 & 0.98 & 1.03 \\
\hline & & Ist Strip & 12 & 11.5 & 8.78 & 0.001 & 0.001 & 1.05 & 0.0042 & 0.0041 \\
\hline & & 2nd Strip & 12 & 11 & 0.25 & $<0.00005$ & 0.0002 & 0.003 & 0.00017 & 0.0009 \\
\hline \multicolumn{11}{|c|}{$3.78 \mathrm{M} \mathrm{HNO}_{3}, 0.092 \mathrm{M} \mathrm{B}, 0.2 \mathrm{M} \mathrm{F}, 0 \mathrm{M} \mathrm{Al}, 4 \mathrm{M} \mathrm{NO}_{3}, 1 \mathrm{~g} / \mathrm{l} \mathrm{Fe}, 0.12 \mathrm{M} \mathrm{Ca}$} \\
\hline \multirow[t]{5}{*}{$0: 0.2$} & Pu100 & Feed A & 12 & & 3.36 & 0.12 & 0.09 & 1 & 1 & $T$ \\
\hline & & Extract & 12 & 12 & 2.86 & 0.12 & 0.09 & 0.85 & 0.98 & 1.01 \\
\hline & & Ist Strip & 12 & 11.5 & & & & & & \\
\hline & & 2nd Strip & 12 & 11 & 0.30 & 0.001 & 0.001 & 0.024 & 0.008 & 0.015 \\
\hline & & 3rd Strip & 12 & 10.5 & 0.22 & $<0.00005$ & 0.001 & 0 & 0.0004 & 0.011 \\
\hline \multicolumn{11}{|c|}{$3.78 \mathrm{M} \mathrm{HNO}{ }_{3}, 0.092 \mathrm{M} \mathrm{B}, 0.2 \mathrm{MF}, 0 \mathrm{M} \mathrm{Al}, 4 \mathrm{M} \mathrm{NO}_{3}, 1 \mathrm{~g} / \mathrm{l} \mathrm{Fe}, 0.12 \mathrm{M} \mathrm{Ca}$} \\
\hline \multirow[t]{5}{*}{$0: 0.2$} & Pu102 & Feed $A$ & 12 & & 3.32 & 0.11 & 0.09 & 1 & 1 & 1 \\
\hline & & Extract & 12 & 12 & 2.83 & 0.10 & 0.09 & 0.85 & 0.97 & 0.98 \\
\hline & & 1st Strip & 12 & 11.5 & 0.57 & 0.01 & 0.003 & 0.17 & 0.048 & 0.030 \\
\hline & & 2nd Strip & 12 & 11 & 0.30 & 0.0006 & 0.0003 & 0.022 & 0.0054 & 0.0037 \\
\hline & & 3rd Strip & 12 & 10.5 & 0.40 & 0.0093 & 0.0002 & 0.055 & 0.0871 & 0.0018 \\
\hline \multicolumn{11}{|c|}{$3.5 \mathrm{M} \mathrm{HNO}_{3}, 0.08 \mathrm{M} \mathrm{B}, 0.11 \mathrm{M} \mathrm{F}, 0.11 \mathrm{M} \mathrm{Al}, 4 \mathrm{M} \mathrm{NO}_{3}, 0.9 \mathrm{~g} / \mathrm{l} \mathrm{Fe}, 0.11 \mathrm{M} \mathrm{Ca}$} \\
\hline \multirow[t]{4}{*}{$1: 1$} & Pul03 & Feed $A$ & 12 & & 2.81 & 0.06 & 0.08 & 1 & 1 & 1 \\
\hline & & Extract & 12 & 12 & 2.36 & 0.06 & 0.08 & 0.84 & 1.02 & 0.99 \\
\hline & & Ist Strip & 12 & 11.5 & 0.51 & 0.001 & 0.001 & 0.18 & 0.016 & 0.0093 \\
\hline & & 2nd Strip & 12 & 11 & 0.19 & $<0.00005$ & 0.0002 & 0 & 0.0009 & 0.0029 \\
\hline \multicolumn{11}{|c|}{$2.41 \mathrm{M} \mathrm{HNO}_{3}, 0.058 \mathrm{M} \mathrm{B}, 0.127 \mathrm{M} \mathrm{F}, 0.51 \mathrm{M} \mathrm{Al}, 4 \mathrm{M} \mathrm{NO}, 0.52 \mathrm{~g} / \mathrm{Fe}, 0.08 \mathrm{M} \mathrm{Ca}$} \\
\hline \multirow[t]{4}{*}{$4: 1$} & Pul00 & Feed B & 12 & & 2.66 & 0.04 & 0.06 & I & 1 & 1 \\
\hline & & Extract & 12 & 12 & 1.73 & 0.03 & 0.06 & 0.65 & 0.85 & 1.02 \\
\hline & & Ist Strip & 12 & 11.5 & & & & & & \\
\hline & & 2nd Strip & 12 & 11 & 0.53 & $<0.00005$ & 0.001 & 0.12 & 0.0015 & 0.0166 \\
\hline \multicolumn{11}{|c|}{$2.41 \mathrm{M} \mathrm{HNO}_{3}, 0.058 \mathrm{M} \mathrm{B}, 0.127 \mathrm{M} \mathrm{F}, 0.51 \mathrm{M} \mathrm{Al}, 4 \mathrm{M} \mathrm{NO}, 0.52 \mathrm{~g} / 1 \mathrm{Fe}, 0.08 \mathrm{M} \mathrm{Ca}$} \\
\hline \multirow[t]{3}{*}{$4: 1$} & Pul02 & Feed B & 12 & & 2.12 & 0.03 & 0.06 & 1 & 1 & 1 \\
\hline & & Extract & 12 & 12 & 1.72 & 0.04 & 0.06 & 0.81 & 1.37 & 1.02 \\
\hline & & 1st Strip & 12 & 11.5 & 0.67 & $<0.00005$ & 0.0004 & 0.23 & 0.0018 & 0.0073 \\
\hline
\end{tabular}




\section{Fluoride Volatility}

\section{Experimental Details}

For each solution matrix that was tested, $150 \mathrm{ml}$ was placed into a $300 \mathrm{ml}$ boiling flask. Each solution was brought to a steady boil and the vapor was condensed with a pair of water-cooled condensers. This distillate was collected in three fractions: first $75 \mathrm{ml}$, middle $30 \mathrm{ml}$, and a last $30 \mathrm{ml}$, corresponding to $50 \%, 20 \%$, and $20 \%$ of the volume of feed solution respectively. Approximately $10 \%$ of the original volume remained in the boiling flask as bottoms. The feed solution and each distillate were sampled and analyzed for fluoride and acid by ISE and Total Acid methods, respectively. The bottoms were not sampled. Due to the possibility of aluminum and boron interference with the fluoride analyses, a set of samples containing $0.1 \mathrm{M} \mathrm{KF}$ in $4 \mathrm{M} \mathrm{HNO}_{3}$ with combinations of boron, aluminum, and iron were generated to test the analytical technique.

\section{Results and Discussion}

The analytical results from the boron/aluminum/iron interference test are shown in Table 20. As anticipated, both aluminum and boron significantly biased the fluoride results low by up to $60 \%$ as compared with the baseline $4 \mathrm{M} \mathrm{HNO}_{3}$ sample. Unexpectedly, the baseline $4 \mathrm{M} \mathrm{HNO}_{3}$ sample appears low by $21 \%$. The potassium content of this sample also was measured by atomic adsorption and gave a value that was $12 \%$ lower than the intended value of $0.1 \mathrm{M} \mathrm{KF}$. This result probably indicates that the baseline sample was made up low in KF and the fluoride analysis is probably within experimental uncertainties of makeup and analysis. However, solutions with aluminum or boron present are biased low and this limitation must be recognized when using this analytical method for performing material balances for this and related work .

The results of the evaporation tests are shown in Table 21. These results show the strong influence of acid in the volatilization of fluoride as HF. Aluminum clearly suppresses this volatilization much more than boric acid. Ferric nitrate appears to provide little suppression. In the case of $4: 1 \mathrm{molar}$ aluminum/fluoride in $4 \mathrm{M} \mathrm{HNO}_{3}$, the distillate had a fluoride concentration that varied from $<0.0001 \mathrm{M}$ to $0.0009 \mathrm{M}$ over the course of evaporation. When the aluminum/fluoride ratio was dropped to $1: 1,30$ times more fluoride was measured in the distillate. With a solution of boric acid (with no aluminum, but $4 \mathrm{M} \mathrm{HNO}_{3}$ ) at a 2.5:1 molar ratio, two to four times more additional fluoride was measured in the distillate as compared to the case of 1:1 aluminum /fluoride. The large amounts of expected fluoride will require large amounts of aluminum to complex the fluoride in order to reduce the corrosion of the evaporation if this material is acid evaporated. This behavior may make the economics of acid recovery unfavorable and suggests that acid neutralization and discard be considered. 
Table 21 Effect of Aluminum, Boric Acid and Ferric Nitrate on ISE Analysis for Total Fluoride

\begin{tabular}{|c|c|c|c|}
\hline \multirow[b]{2}{*}{ Description } & \multicolumn{3}{|c|}{ Measured by $F$ by ISE } \\
\hline & $\mathrm{M}, \mathrm{F}$ & $\begin{array}{c}\% \mathrm{~F} \text { in } \\
\mathrm{Std}\end{array}$ & $\begin{array}{l}\% \mathrm{~F} \text { of } \\
\text { Actual }\end{array}$ \\
\hline $0.1 \mathrm{M} \mathrm{KF} / 4 \mathrm{M} \mathrm{HNO} 3$ & 0.0787 & $100 \%$ & $79 \%$ \\
\hline $0.1 \mathrm{M} \mathrm{KF} / 0.1 \mathrm{M} \mathrm{B}(\mathrm{OH})_{3} / 4 \mathrm{M} \mathrm{HNO} 3$ & 0.0591 & $75 \%$ & $59 \%$ \\
\hline $0.1 \mathrm{M} \mathrm{KF} / 0.25 \mathrm{M} \mathrm{B}(\mathrm{OH})_{3} / 4 \mathrm{M} \mathrm{HNO}_{3}$ & 0.0612 & $78 \%$ & $61 \%$ \\
\hline $0.1 \mathrm{M} \mathrm{KF} / 0.1 \mathrm{M} \mathrm{ANN} / 4 \mathrm{M} \mathrm{HNO}_{3}$ & 0.0689 & $88 \%$ & $69 \%$ \\
\hline $0.1 \mathrm{M} \mathrm{KF} / 0.2 \mathrm{M}$ ANN $/ 4 \mathrm{M} \mathrm{HNO}_{3}$ & 0.0626 & $80 \%$ & $63 \%$ \\
\hline $0.1 \mathrm{M} \mathrm{KF} / 0.4 \mathrm{M}$ ANN $/ 4 \mathrm{M} \mathrm{HNO}_{3}$ & 0.0470 & $60 \%$ & $47 \%$ \\
\hline $0.1 \mathrm{M} \mathrm{KF} / 0.8 \mathrm{M}$ ANN $/ 4 \mathrm{M} \mathrm{HNO}_{3}$ & 0.0310 & $39 \%$ & $31 \%$ \\
\hline $0.1 \mathrm{M} \mathrm{KF} / 0.1 \mathrm{M} \mathrm{B}(\mathrm{OH})_{3} / 0.1 \mathrm{M}$ ANN $/ 4 \mathrm{M} \mathrm{HNO}_{3}$ & 0.0650 & $83 \%$ & $65 \%$ \\
\hline $0.1 \mathrm{M} \mathrm{KF} / 0.25 \mathrm{M} \mathrm{B}(\mathrm{OH})_{3} / 0.4 \mathrm{M}$ ANN $/ 4 \mathrm{M} \mathrm{HNO}_{3}$ & 0.0582 & $74 \%$ & $58 \%$ \\
\hline $0.1 \mathrm{M} \mathrm{KF} / 0.25 \mathrm{M} \mathrm{B}(\mathrm{OH})_{3} / 0.8 \mathrm{M} \mathrm{ANN} / 4 \mathrm{M} \mathrm{HNO}$ & 0.0350 & $44 \%$ & $35 \%$ \\
\hline $0.1 \mathrm{M} \mathrm{KF} / 0.1 \mathrm{M}$ ANN $/ 0.1 \mathrm{M} \mathrm{Fe} \mathrm{NO}_{3} / 4 \mathrm{M} \mathrm{HNO}_{3}$ & 0.0642 & $82 \%$ & $64 \%$ \\
\hline
\end{tabular}


Table 22 Volatilization of Fluoride during the Evaporation of Solutions Containing Fluoride, Boric acid, Aluminum in Nitric Acid

\begin{tabular}{|c|c|c|c|c|c|c|}
\hline Description & & Vol., ml & Total Acid & $\mathrm{M}, \mathrm{F}$ & $\%$ Acid in Feed & $\% \mathrm{~F}$ in Feed \\
\hline \multirow{4}{*}{$\begin{array}{l}0.1 \mathrm{M} \mathrm{KF} / 0.25 \mathrm{M} \\
\mathrm{H}_{3} \mathrm{BO}_{3}\end{array}$} & Feed & 150 & $<0.002$ & 0.0908 & $100.0 \%$ & $90.8 \%$ \\
\hline & Ist Cut & 75 & 0.040 & $<0.0001$ & $987.5 \%$ & $<0.03 \%$ \\
\hline & 2nd Cut & 30 & $<0.002$ & $<0.0001$ & $<20.0 \%$ & $<0.01 \%$ \\
\hline & 3 rd Cut & 30 & $<0.002$ & $<0.0001$ & $<20.0 \%$ & $<0.01 \%$ \\
\hline \multirow[t]{4}{*}{$0.1 \mathrm{M} \mathrm{KF} / 0.4 \mathrm{M}$ ANN } & Feed & 150 & 1.123 & 0.0239 & $100.0 \%$ & $23.90 \%$ \\
\hline & Ist Cut & 75 & 0.031 & $<0.0001$ & $1.4 \%$ & $<0.03 \%$ \\
\hline & 2nd Cut & 30 & 0.022 & $<0.0001$ & $0.4 \%$ & $<0.01 \%$ \\
\hline & 3rd Cut & 30 & 0.135 & $<0.0001$ & $2.4 \%$ & $<0.01 \%$ \\
\hline \multirow[t]{4}{*}{$0.1 \mathrm{M}$ KF/0.1M ANN } & Feed & 150 & 0.260 & 0.0817 & $100.0 \%$ & $81.74 \%$ \\
\hline & $1 \mathrm{st}$ Cut & 75 & 0.012 & $<0.0001$ & $2.3 \%$ & $<0.03 \%$ \\
\hline & 2nd Cut & 30 & 0.016 & $<0.0001$ & $1.3 \%$ & $<0.01 \%$ \\
\hline & 3rd Cut & 30 & 0.561 & 0.0039 & $43.2 \%$ & $0.78 \%$ \\
\hline \multirow{4}{*}{$\begin{array}{l}0.1 \mathrm{M} \mathrm{KF} / 0.4 \mathrm{M} \mathrm{ANN} \\
\text { in } 4 \mathrm{M} \mathrm{HNO} 3\end{array}$} & Feed & 150 & 4.911 & 0.0374 & $100.0 \%$ & $37.42 \%$ \\
\hline & 1st Cut & 75 & 0.507 & $<0.0001$ & $5.2 \%$ & $<0.03 \%$ \\
\hline & 2nd Cut & 30 & 4.329 & 0.0009 & $17.6 \%$ & $0.18 \%$ \\
\hline & 3rd Cut & 30 & 10.564 & 0.0009 & $43.0 \%$ & $0.18 \%$ \\
\hline \multirow{4}{*}{$\begin{array}{l}\text { Ron's B-F-H }{ }^{+}-\mathrm{Al} \\
6.74 \mathrm{M} \mathrm{HNO} \\
\mathrm{KF}, 3.48 \mathrm{~g} / \mathrm{Fe}, 0.58 \mathrm{M} \\
\mathrm{AI}\end{array}$} & Feed & 150 & 8.764 & 0.0580 & $100.0 \%$ & $100 \%$ \\
\hline & 1st Cut & 75 & 4.818 & 0.0016 & $27.5 \%$ & $\mathrm{I} .4 \%$ \\
\hline & 2nd Cut & 30 & 11.082 & 0.0023 & $25.3 \%$ & $0.8 \%$ \\
\hline & 3rd Cut & 30 & 12.599 & 0.0028 & $28.8 \%$ & $1.0 \%$ \\
\hline \multirow{4}{*}{$\begin{array}{l}0.1 \mathrm{M} \mathrm{KF} / 0.1 \mathrm{M} \mathrm{ANN} \\
\text { in } 4 \mathrm{M} \mathrm{HNO}_{3}\end{array}$} & Feed & 150 & 4.233 & 0.0756 & $100.0 \%$ & $76 \%$ \\
\hline & Ist Cut & 75 & 0.561 & 0.0036 & $6.6 \%$ & $2 \%$ \\
\hline & 2nd Cut & 30 & 2.702 & 0.0112 & $12.8 \%$ & $2 \%$ \\
\hline & 3rd Cut & 30 & 7.924 & 0.0154 & $37.4 \%$ & $3 \%$ \\
\hline \multirow{4}{*}{$\begin{array}{l}0.1 \mathrm{M} \mathrm{KF} / 0.25 \mathrm{M} \\
\mathrm{B}(\mathrm{OH})_{3} \text { in } 4 \mathrm{M} \mathrm{HNO} 3\end{array}$} & $\overline{\text { Feed }}$ & 150 & 3.995 & 0.0720 & $100.0 \%$ & $72 \%$ \\
\hline & lst Cut & 75 & 0.513 & 0.0078 & $6.4 \%$ & $4 \%$ \\
\hline & 2nd Cut & 30 & 2.960 & 0.0313 & $14.8 \%$ & $6 \%$ \\
\hline & $3 \mathrm{rd} \mathrm{Cut}$ & 30 & 9.495 & 0.0647 & $47.5 \%$ & $13 \%$ \\
\hline \multirow{4}{*}{$\begin{array}{l}0.1 \mathrm{M} \mathrm{KF} / 0.1 \mathrm{M} \mathrm{Fe} \\
\text { Nitrate in } 4 \mathrm{M} \mathrm{HNO} 3\end{array}$} & Feed & 150 & 4.265 & 0.0883 & $100.0 \%$ & $88 \%$ \\
\hline & ist Cut & 75 & 0.509 & 0.0333 & $6.0 \%$ & $17 \%$ \\
\hline & 2nd Cut & 30 & 3.037 & 0.1178 & $14.2 \%$ & $24 \%$ \\
\hline & 3rd Cut & 30 & 9.078 & 0.1015 & $42.6 \%$ & $20 \%$ \\
\hline \multirow[t]{4}{*}{$0.3 \mathrm{M} \mathrm{KF} / 4 \mathrm{M} \mathrm{HNO} 3$} & Feed & 150 & 3.5414 & 0.0620 & $100.0 \%$ & $21 \%$ \\
\hline & Ist Cut & 75 & 0.6571 & 0.2628 & $9.3 \%$ & $44 \%$ \\
\hline & 2nd Cut & 30 & 2.1948 & 0.3674 & $12.4 \%$ & $24 \%$ \\
\hline & 3 rd Cut & 30 & 6.9677 & 0.1637 & $39.3 \%$ & $11 \%$ \\
\hline \multirow[t]{4}{*}{$0.1 \mathrm{M} \mathrm{KF} / 8 \mathrm{M} \mathrm{HNO} 3$} & Feed & 150 & 8.665 & 0.0918 & $100.0 \%$ & $\overline{92 \%}$ \\
\hline & Ist Cut & 75 & 4.360 & 0.1340 & $25.2 \%$ & $67 \%$ \\
\hline & 2nd Cut & 30 & 6.805 & 0.0727 & $15.7 \%$ & $15 \%$ \\
\hline & 3rd Cut & 30 & 13.136 & 0.0152 & $30.3 \%$ & $3 \%$ \\
\hline
\end{tabular}




\section{Corrosion Studies}

\section{A. Experimental Details}

Coupon immersion tests were conducted following the guidelines of ASTM standard practices for preparing test coupons and conducting laboratory immersion tests. 8 Three coupon tests were conducted on a total of 18 different solutions. For the first test, the coupons were suspended with Teflon ${ }^{\mathrm{TM}}$ tape in $500 \mathrm{ml}$ of the solutions which were in polyethylene bottles. The bottles were placed into a furnace at $90^{\circ} \mathrm{C}$ for 21 hours. The other two tests used glass flasks in which the temperatures were individually controlled. The flasks were placed on stirrer/hot plates for agitation and heating. The flasks were set up with condensers, thermometers, and magnetic stirrer bars. Solution temperatures ranged between $85-90^{\circ} \mathrm{C}$. The second test was conducted for 20 hours. For the third test, the coupons were removed, weighed, and re-immersed to obtain corrosion rates for more extended periods. Weights were measured for one, three and seven days.

The composition of test solutions are summarized in Table 21. The solutions all contained 9.3M $\mathrm{HNO}_{3}$ and $0.23 \mathrm{M}$ boron, which was added as boric acid. Concentrations of fluoride, calcium, aluminum, and iron were varied.

The test coupons were made of $304 \mathrm{~L}$ stainless steel; both welded and unwelded coupons were used. The welded coupons were 2 -inches $X 0.75$-inches $X 0.125$-inches and the unwelded were 2 -inch X 1.0-inch X 0.125 -inch. The weld was across the width of the coupon; however, the welding procedure is unknown. A hole was drilled near one end for suspending the coupons. The coupons were ground on 600 grit silicon paper, cleaned, and weighed prior to immersion. After testing the coupons were removed, rinsed, blown dry, and re-weighed. The welded and unwelded coupons were used for the third (\#15-18) test only, while welded coupons were used for the first $(\# 1-8)$ and the second (\#9-14) tests.

The corrosion rates were calculated from the measured weight losses. The equation for calculating this rate (CR) in units of mils per year (mpy) is shown as equation (20), ${ }^{9}$

$$
C R=(K \times W) /(A \times T \times D)
$$

where $\mathrm{K}$ is a constant $\left(3.45 \times 10^{6}\right), \mathrm{W}$ is the weight loss (grams), $\mathrm{A}$ is the coupon surface. area $\left(\mathrm{cm}^{2}\right), \mathrm{T}$ is the exposure time $(\mathrm{hr})$, and $\mathrm{D}$ is the density $\left(\mathrm{g} / \mathrm{cm}^{3}\right)$. The areas of the welded and unwelded coupons were $22.077 \mathrm{~cm}^{2}$ and $30.645 \mathrm{~cm}^{2}$, respectively. The density for $304 \mathrm{~L}$ was $7.94 \mathrm{~g} / \mathrm{cm}^{3}$ 
Table 23 Summary of Corrosion Rates and Solution Chemistries

Notes:

All solutions contained $9.3 \mathrm{M} \mathrm{HNO}_{3}$

a Al expressed as Al:F ratio

b unwelded coupon $\mathrm{ND}=$ not determined

\begin{tabular}{|c|c|c|c|c|c|c|c|c|c|c|}
\hline & & \multicolumn{9}{|c|}{ Solution Chemistry } \\
\hline & Corrosion & $\mathrm{KF}$ & $\mathrm{CaF}_{2}$ & $\mathrm{Ca}^{+2}$ & $\mathrm{~F}^{-}$ & $\mathrm{B}$ & $\mathrm{Fe}$ & $\mathrm{MgO}$ & $\mathrm{Al}$ & Free $\mathrm{F}$ \\
\hline Solution & Rate (mpy) & $(\mathrm{M})$ & $(\mathrm{M})$ & (M) & $(\mathrm{M})$ & $(\mathrm{M})$ & (g/liter) & (g/liter) & (M) & $(\mathrm{ppm})$ \\
\hline 1 & 77.45 & 0.05 & 0 & $x^{2}+3$ & 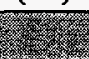 & 0 & 0 & 0 & 0 & 128 \\
\hline 2 & 24.66 & 0.05 & 0 & & $x$ & 0.23 & 0 & 0 & 0 & 17 \\
\hline 3 & 26.51 & 0.1 & 0 & (2) & 8 & 0.23 & 0 & 0 & 0 & 24 \\
\hline 4 & 35.31 & 0.2 & 0 & & 31 & 0.23 & 0 & 0 & 0 & 32 \\
\hline 5 & 42.84 & 0.3 & 0 & 12 & $\sqrt{2+2}$ & 0.23 & 0 & 0 & 0 & 38 \\
\hline 6 & 3.94 & 0.2 & 0 & & 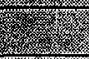 & 0.23 & 0 & 0 & 0.8 & 10 \\
\hline 7 & 38.21 & 0.05 & 0.075 & & & 0.23 & 0 & 0 & 0 & 32 \\
\hline 8 & 64.02 & 0.2 & 0 & 4 & (3) & 0.23 & 1.2 & 1.25 & 0 & 34 \\
\hline 9 & 46.86 & 0.2 & & & $\sqrt{53}$ & 0.23 & 0.043 & & $0^{a}$ & 35 \\
\hline 10 & 34.03 & 0.2 & & & & 0.23 & 0.043 & & $1: 1^{a}$ & 42 \\
\hline 11 & 14.09 & 0.2 & & & & 0.23 & 0.043 & & $4: 1^{a}$ & 13 \\
\hline 12 & 61.20 & 0.2 & & & & 0.23 & 0.086 & & $0^{a}$ & ND \\
\hline 13 & 24.89 & 0.2 & & & 4 & 0.23 & 0.086 & & $1: 1^{a}$ & 26 \\
\hline 14 & 6.35 & 0.2 & & & & 0.23 & 0.086 & & $4: 1^{a}$ & 12 \\
\hline 15 & 30.61 & & 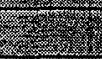 & 0.3 & 0.3 & 0.23 & 0 & & & ND \\
\hline $15^{b}$ & 56.57 & & & $\overline{0.3}$ & 0.3 & 0.23 & 0 & & & $\overline{N D}$ \\
\hline 16 & 40.05 & & & $\overline{0.3}$ & 0.5 & 0.23 & 0 & & 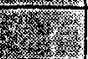 & ND \\
\hline 17 & 18.99 & & & $\overline{0.3}$ & 0.3 & 0.23 & 2.4 & & 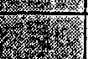 & $\overline{N D}$ \\
\hline $16^{b}$ & 58.13 & & & 0.3 & 0.5 & 0.23 & 0 & & x- & $\overline{N D}$ \\
\hline $17^{b}$ & 25.81 & & & 0.3 & 0.3 & 0.23 & 2.4 & & (2) & ND \\
\hline 18 & 61.90 & & & 0.3 & 0.5 & 0.23 & $\overline{2.4}$ & & y & ND \\
\hline $18^{b}$ & 65.36 & & & $\overline{0.3}$ & 0.5 & 0.23 & 2.4 & & & ND \\
\hline
\end{tabular}




\section{B. Results and Discussion}

The performance of $304 \mathrm{~L}$ in $\mathrm{HNO}_{3}$ solutions containing $\mathrm{KF}, \mathrm{CaF}_{2}$, and the fluoridecomplexing elements boron, iron and aluminum was unknown. The corrosion rate in $\mathrm{HNO}_{3}$ /fluoride solutions would represent a conservative case. The effect of $\mathrm{HF}$ had been previously studied by Ondrejcin and McLaughlin and Kranzlein. 10,11 In 10M $\mathrm{HNO}_{3}$ solutions, Ondrejcin and McLaughlin reported rates for wrought material of $21 \mathrm{mpy}$ for $0.01 \mathrm{M} \mathrm{HF}$ and $248 \mathrm{mpy}$ for $0.1 \mathrm{M} \mathrm{HF}$. These tests were conducted at $95{ }^{\circ} \mathrm{C}$. Kranzlein tested over a range of temperatures $\left(24^{\circ} \mathrm{C}\right.$ up to boiling). For boiling $8 \mathrm{M} \mathrm{HNO} 3$, the corrosion rate ranged from approximately $50 \mathrm{mpy}$ for $0.01 \mathrm{M} \mathrm{HF}$ up to above $500 \mathrm{mpy}$ for $0.1 \mathrm{M} \mathrm{HF}$. Although at a temperature of $60^{\circ} \mathrm{C}$ and $10 \mathrm{M} \mathrm{HNO}_{3}$, the rate ranged from less 10 mpy to 50 mpy. Both studies found that there was not a preferential attack of welded coupons for their test conditions.

The corrosion rates in this study were, in general, much lower than uncomplexed $\mathrm{HNO}_{3} /$ fluoride solutions. The rates and corresponding chemistries are shown in Table 21. The maximum rate of $77.5 \mathrm{mpy}$ was found for the uncomplexed solution (\#1) with $0.05 \mathrm{M} \mathrm{KF}$. This rate is similar to the rates measured by Ondrejcin and McLaughlin and Kranzlein. Some variability in the results was expected since test conditions were not identical. Additionally, the difference between KF and HF is not known. This rate is significantly larger than for nitric acid service. The corrosion rate of $304 \mathrm{~L}$ is approximately 5 mpy for similar concentrations and temperatures. As in the previous studies, increasing fluoride concentration accelerated the corrosion (Figure 23). For solutions \#2-5, the rate increased from 25 to 43 mpy with a change from 0.05 to $0.3 \mathrm{M}$ KF.

The presence of other solution constituents also affected the corrosion rate of $304 \mathrm{~L}$, especially when fluoride was complexed. Boron, which is being used as a soluble nuclear poison, complexed the fluoride and decreased the corrosion rate as shown by the lower rate for \#2 as compared to \#1. Aluminum had a similar effect as evidenced by the inverse trend shown by solutions \#9-11 and \#12-14. The effect of iron remains uncertain since during the first test (\# 4 and 8 ) the presence of iron accelerated corrosion, while for the third test (\#15 and 17, 16 and 18) there was no effect. However, for solutions \#15-18, the presence of $\mathrm{CaF}_{2}$ may impact the corrosion reactions. Additional testing would be required to delineate the role of iron.

During the third test (\#15-18), the effect of the weld was evaluated by immersing both welded and unwelded coupons. The corrosion rate of the welded coupons was lower than that of unwelded coupons. Since the weld area was small compared to the total surface area, another test was conducted in which a welded coupon was cut in half. Both halves were exposed to Solution \#15. Again, the rates were similar, approximately $30 \mathrm{mpy}$. These weld results were similar to those reported by Ondrejcin and McLaughlin. Kranzlein also reported similar corrosion resistances for weld and wrought $304 \mathrm{~L}$. 
The test procedure was probably not sensitive enough to determine the effect of the weld through weight loss. After testing, the welds were microscopically examined. The weld regions were heavily etched and weld striations were clearly observable; whereas, on the base material, the initial grinding marks were still present. There were some indications of intergranular attack, but they were limited to a region 10-20 microns from the weld. Further study is necessary to determine if welds are preferentially attacked. 


\section{References}

1. J. H. Gray, D. G. Karraker, T. S. Rudisill, and G. T. Chandler, "Dissolution of Sand, Slag, and Crucible Residues in the F-Canyon Dissolvers," WSRC-TR-97-00367, Westinghouse Savannah River Company, Aiken, SC (December 1997).

2. "Model 94-09, 96-09. Fluoride/combination Fluoride Electrodes Instruction Manual," Orion PN 502700-3 Form 1M94, 9609/ 1/91, Rev. 6, p. 30.

3. R. M. Smith and A. E. Martel, Critical Stability Constants, Volume 4: Inorganic Complexes, Plenum Press, New York, NY (1976).

4. B. D. Lichter and M. A. Bredig, J. Electrochem. Soc., 112508 (1965).

5. "Gmelin Handbuch der Anorganishchen Chemie, Band 21, Transurane, Teil D2: Chemie in Losung," Gunter Koch, Karl-Christian Buschbeck, Springer-Verlag, New York, 1975, pg 59-60.

6. Science and Technology of Tributyl Phosphate, Volume IV: Extraction of Water and Acids, Supplement: Tabulated Data for Extraction of Inorganic Acids by TBP, W. W. Schulz, J. D. Navratil, A.S. Kertes, Editors, CRC Press, 1991.

7. P.A. Anderson, J. D. Christian, "Alternative Reagent to Mercuric Nitrate Catalyst for Dissolution of Aluminum-Clad Nuclear Fuels in Nitric Acid," Journal of Nuclear Materials in press.

8. G 1-88 "Standard Practice for Preparing, Cleaning, and Evaluating Corrosion Test Specimens," American Society of Testing and Materials, Philadelphia, PA, 1997.

9. G 31-72 (reapproved 1985) "Standard Practice for Preparing, Cleaning, and Evaluating Corrosion Test Specimens," American Society of Testing and Materials, Philadelphia, PA, 1997.

10. R. S. Ondrejcin and B. D. McLaughlin, "Corrosion Of High Ni-Cr Alloys And Type 304 L Stainless Steel In $\mathrm{HNO}_{3}$-HF," DP-1550, April, 1980.

11. P. M. Kranzlein, "Corrosion Of Stainless Steel in $\mathrm{HNO}_{3}$-HF Solutions," SP-486, July, 1960. 


\section{This page has been left blank intentionally.}


Figure 1 Charging Bundle and Dissolver Insert for SS\&C Dissolution

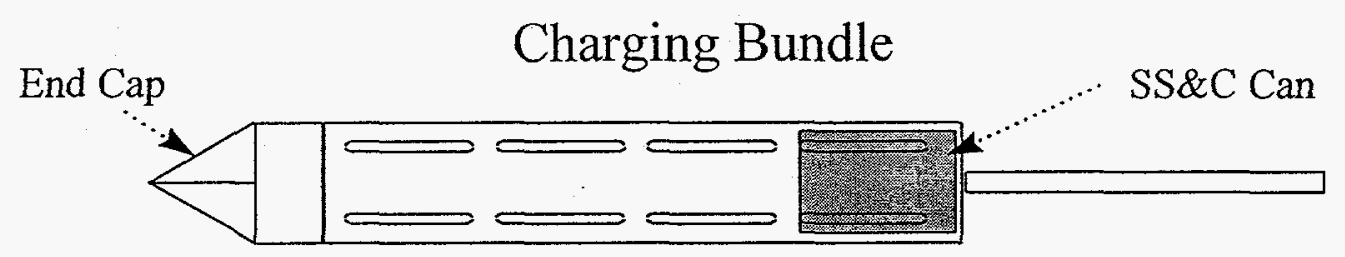

Charging Bundle with Insert

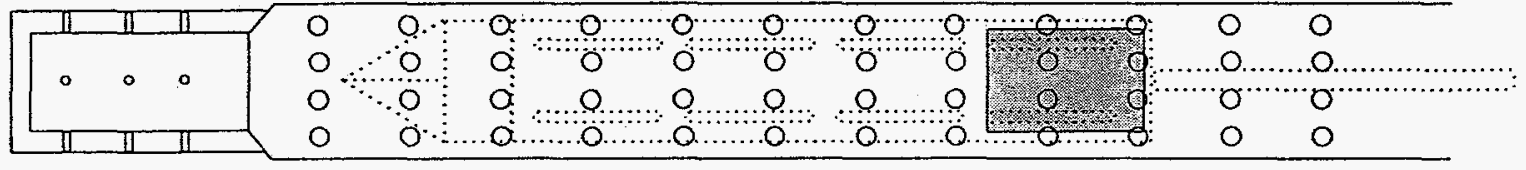

**Not drawn to scale 


\section{This page has been left blank intentionally.}


Figure 2 Ionization of Hydrogen Fluoride as a Function of $\mathrm{pH}$

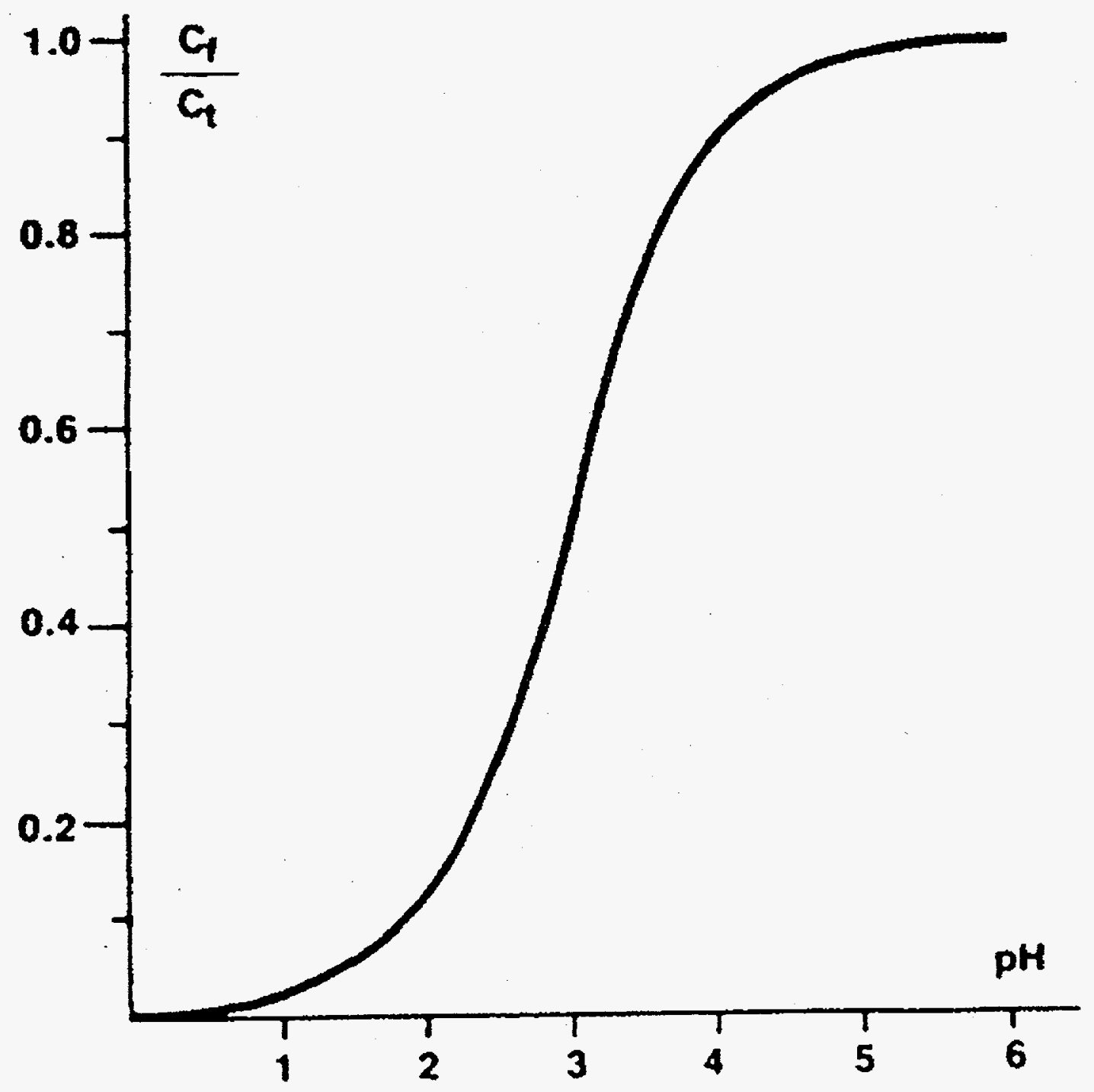




\section{This page has been left blank intentionally.}


Figure 3 Typical Calibration Curve for Free Fluoride

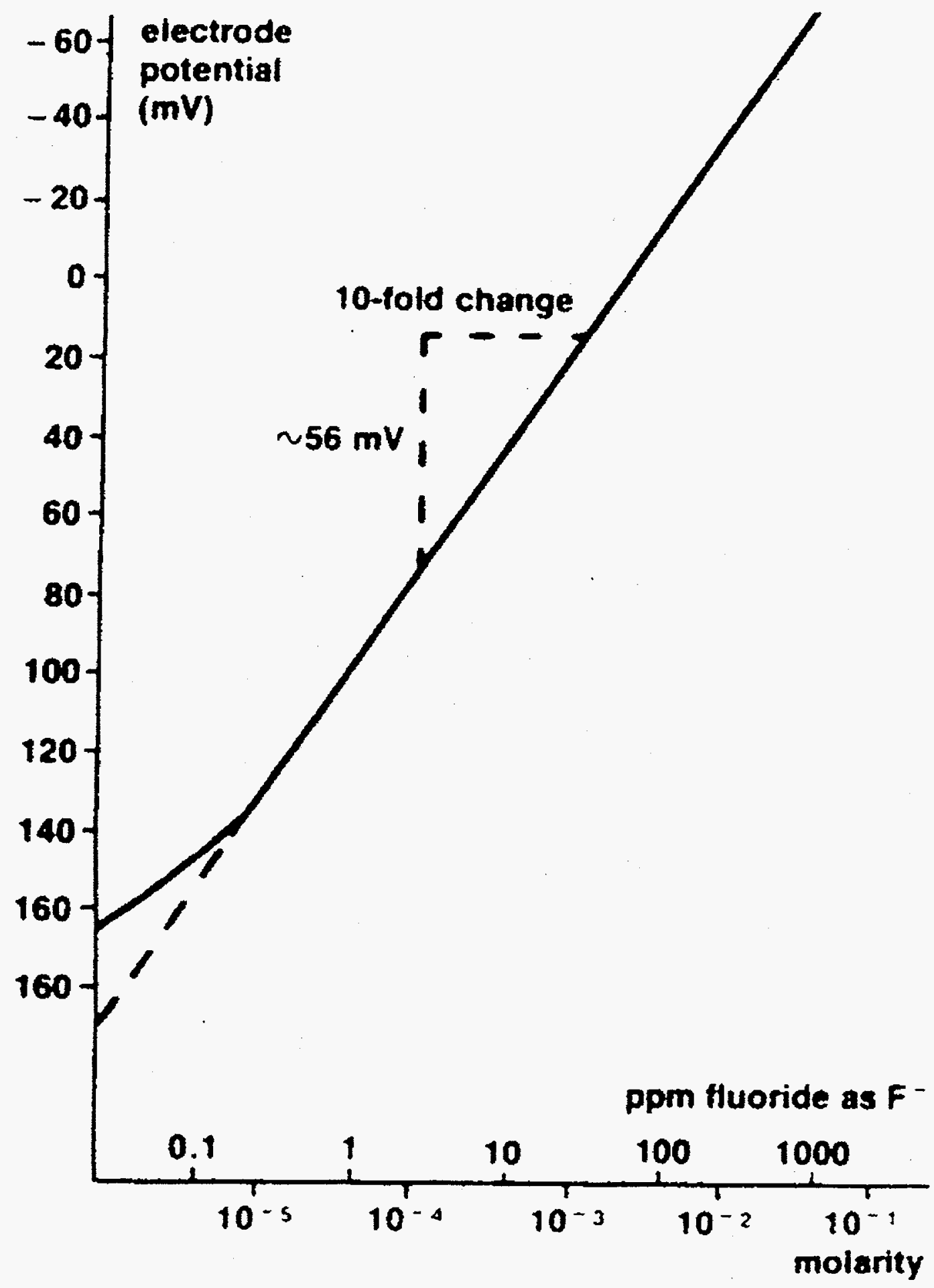




\section{This page has been left blank intentionally.}


Figure 4 Free Fluoride in Dissolver Solution

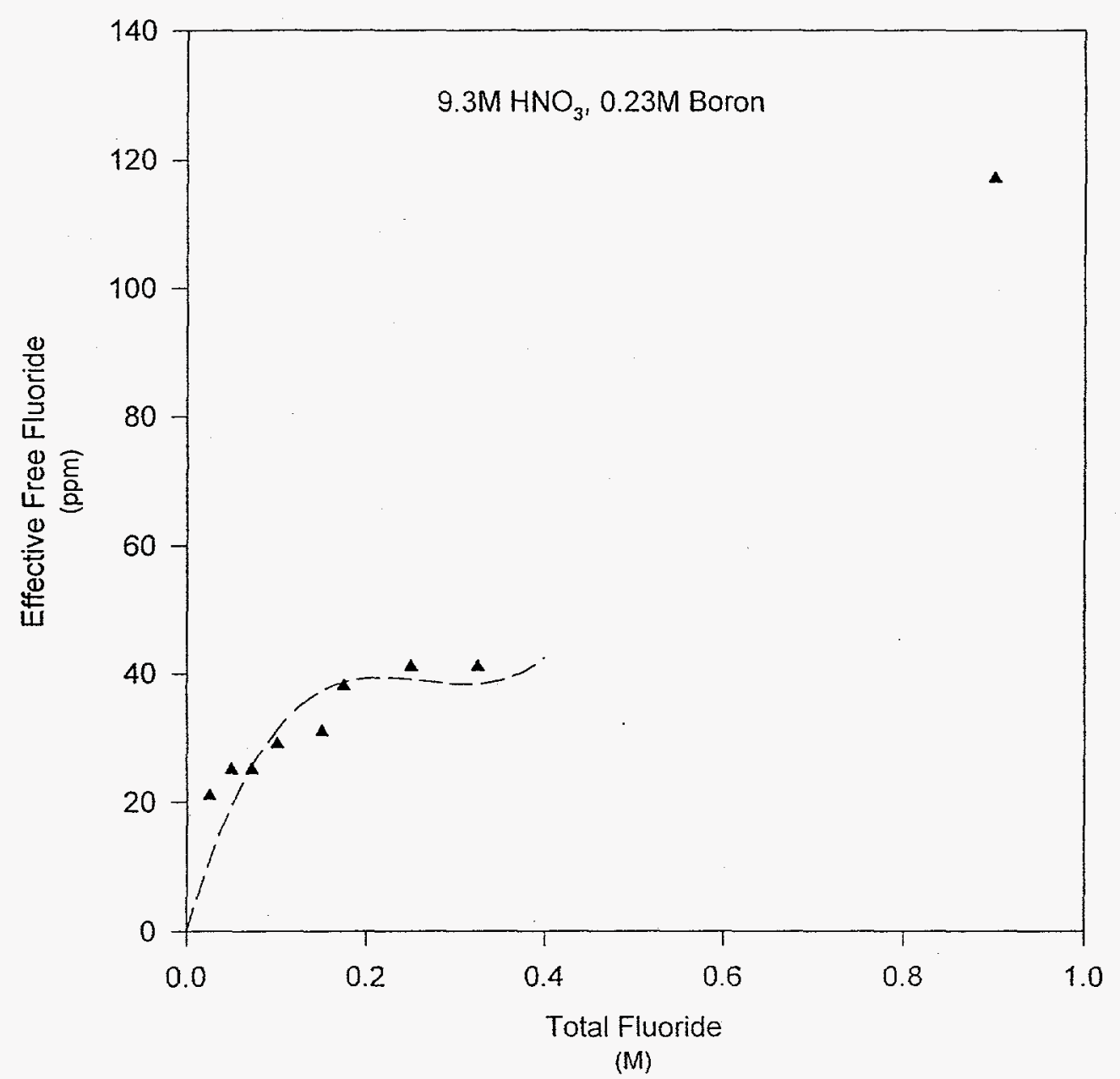




\section{This page has been left blank intentionally.}




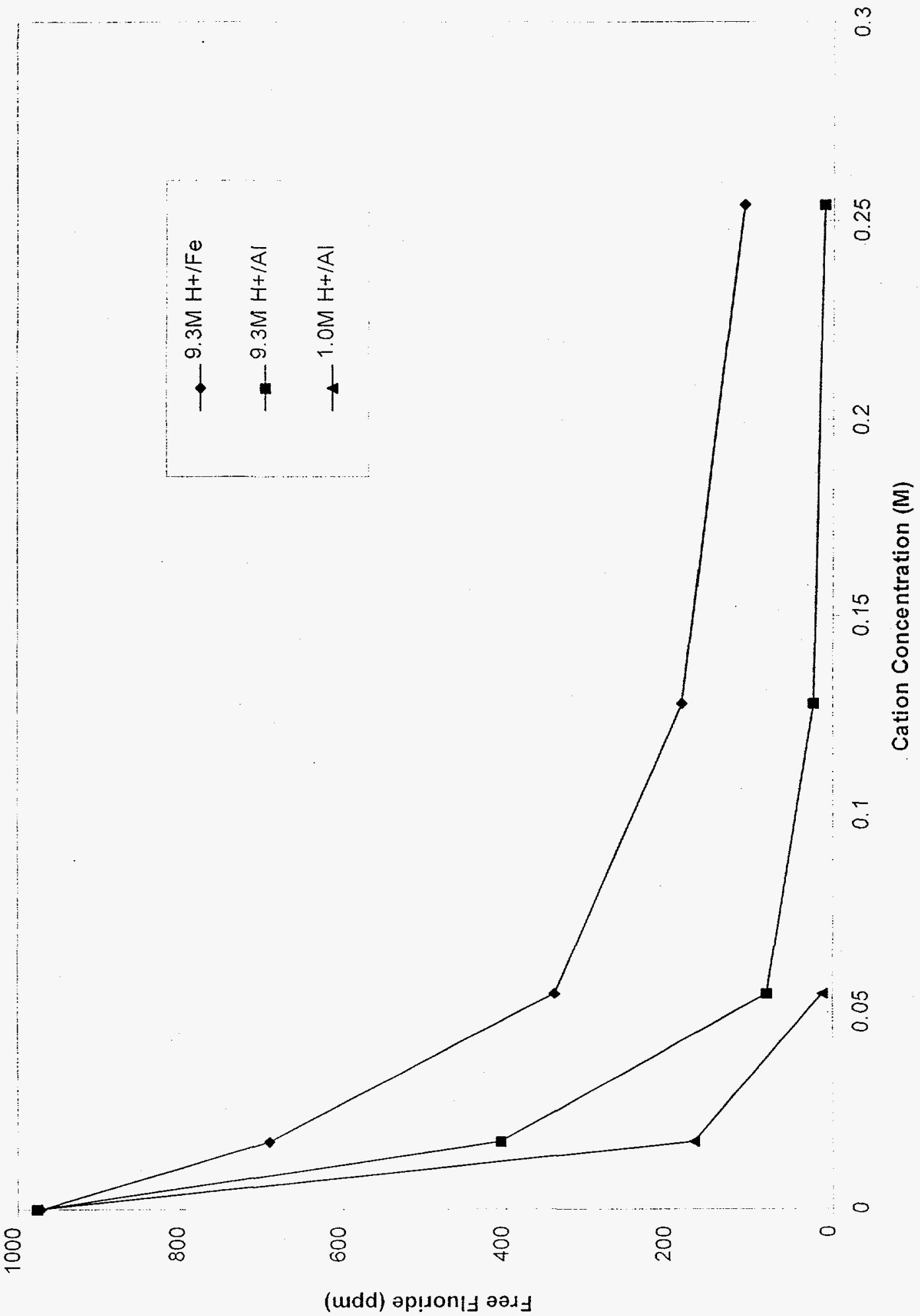




\section{This page has been left blank intentionally.}




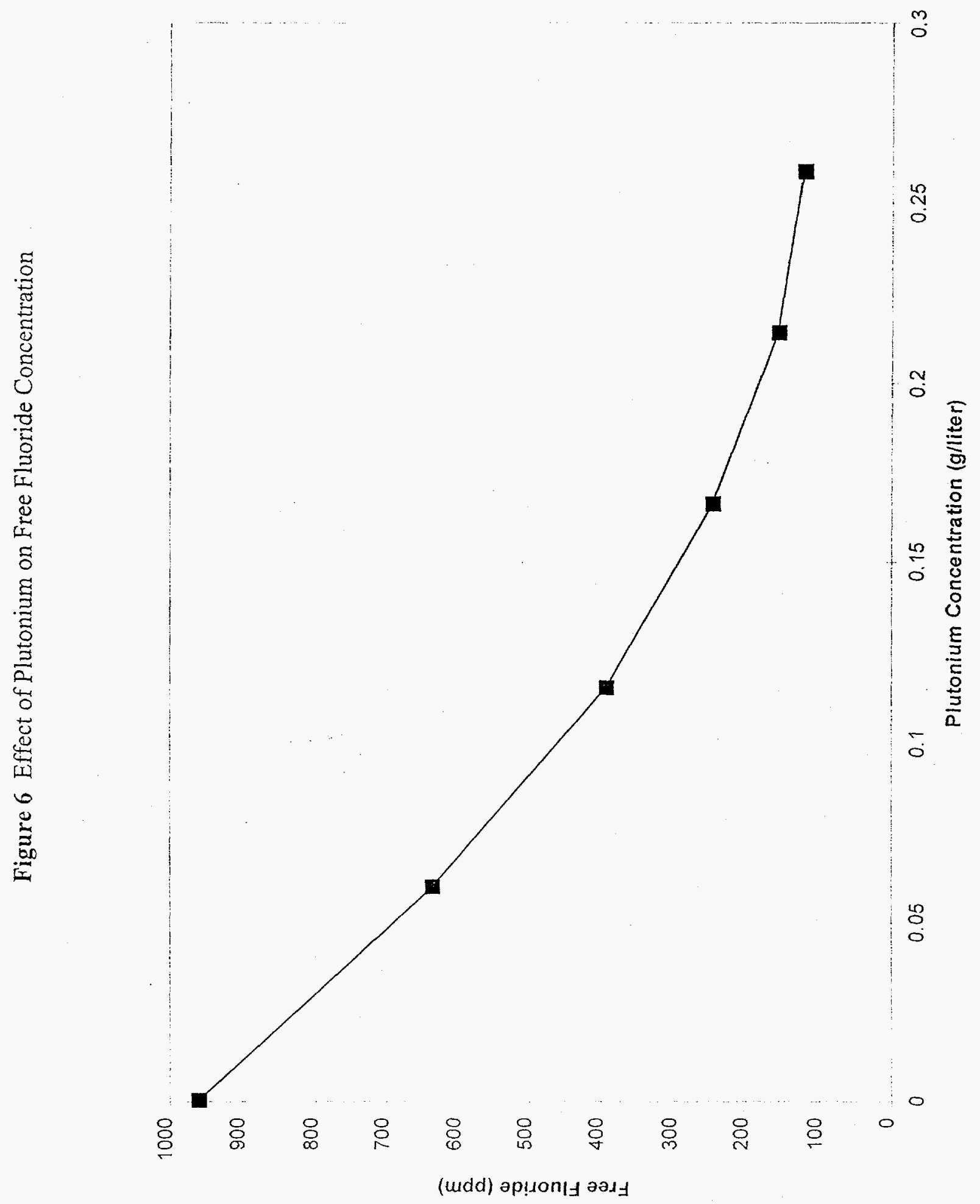




\section{This page has been left blank intentionally.}


Figure 7 Effect of Boron on Free Fluoride Concentration

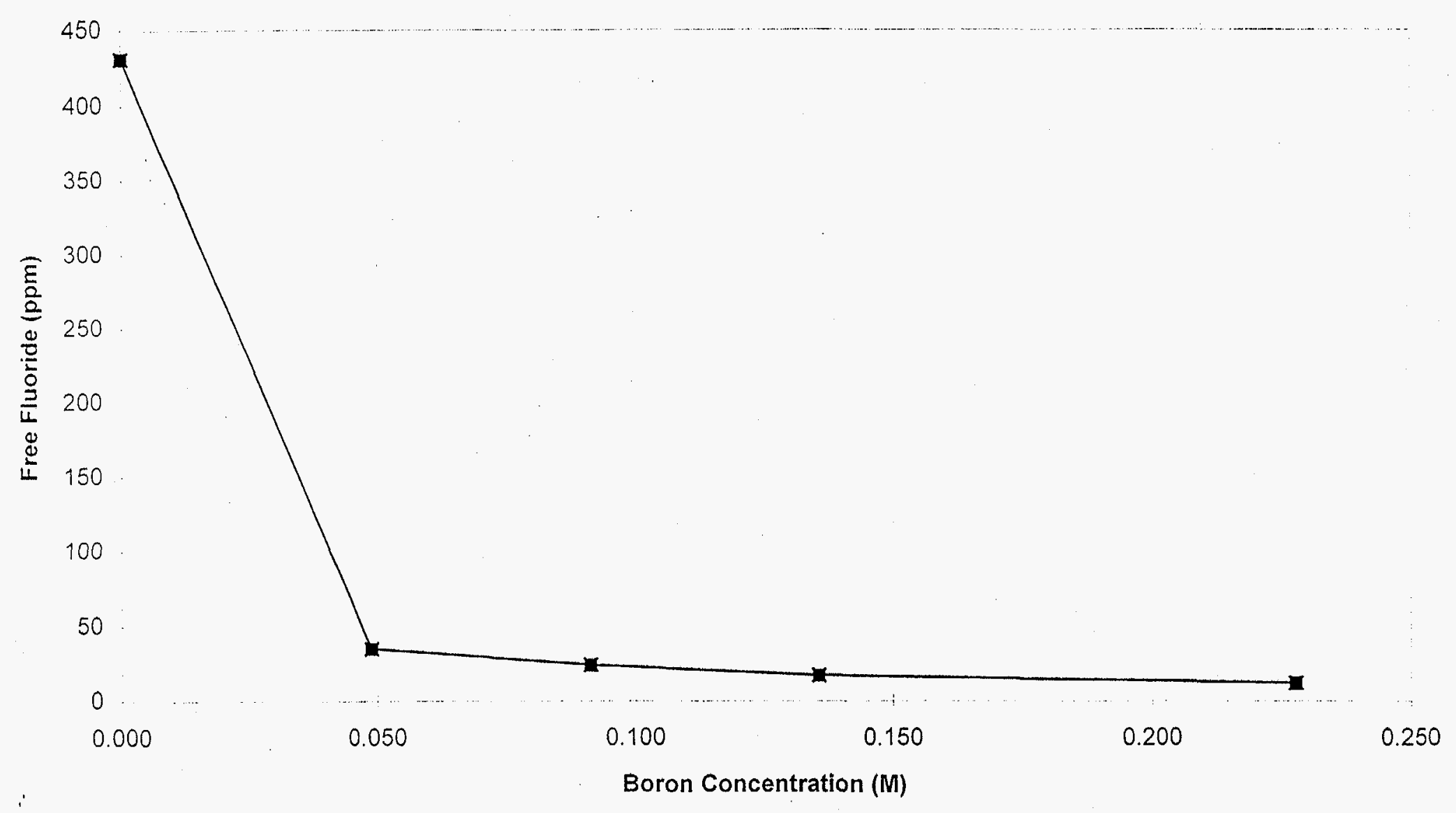




\section{This page has been left blank intentionally.}




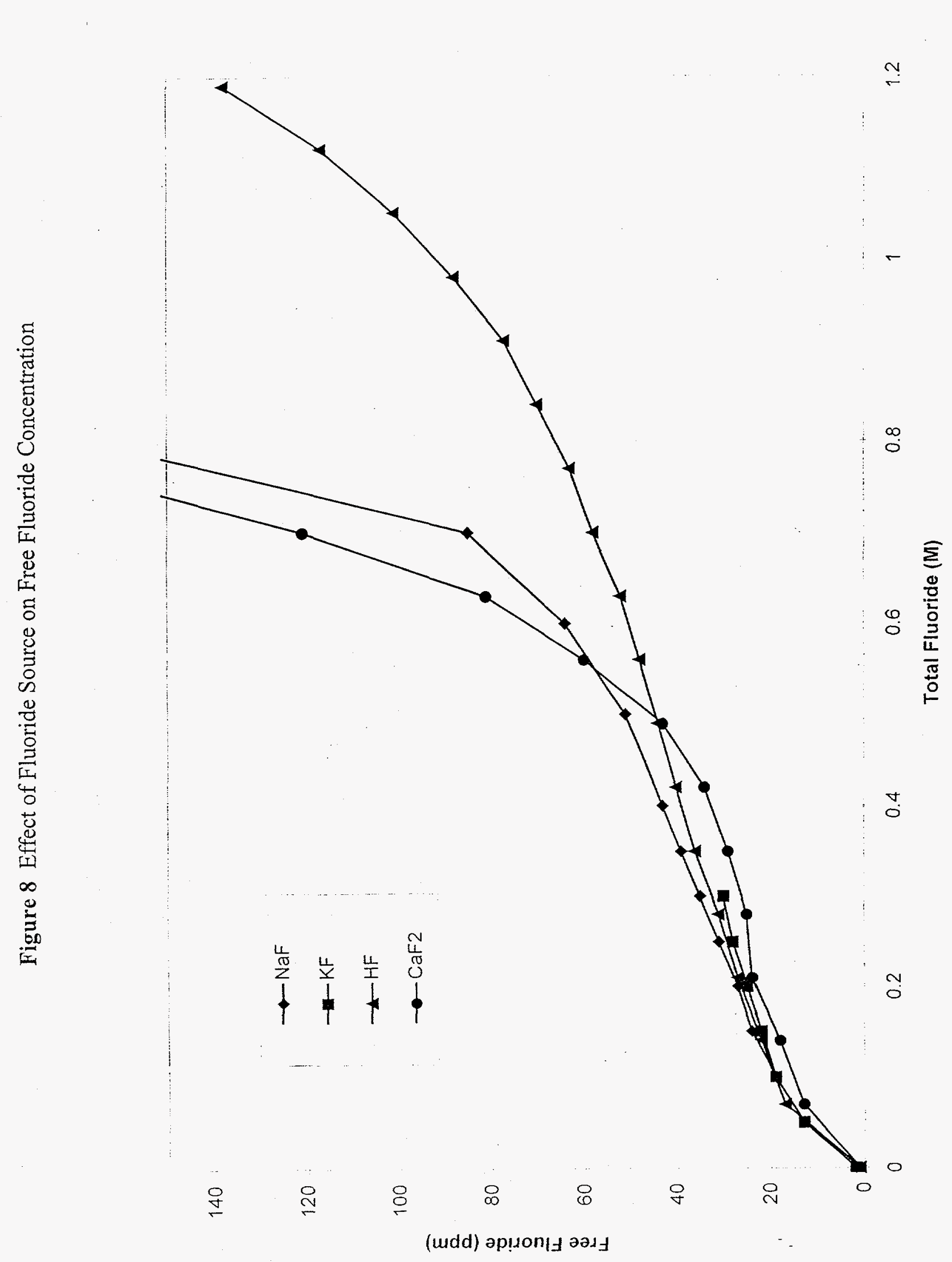



Figure 9 Dissolution of SS\&C Fines at $85^{\circ} \mathrm{C}$

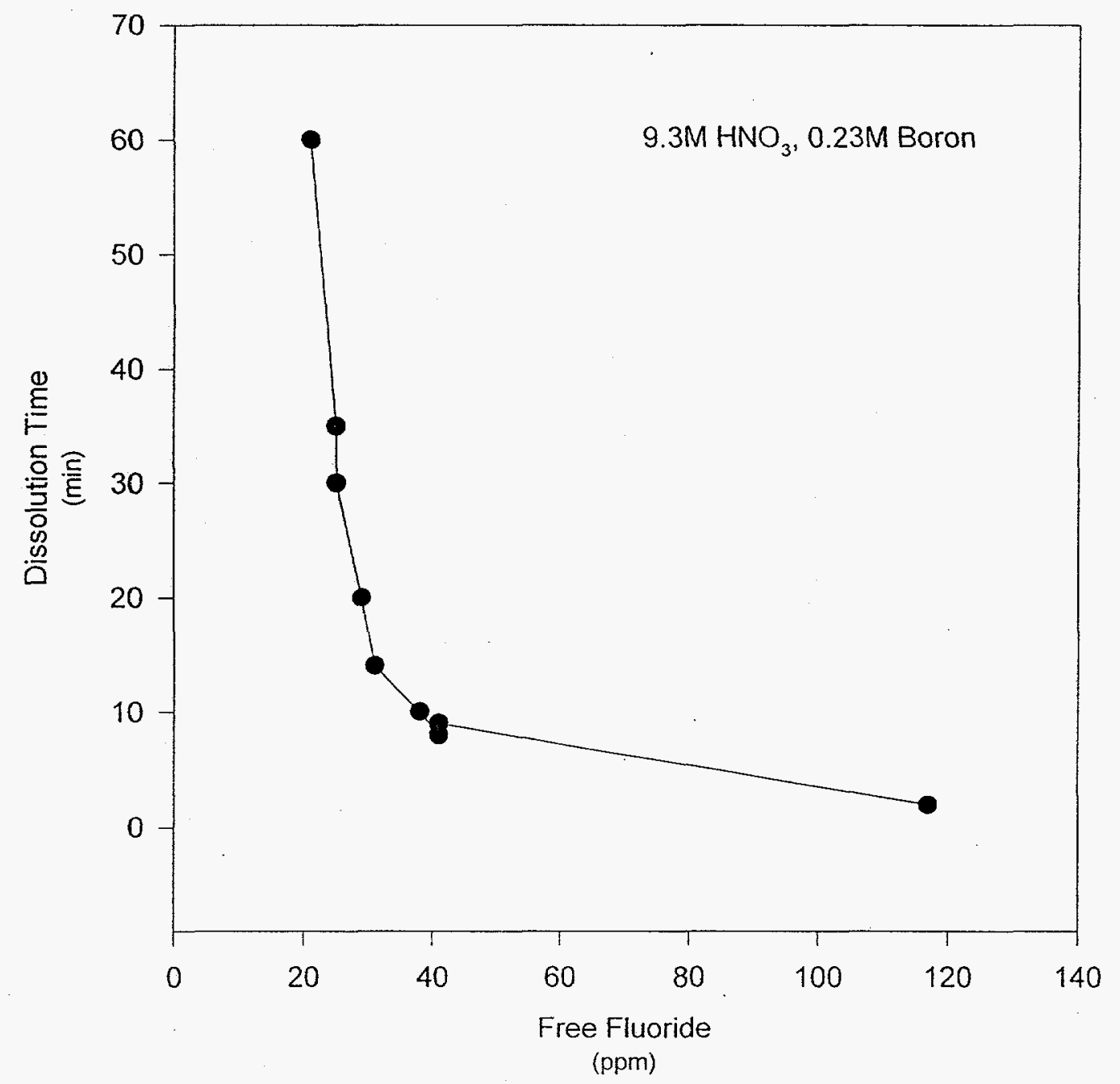




\section{This page has been left blank intentionally.}


5
00
0
0
-10
00
0
0
0
0
60
00
20
0
5
0
9
0
0

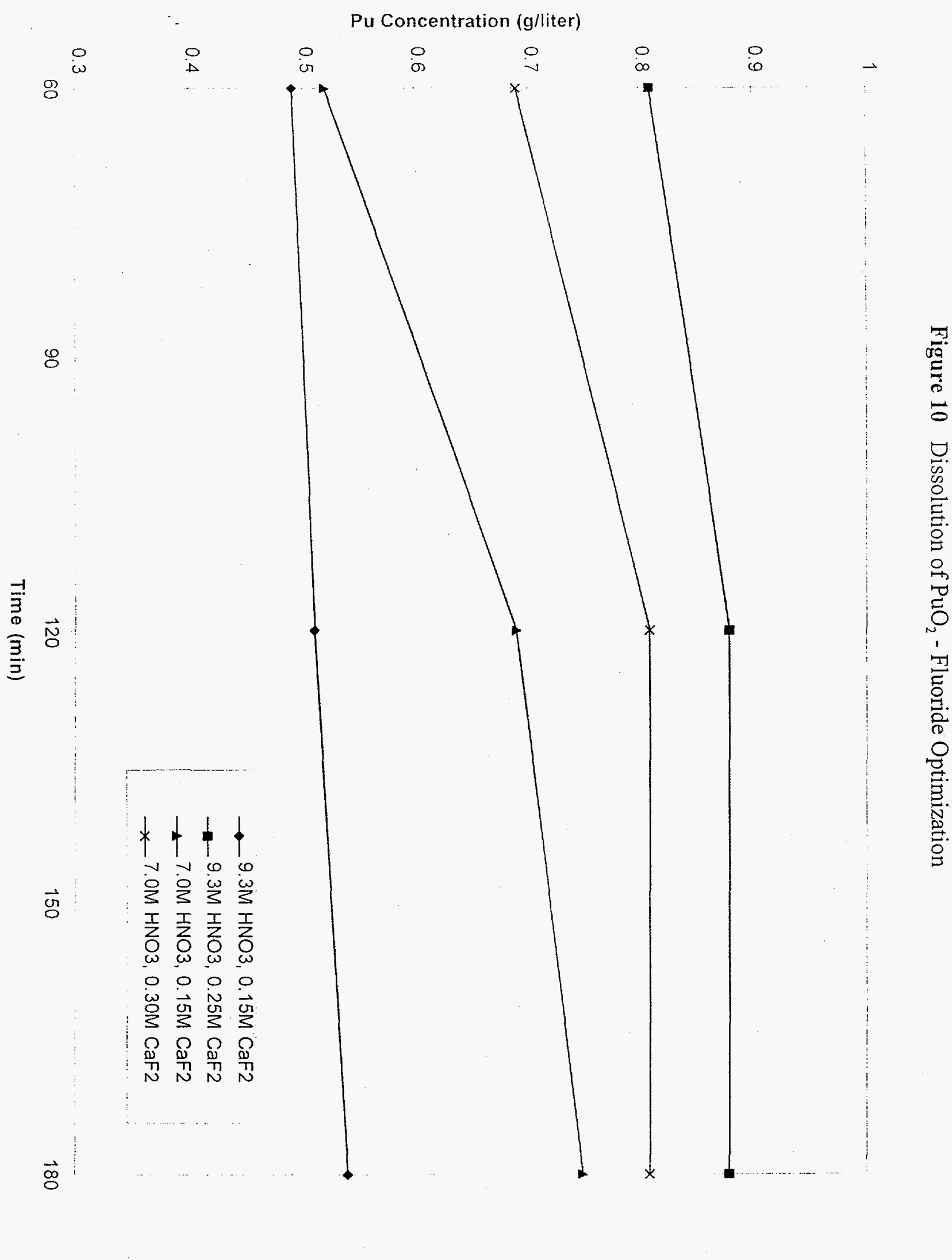




\section{This page has been left blank intentionally.}


Figure 11 Dissolution of $\mathrm{PuO}_{2}$ - Calcium Effect

$120 \%$

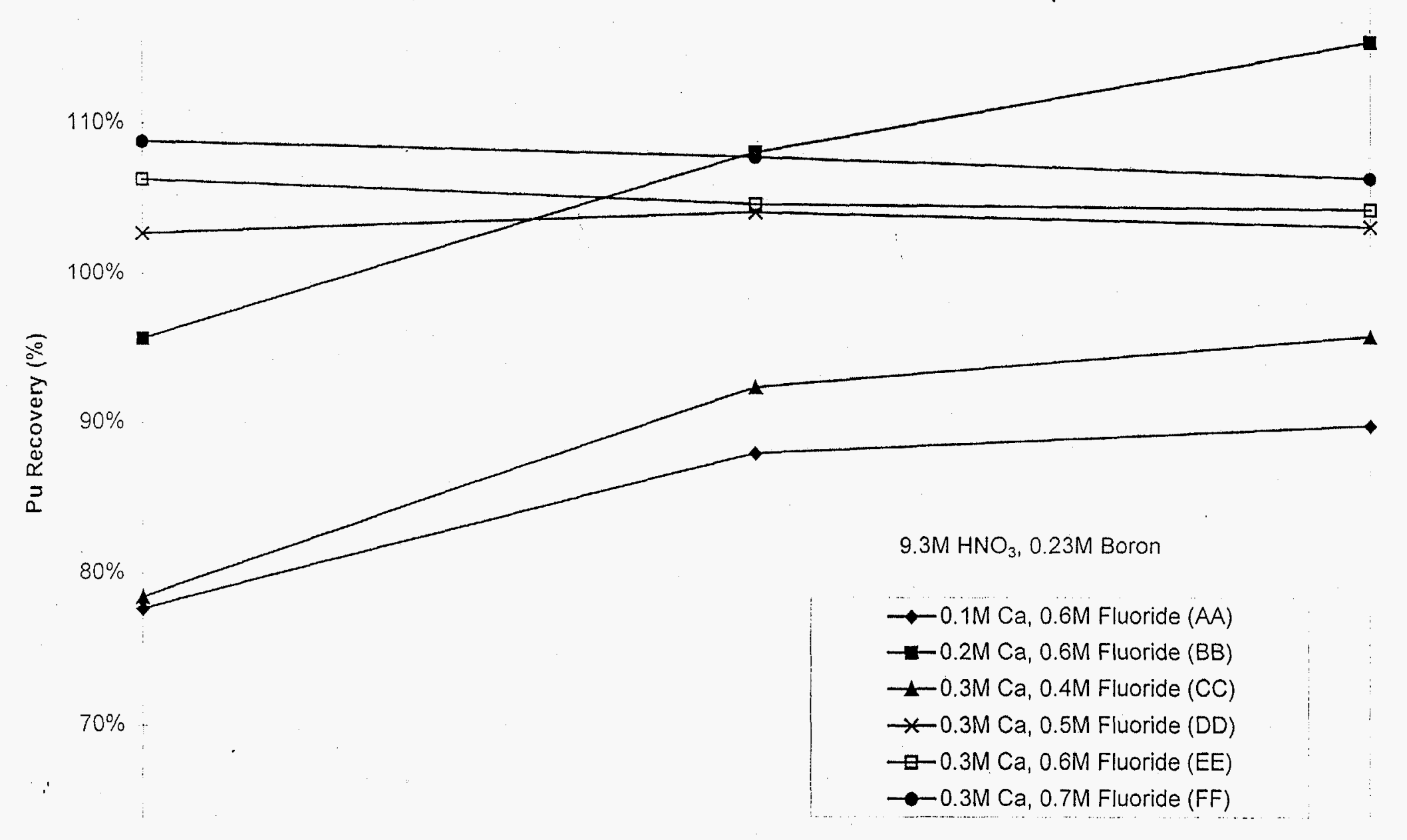

$60 \%$ 


\section{This page has been left blank intentionally.}




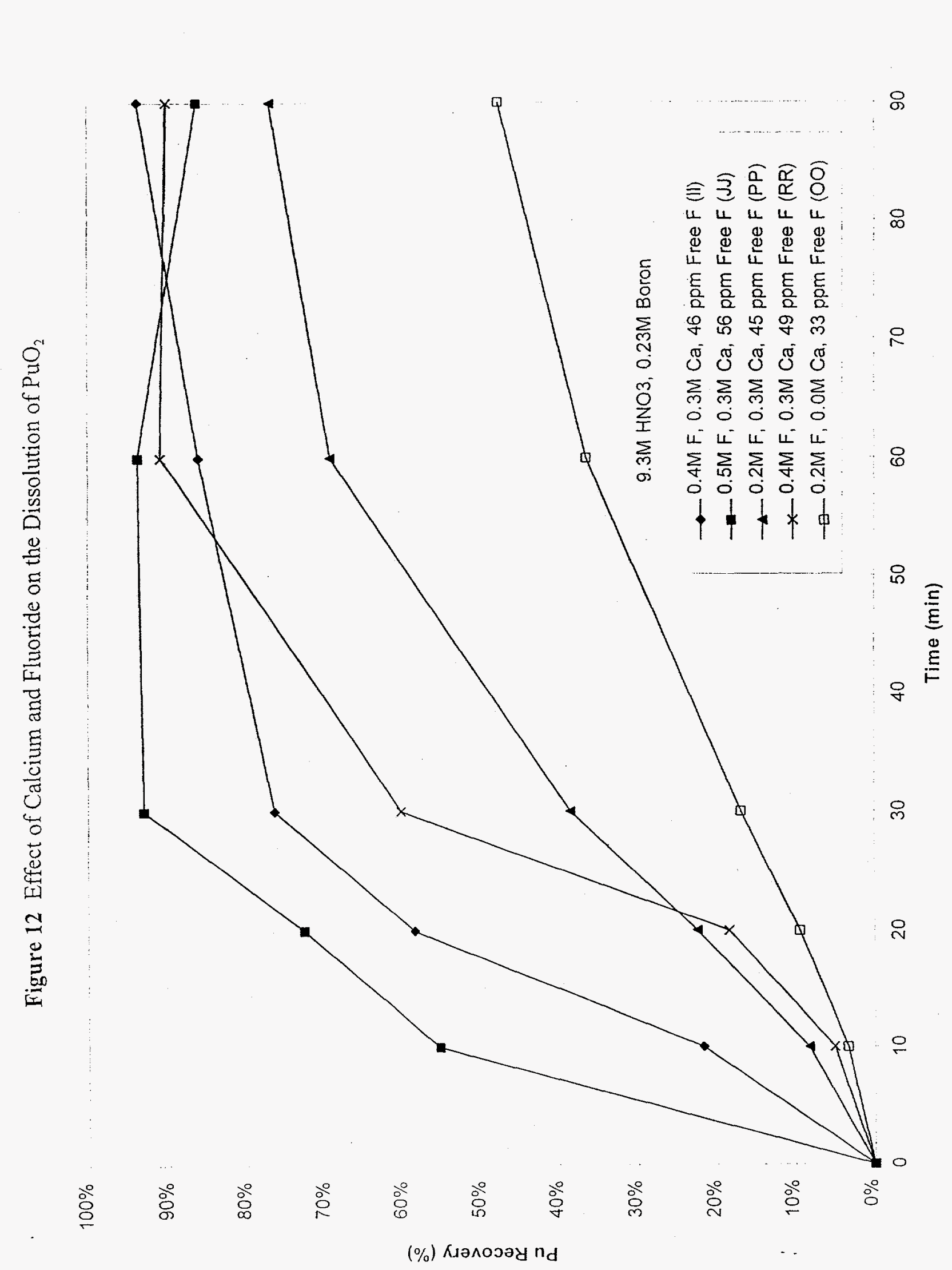

$\alpha$
$a$
0
0
0 


\section{This page has been left blank intentionally.}


Figure 13 Dissolution of $\mathrm{PuO}_{2}$ without Iron

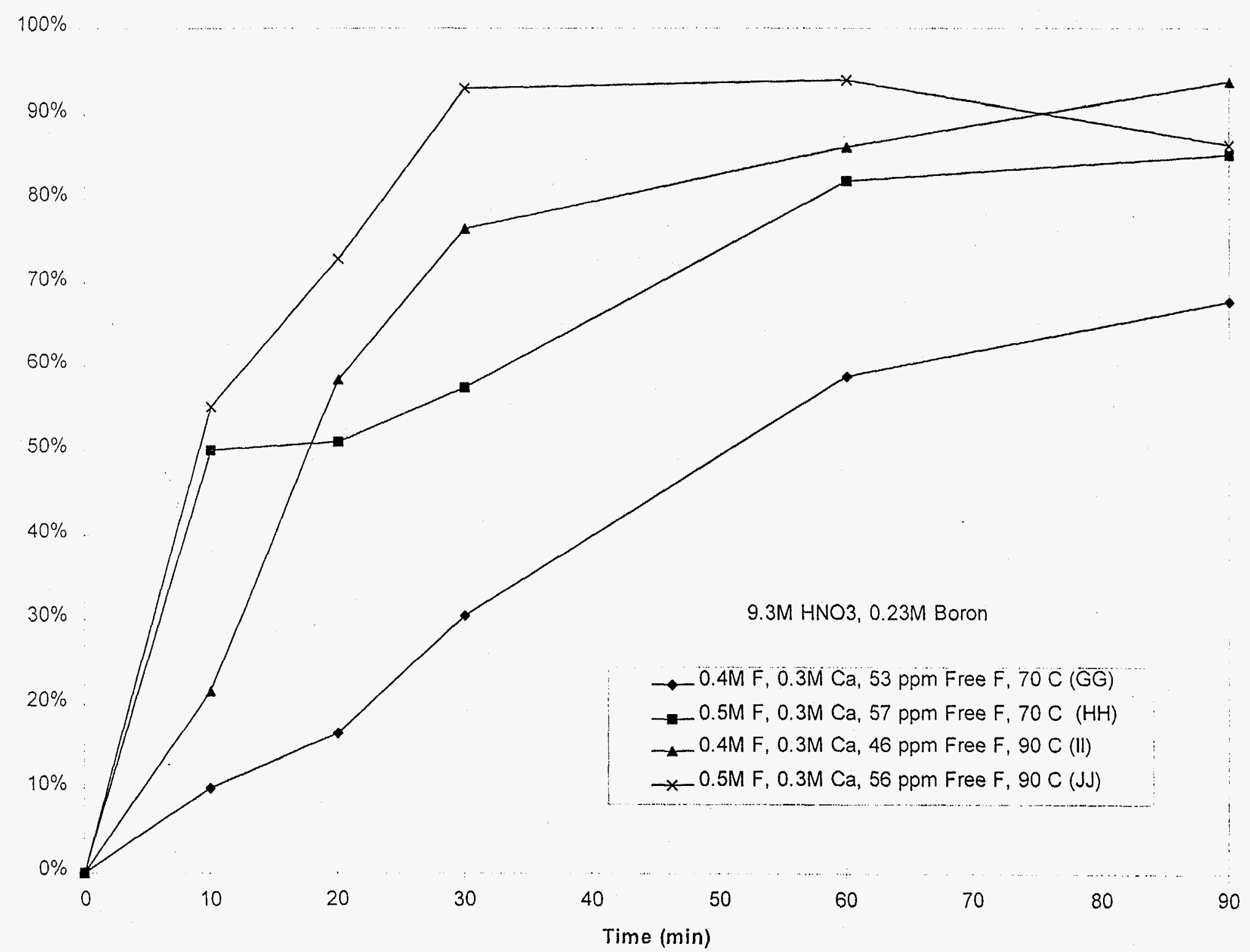




\section{This page has been left blank intentionally.}




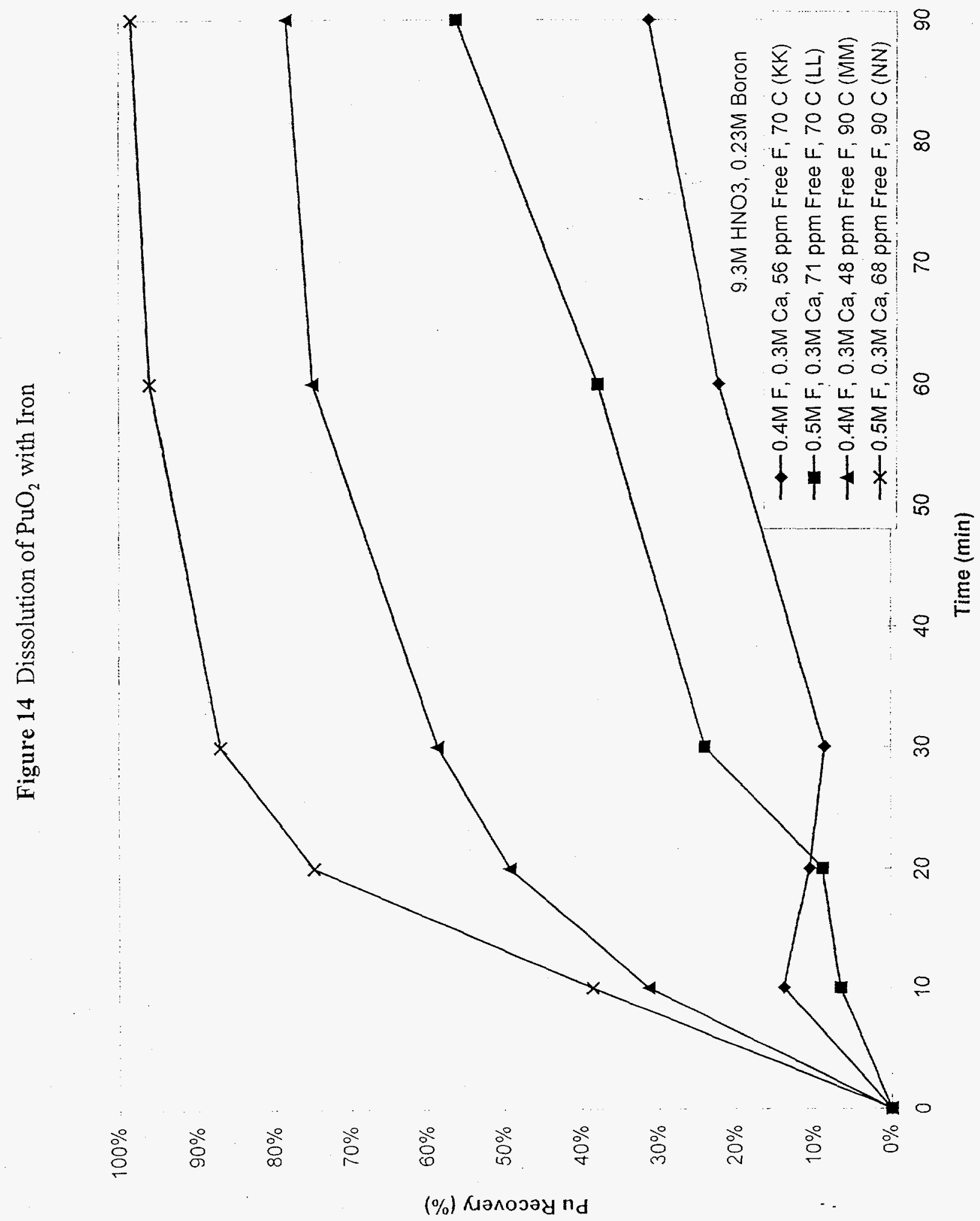



Figure 15 Effect of Free Fluoride on the Dissolution of $\mathrm{PuO}_{2}$

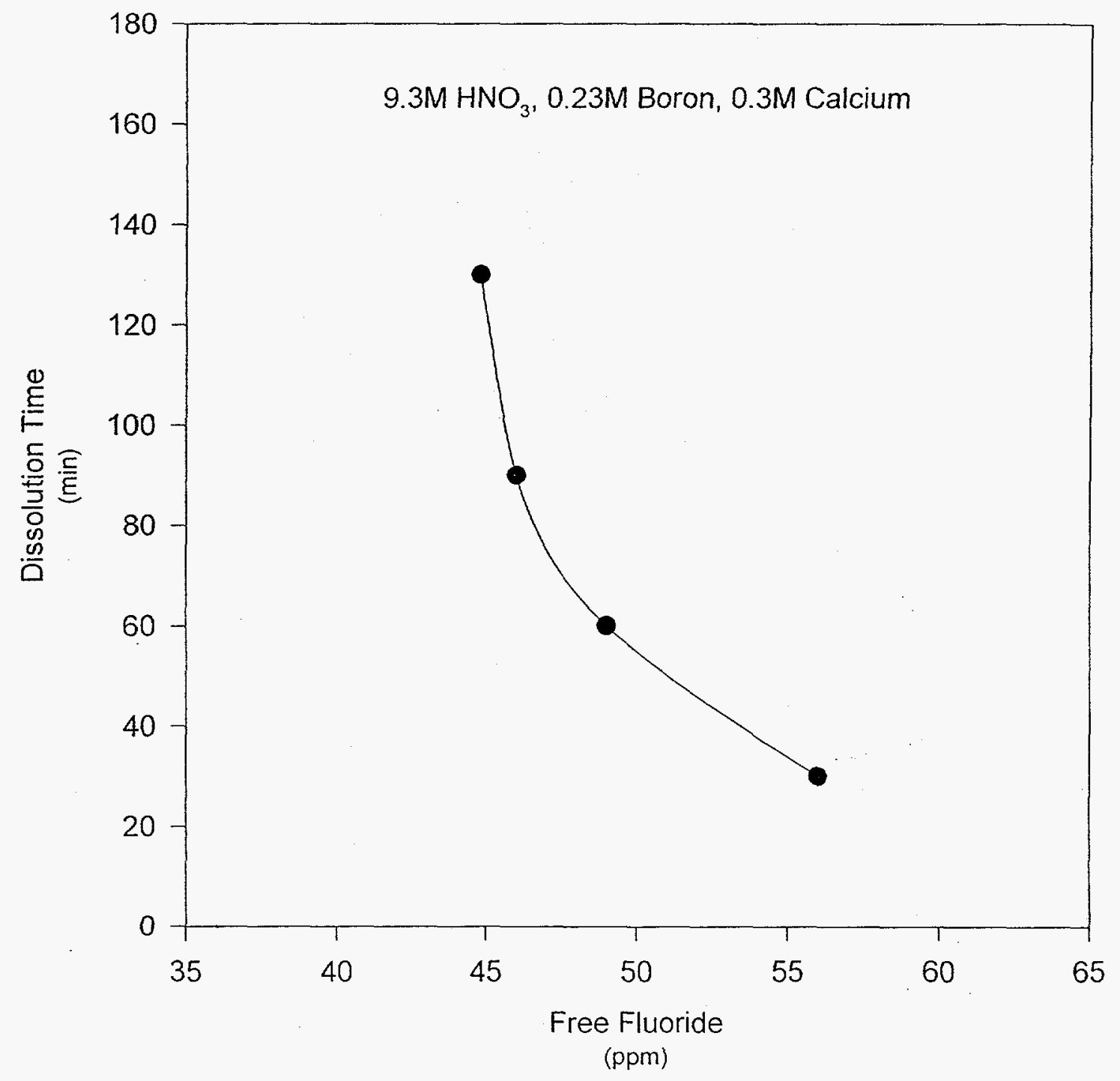




\section{This page has been left blank intentionally.}




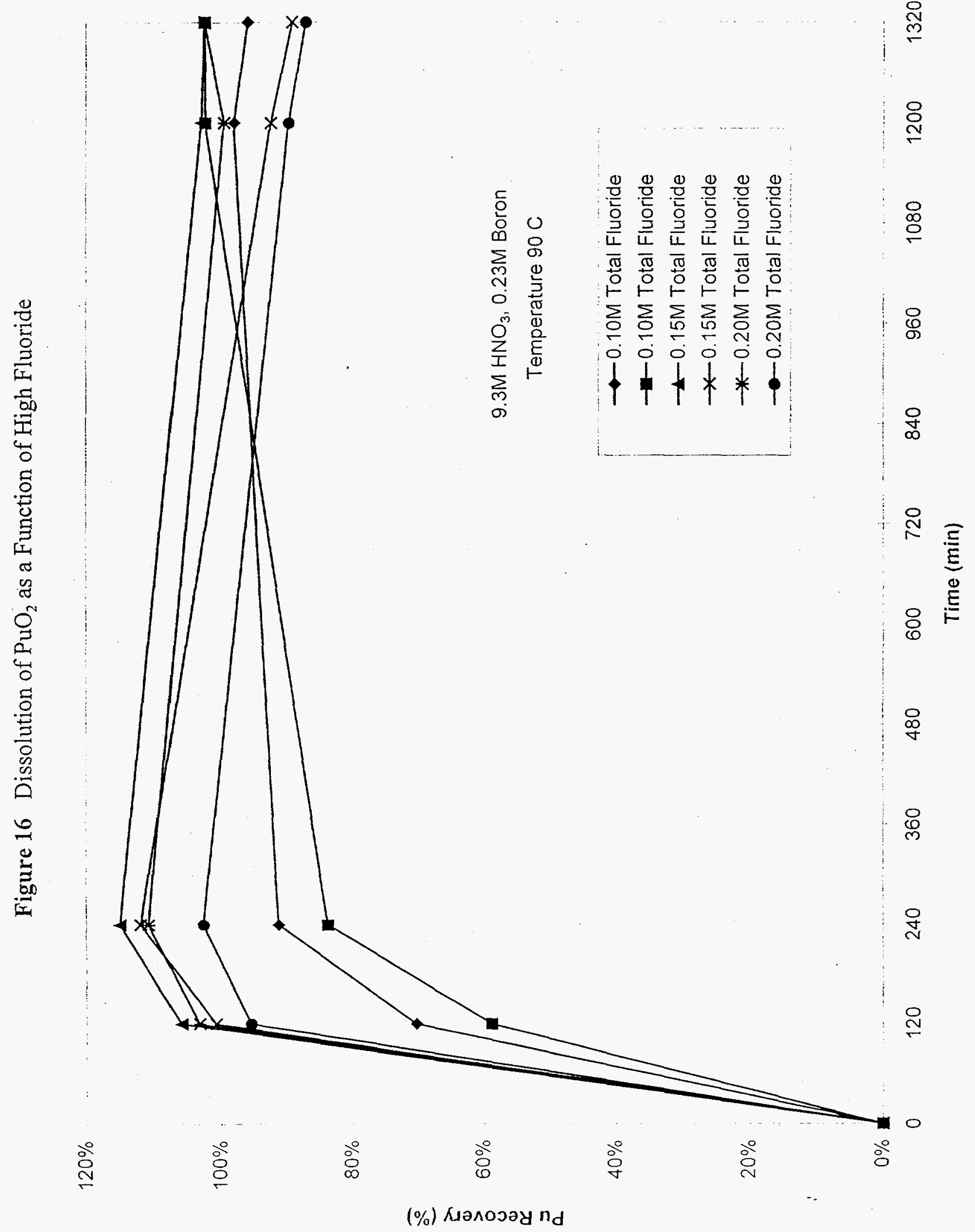

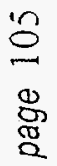




\section{This page has been left blank intentionally.}


Figure 17 Dissolution of $\mathrm{PuO}_{2}$ as a Function of Low Fluoride

$120 \%$

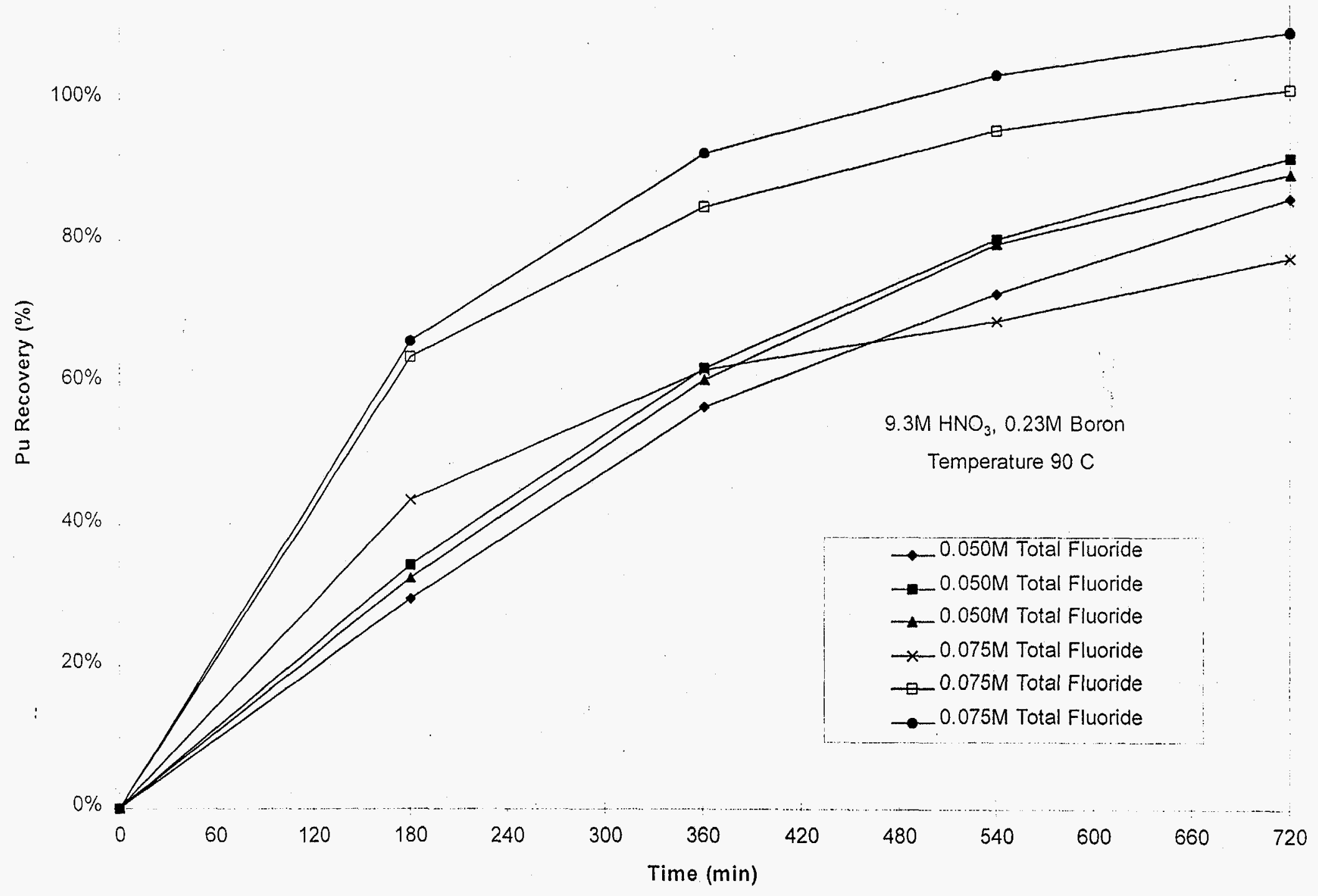




\section{This page has been left blank intentionally.}


Figure 18 Hydrogen Generation Rate from Spherical Pieces of Slag

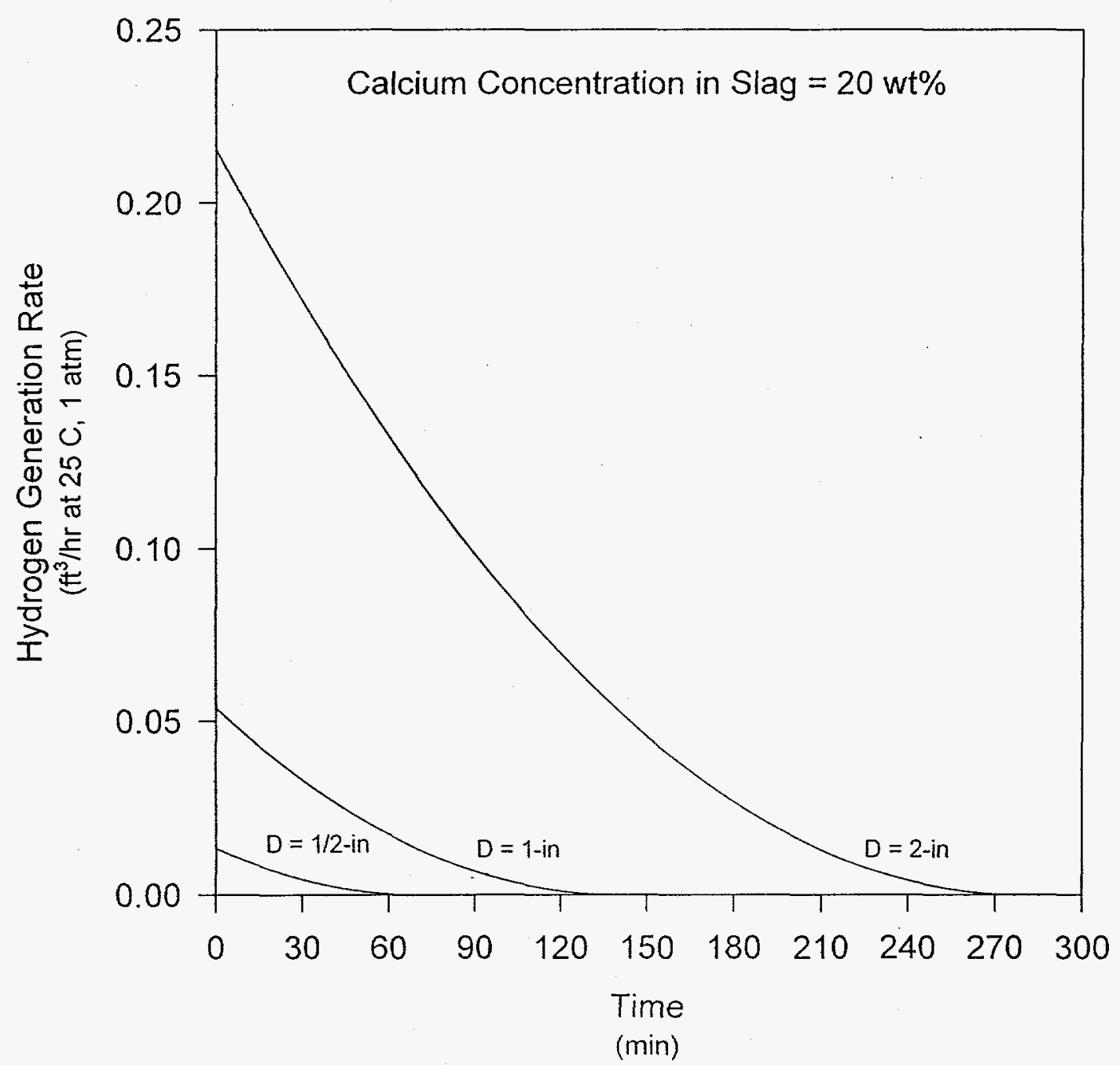

Generation Rates are for a Single Piece of Slag with Diameter D. 


\section{This page has been left blank intentionally.}


Figure $19 \mathrm{Pu}^{+3}, \mathrm{Pu}^{+4}$, and $\mathrm{Pu}^{+6}$ Spectra of SS\&C Dissolver Solution

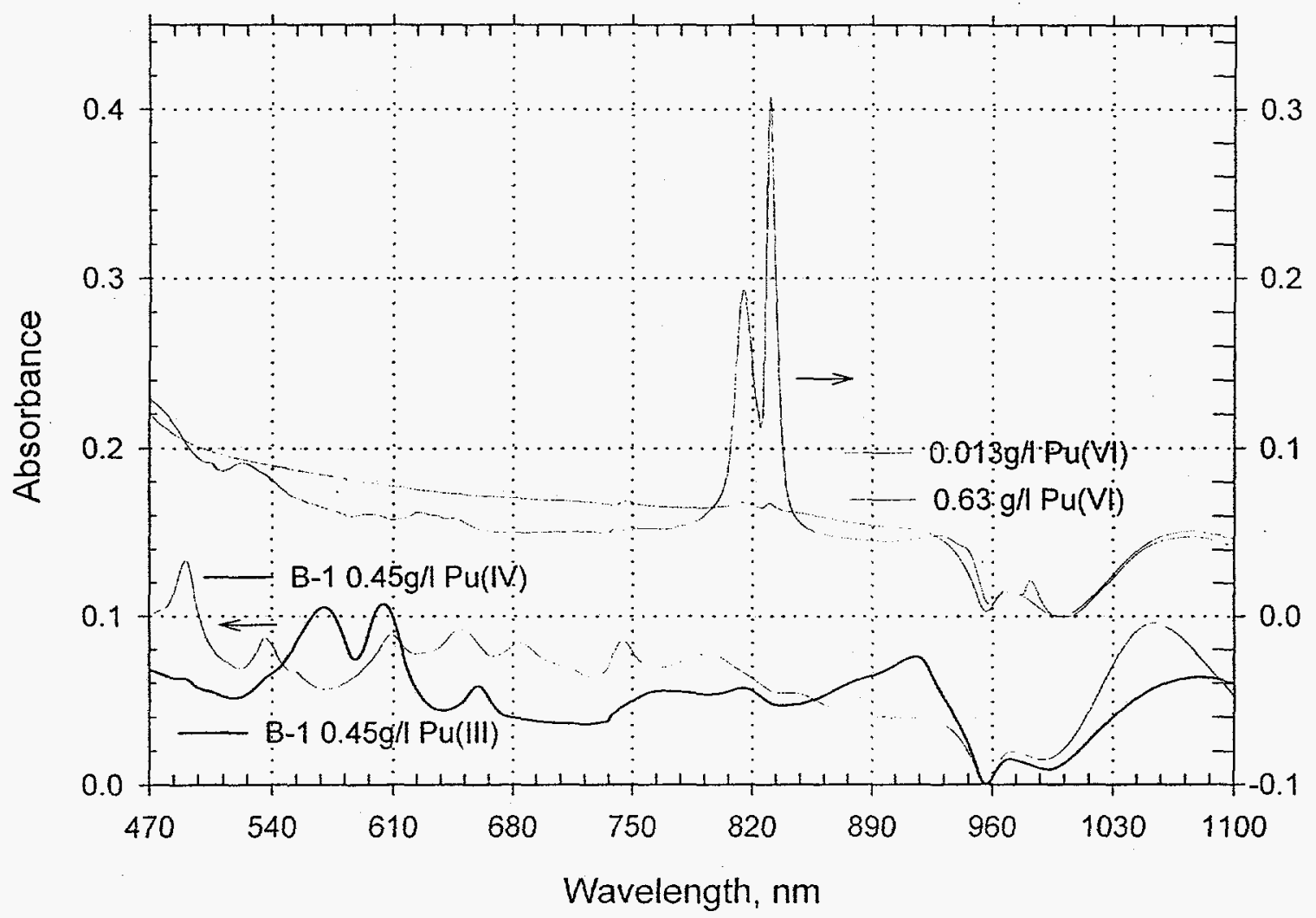

$\mathrm{Pu}^{+3}$ and $\mathrm{Pu}^{+4}$ spectra are plotted on the left ordinate axis. For clarity, the two $\mathrm{Pu}^{+6}$ spectra are plotted on the right ordinate axis. 


\section{This page has been left blank intentionally.}


Figure 20 Dissolved SS\&C and High Fired Oxide Spectra

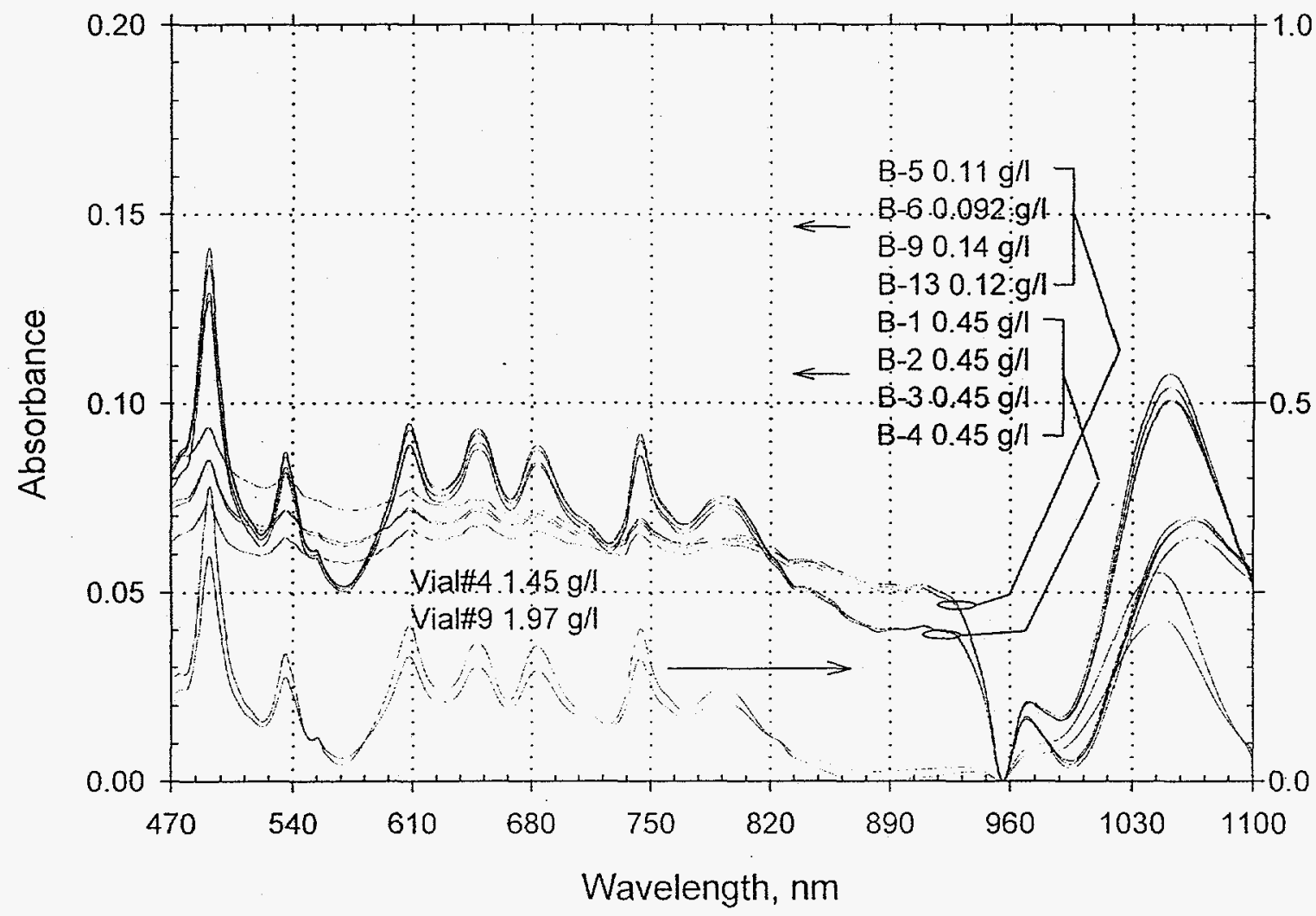

B-series solutions from SS\&C dissolution tests are plotted on the left ordinate axis. Vial \#4 (Table 13, Solution B) and Vial \#9 (Table 13, Solution C) from the oxide dissolution tests are plotted on the right ordinate axis. 


\section{This page has been left blank intentionally.}


Figure $21 \mathrm{Pu}^{+6}$ Sensitivity using Spectral Absorbance in the 800 to $840 \mathrm{~nm}$ Range

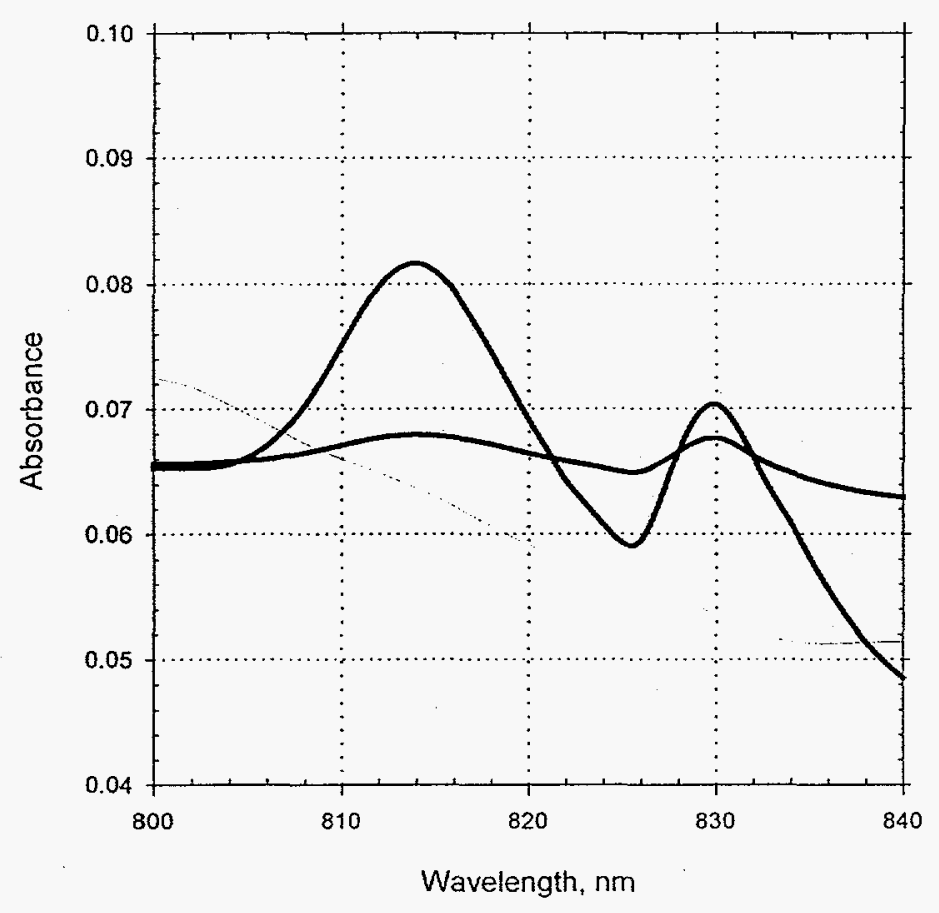

B-3 $0.45 \mathrm{~g} / 1 \mathrm{Pu}^{+4}$ and $\mathrm{Pu}^{+6}$ was prepared by $\mathrm{Ce}^{+4}$ oxidation. Trace $\mathrm{Pu}^{+6}$ was prepared by $\mathrm{Ag}^{+2} /$ persulfate oxidation of $\mathrm{Pu}^{+4}$ in low acid and then dilution with corrosion solution \#18. B-series solutions from SS\&C dissolution tests and Vials \#4 (Table 13, Solution B) and \#9 (Table 13, Solution C) from the oxide dissolution tests illustrate the absence of $\mathrm{Pu}^{+6}$ peaks at 814 and $830 \mathrm{~nm}$. 


\section{This page has been left blank intentionally.}


Figure $22 \mathrm{Pu}^{+6}$ Sensitivity using Second Derivatives of Absorbance in the 800 to $840 \mathrm{~nm}$ Range

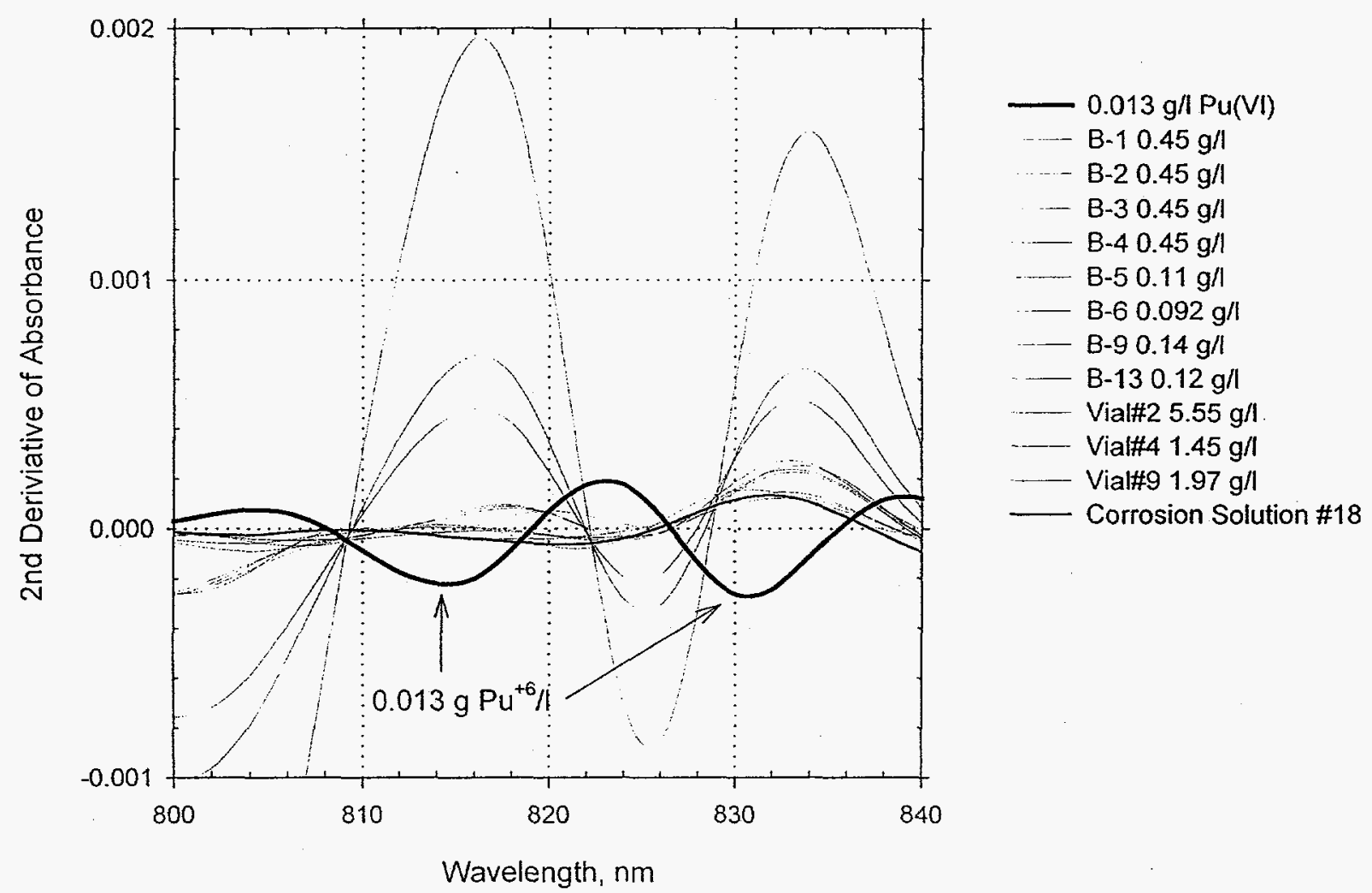

Trace $\mathrm{Pu}^{+6}$ in corrosion solution \#18 showing distinctive $\mathrm{Pu}^{+6}$ absorbance changes at 814 and $830 \mathrm{~nm}$ compared with other process matrix solutions. B-series solutions are from SS\&C dissolution tests and Vials \#2 (Table 13, Solution A), Vials \#4 (Table 13, Solution B) and \#9 (Table 13, Solution C) are from the oxide dissolution tests. These illustrate the absence of $\mathrm{Pu}^{+6}$ peaks at 814 and $830 \mathrm{~nm}$ and indicate a high sensitivity for $\mathrm{Pu}^{+6}$. 
This page has been left blank intentionally. 
Figure 23 Corrosion of 304 L Stainless Steel Coupons

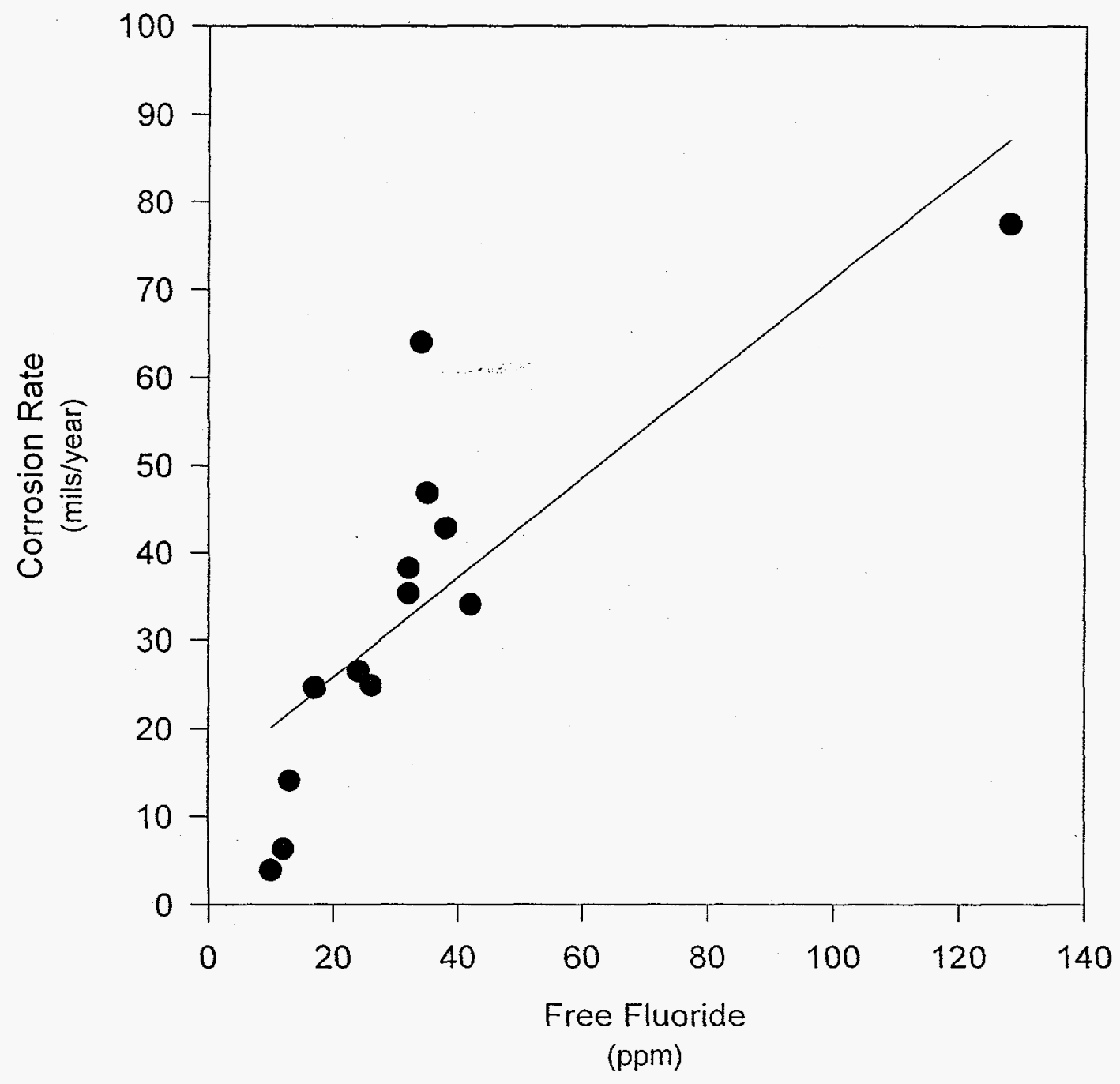




\section{This page has been left blank intentionally.}




\section{Appendix I Estimated Dissolver Solution Concentrations}

\section{General Assumptions}

1. Bomb Reduction Yield:

$90 \%$

2. Mass of Crucible Remaining Following SS\&C Repackaging:

275 grams

(75\% of an 1100 gram crucible removed)

3. Plutonium Charged per Reduction:

2315 grams

4. Percent $\mathrm{PuF}_{4}$ Following Conversion:

$68 \%$

5. Percent $\mathrm{PuO}_{2}$ Following Conversion:

$32 \%$

6. Excess Calcium per Charge:

$32.5 \%$ (1027 grams per charge)

7. Percent Metal in Slag (Plutonium Basis):

$50 \%$

8. Percent $\mathrm{PuF}_{4}$ in Slag (Plutonium Basis):

$30 \%$

9. Percent $\mathrm{PuO}_{2}$ in Slag (Plutonium Basis):

$20 \%$

10. Volume of Solution in Dissolver:

7000 liters

11. $\mathrm{HNO}_{3}$ Concentration in Dissolver:

$9.3 \mathrm{M}$

12. KF Concentration in Dissolver:

$0.075 \mathrm{M}$

13. Boron Concentration in Dissolver:

$0.23 \mathrm{M}$

14. Number of Dissolver Wells:

8 wells

15. Maximum Number of Cans:

32 cans

16. Maximum Plutonium per Well:

400 grams

17. Maximum Bulk per Well:

3.8 kilograms

18. Mass of Iron per Can:

292 grams

19. Mass of Iron per Charging Bundle:

360 grams

\section{Assumptions for Charging Dissolver}

1. Charge Maximum Number of Cans

2. Charge Maximum Bulk per Well

3. No Volume Loss from Dissolver

4. $50 \%$ of the Calcium Oxidizes Before Dissolution 
Mechanisms for $\mathrm{HNO}_{3}$ Depletion

$$
\begin{aligned}
& \mathrm{Fe}+6 \mathrm{HNO}_{3} \rightarrow \mathrm{Fe}\left(\mathrm{NO}_{3}\right)_{3}+3 \mathrm{NO}_{2}+3 \mathrm{H}_{2} \mathrm{O} \\
& 3 \mathrm{Ca}+8 \mathrm{HNO}_{3} \rightarrow 2 \mathrm{NO}+4 \mathrm{H}_{2} \mathrm{O}+3 \mathrm{Ca}\left(\mathrm{NO}_{3}\right)_{2} \\
& \mathrm{MgO}+2 \mathrm{HNO}_{3} \rightarrow \mathrm{Mg}\left(\mathrm{NO}_{3}\right)_{2}+\mathrm{H}_{2} \mathrm{O} \\
& \mathrm{CaO}+2 \mathrm{HNO}_{3} \rightarrow \mathrm{Ca}\left(\mathrm{NO}_{3}\right)_{2}+\mathrm{H}_{2} \mathrm{O}
\end{aligned}
$$

1. The moles of $\mathrm{HNO}_{3}$ depleted per mole of iron was reduced from 6 to 4.5 to account for reforming and condensing of $\mathrm{HNO}_{3}$ in the dissolver condenser.

2. $55 \%$ of the calcium was assumed to react with the nitric acid and $45 \%$ assumed to react with water.

3. Any reaction of plutonium with $\mathrm{HNO}_{3}$ was ignored due to the small concentration.

Table A.1 Composition of SS\&C from One Reduction

\begin{tabular}{|c|c|c|}
\hline Component & Mass & Composition \\
\hline & (grams) & (wt\%) \\
\hline $\mathrm{MgO}$ & 550 & 23 \\
\hline $\mathrm{CaF} 2$ & 925 & 39 \\
\hline $\mathrm{CaO}$ & 312 & 13 \\
\hline $\mathrm{Ca}$ & 329 & 14 \\
\hline Pu Metal & 116 & 5 \\
\hline PuF4 & 92 & 4 \\
\hline PuO2 & 52 & 2 \\
\hline (Total Pu) & $(232)$ & $(11)$ \\
\hline & & 100 \\
\hline Total Mass & 2376 & \\
\hline
\end{tabular}




\section{Calculated Dissolver Loading}

1. Number of Cans: 32

2. Reduction Charges per Well: $\quad 1.6$

3. Reduction Charges per Dissolver: 12.8

4. Mass off SS\&C per Can: 950 grams

5. Mass of SSC per Well: 3.8 kilograms

6. Mass of SS\&C per Dissolver: 30.4 kilograms

Table A.2 Dissolver Charge Composition

\begin{tabular}{|c|c|c|}
\hline Component & Mass & Composition \\
\hline & (grams) & (wt\%) \\
\hline $\mathrm{MgO}$ & 7036 & 17 \\
\hline $\mathrm{CaF} 2$ & 11830 & 28 \\
\hline $\mathrm{CaO}$ & 3997 & 9 \\
\hline $\mathrm{Ca}$ & 4213 & 3 \\
\hline $\mathrm{Pu} \mathrm{Metal}$ & 1481 & 3 \\
\hline $\mathrm{PuF} 4$ & 1171 & 2 \\
\hline $\mathrm{PuO} 2$ & 672 & 29 \\
\hline $\mathrm{Fe}$ & 12224 & $(8)$ \\
\hline (Total Pu) & $(2962)$ & 100 \\
\hline & & \\
\hline Total Mass & 42624 & \\
\hline
\end{tabular}


Table A.3 Dissolver Solution Composition

\begin{tabular}{|c|c|c|c|c|c|c|c|c|}
\hline Component & $\mathrm{HNO}_{3}$ & $\mathrm{~F}$ & $\mathrm{~B}$ & $\mathrm{~K}$ & $\mathrm{Ca}$ & $\mathrm{Fe}$ & $\mathrm{Mg}$ & $\mathrm{Pu}$ \\
\hline & $(\mathrm{M})$ & $(\mathrm{M})$ & $(\mathrm{M})$ & $(\mathrm{M})$ & $(\mathrm{M})$ & $(\mathrm{M})$ & $(\mathrm{M})$ & $\mathrm{g} /$ liter \\
\hline & & & & & & & & \\
\hline Initial & 9.3 & 0.075 & 0.23 & 0.075 & & & & \\
\hline $1^{\text {st }}$ Charge & 9.1 & 0.13 & 0.23 & 0.075 & 0.05 & 0.03 & 0.01 & 0.48 \\
\hline $2^{\text {nd }}$ Charge & 8.9 & 0.18 & 0.23 & 0.075 & 0.11 & 0.06 & 0.03 & 0.96 \\
\hline $3^{\text {rd }}$ Charge & 8.7 & 0.23 & 0.23 & 0.075 & 0.16 & 0.09 & 0.04 & 1.20 \\
\hline $4^{\text {th }}$ Charge & 8.5 & 0.28 & 0.23 & 0.075 & 0.21 & 0.13 & 0.06 & 1.44 \\
\hline $5^{\text {th }}$ Charge & 8.3 & 0.33 & 0.23 & 0.075 & 0.27 & 0.16 & 0.07 & 1.67 \\
\hline
\end{tabular}




\section{Distribution}

N. E. Barnett, 707-F

T. G. Campbell, 221-F

T. L. Capeletti, 773-41A

W. H. Clifton, 221-41A

O. M. Ebra-Lima, 707-F

J. S. Evans, 703-F

F. R. Graham, 773-A

J. H. Gray, 773-A

J. Greggi, Jr., 707-F

T. D. Harrington, 221-F

N. M. Hassan, 773-A

M. L. Hyder, 773-A

N. C. Iyer, 773-A

J. R. Knight, 773-A

E. A. Kyser, 773-A

R. R. Livingston, 773-A

J. W. McClard, 703-F

J. I. Mickalonis, 773-A

A. P. Mock, 703-F

A. M. Murray, 773-A

R. A. Pierce, 773-A

M. R. Price, 221-F

T. S. Rudisill, 773-A

J. B. Schaade, 703-F

M. A. Schmitz, 221-F

R. H. Spires, 221-F

D. Stimac, 703-F

M. C. Thompson, 773-A

G. J. Winkler, 703-F

C. R. Wolfe, 773-A

CT Files, 773-A 